i

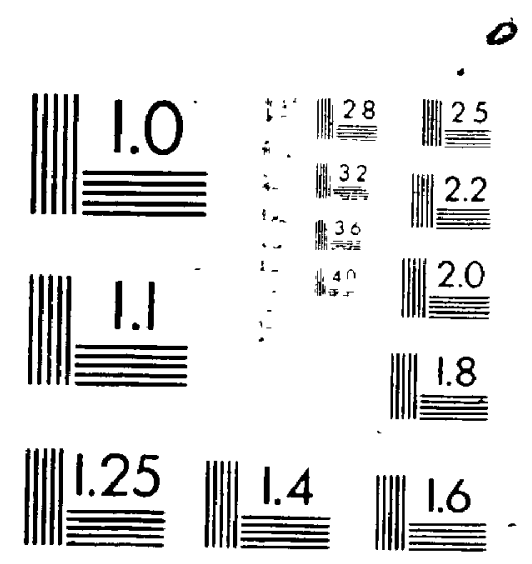

Indus 
National Library

of Canada

Canadian Theses Service

Ottawa Canada

KIA ON4
Bibliothéque nationale

du Canada .

Service des thèses canadiennes

$\lambda$

NOTICE

he quality of this microform is heavily dependent upon the uality of the original thesis submitted for microfilming ivery effor has been made to ensure the highest quality of eproduction possible

, pages are missing, contact the unversity which granted ie degree

Some pages may have indistınct print especially if the riginal pages were typed with a poor typewriter ribbon or the university sent us an inferior photocopy

reviously copyrighted materiais (journal anticles, pubshed tests, elc ) are not filmed

Reproduction in full or in part of this microform is governed y the Canadian Copyright ACt, R S C 1970 , c. C.30

\begin{abstract}
AVIS
La quatté de celte mieroforme deprend grandement de la qualite de la these soumise au microilmage Nous avons tout fall pour assurer une quallte superiteure de reproduc. tion

S'il manque des pages, veurlez commumquer an:c l'universıte qui a contéré le grade

La qualité dimpression de certaines pages peut laisser a désirer, surtout sı les pages originales ont ele dactylogra phiées à l'aide d'un ruban usé ou sı l'unversite nous a latt parvenir une photocopie de qualité inférieure

Les documents qui font déà l'objet d'un drolt d'auteur (articles de revue, tests publiés, etc) ne sont pas microfilmés
\end{abstract}

La reproduction, mérne partielle, de cette microforme est soumise à la Lo canadienne sur le droit d'auteur. SRC 1970, c C.30 


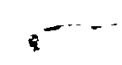

\title{
A Case Study of the Marketing Plan Development Process in High Technology Firms
}

by

\section{Michael H. MacInnis, B.Comm.}

\author{
A thesis submitted to \\ the Faculty of Graduate Studies and Research \\ in partial fulfilment of \\ the requirements for the degree of \\ Master of Management Studies \\ School of Business

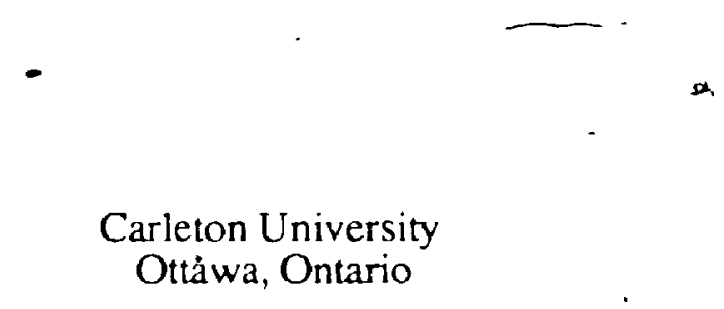

November 30, 1987

(C) copyright

1987. Michael H. Macinnıs 
Permission has been granted to the National Library of Canada, to microfilm this thesis and to lend or sell copies of the film.

The author (copyright owner) inas reserved other publication rights, and neither the thesis nor extensive extracts from it may be printed or otherwise reproduced without his/her written permission.
L'autorisation a été accordée à la Bibliothèque nationale du Canada de microfilmer cette thèse et de prêter ou de vendre des exemplaires du film.

L'auteur (ttulaire du droit d'auteurl se réserve les autres droits de publication; ni la thèse ni de longs extraits de. celle-ci ne doivent être imprimés ou autrement reproduits sans son autorisation écrite.

I SBN $\quad 0-315-40621-6$ 
The undersigned recommend to the Faculty of Graduate Studies

- and Research acceptance of the thesis

A Case Study of

the Marketing Plan Development Process in High Technology Firms

submitted by Michael H. MacInnis, B. Comm. (Honours)

in partial fulfilment of the requirements for the degree of Master of Management Studies

$\therefore$
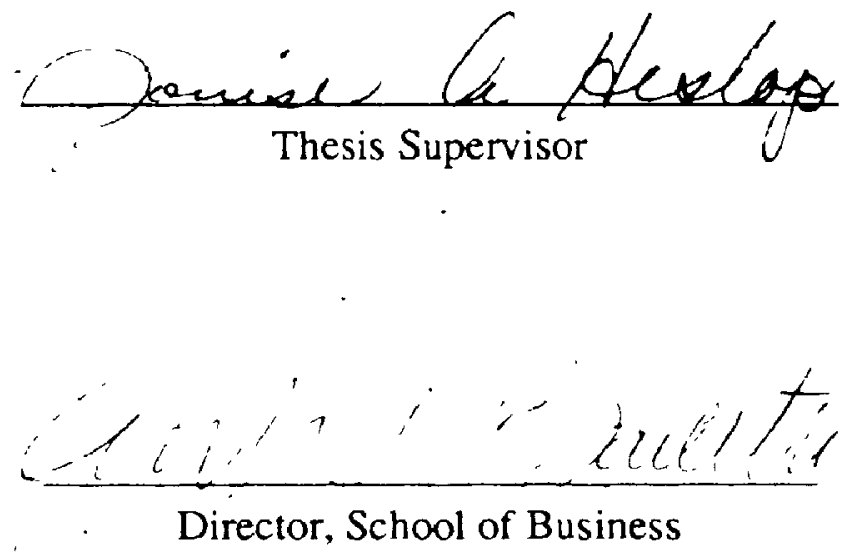


\begin{abstract}
This thesis provides an examination of the marketing plan development process in small to medium-sized high technology firms utilizing a case research methodology. Very little empirical literature is available about the marketing plan development process in general, and specifically, about the process when the firm is operating in a high technology environment. This lack of empirical research is surprising when one considers that a difference between the marketing functions in high technology firms and non-high technology firms has been assumed in most of the marketing high technology literature.

In this thesis a high technology firm was utilized as a case study to explore the applicability of a marketing plan development schema formulated from the marketing planning literature. This schema is concerned with the annual marketing plan development and as such assumes that strategic marketing issues have been formulated in some way so ' that they can be incorporated into the annual marketing plan. Anomalies in the application of this schema were identified by developing an annual marketing plan for the firm. Several of the anomalies were atributed to the technological environment in which the planning was conducted. The turbulence of the planning environment, the lack of availability and utilization of relovant information sources, management's product orientation, their lack of marketing experience and expertise, a complex competitive environment and the difficulty of using the product life cycle concept affected the plan and planning process significantly.

In spite of the difficulties in applying the schema, it was concluded to be a useful guide to follow when developing an annual marketing plan. Minor modifications were made to the schema to reflect the problems encountered so that it would be more appropriate for the case firm and perhaps other firms operating in similar technology environments. Implications of the results were provided for the case firm used in the research, marketing practitioners and researchers.
\end{abstract}




\section{Acknowledgements:}

The author would like to thank Dr. David Cray, Dr. Vijay Jog, and Dr. Judith Marshall who provided excellent comments on various versions of this document. Special thanks go to Dr. Louise Heslop, the Thesis Advisor, who provided the needed guidance and performed above and beyond the call of duty throughout the entire project.

The author would also like to acknowledge the time and support of the employees of the firm studied in this thesis. I especially thank the President and Marketing Manager for their time and cooperation. 


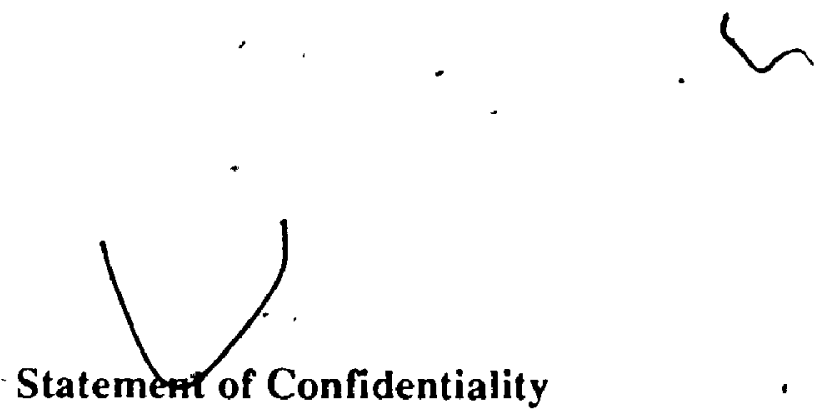

For reasons of confidentiality, the names of the company, products, main competitors and suppliers have been disguised. The financial and other figures and analysis throughout the thesis have not been changed from their original form. This was done so that no information would be lost in reporting the results of the research.

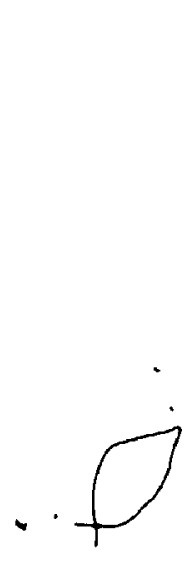




\section{Table of Contents}

Section

Acceptance Sheet

Abstract

Acknowledgements

Statement of Confidentiality

Table of Contents

List of Figures

List of Appendices

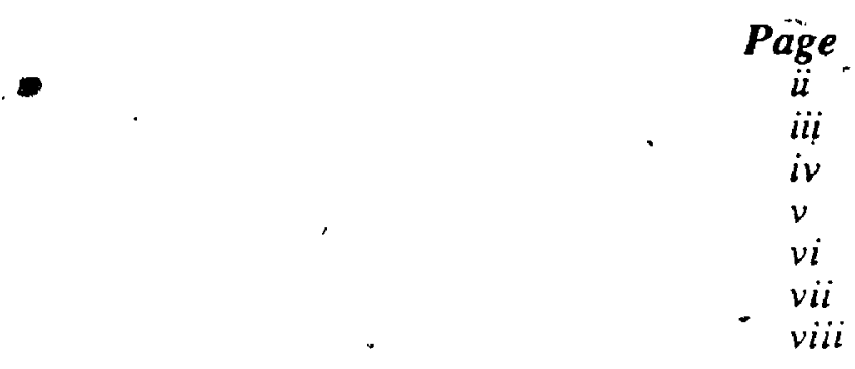

1. Introduction

2. Literature Review

2.1 Marketing Planning Literature

2.1.1 The Marketing Plan Development Process

-2.2 A Review of High Techñology Marketing Planning

2.2.1 Marketing in High Technology Industries

2.3 Summary of Literatuge

3. Research Objectives

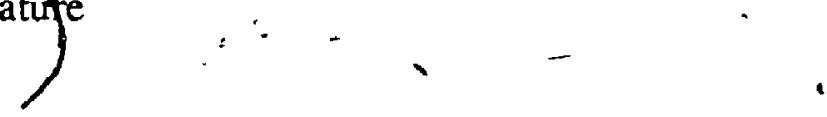

4. Research Methodology

4.1 The Research Process

4.2 Analysis Procedures

4.3 Limitations of Research

5. Results, and Discussion

5.1 Historical Marketing Plannjng Efforts

26

5.2 Development of the Markefing Plan

27

5.3 Discussion of Anticipated Difficulties

5.4 Discussion of Unanticipat d Difficulties

5.5 Anomalies

5.5.1 Anomalies Not Attributed to the Technology Environment

5.5.2 Anomalies Attributed to the Technology Environment

6. Conclusions

7. Value and Implications of Résearch

60.

8.1 Techsys Electronics Inc.

60

- 8.2 Marketing Practitioners and High-Tech Managers

8.3 Researchèrs

References

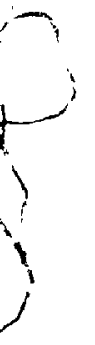

60 
List of Figures

Description

1. The Strategic Marketing Planning Process

2. A Flowchart of Marketing Plan Components

3. A Summary of the Schema for Marketing Plan Development

4. Techsys' Historical Sales and Profits

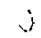
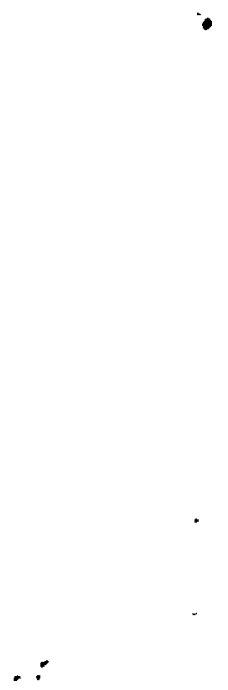

Page

4

5

19

31 


\section{List of Appendices}

Page

1. The Technology Life Cycle $\quad 69$

2. Glossary of Terms $\quad 070$

3. A Schema for Marketing Plan Development

4. Background on Techsys Inc. 81

5. Semi-Structured Interview Questions - Familiarization Session 82

6. Sample Interaction Summary Sheet 83

7. Questions for Review of Plan and Planning Process 84

8. Marketing Plan for Techsys Electronics Inc. 85

9. Operational Marketing Plan for Techsys Electronics Inc. 140

10. Amended Schema for Marketing Plan Development 157 


\section{Introduction}

The purpose of this research was to examine the marketing plan development process in high technology firms. The ise in the number of Canadian high-tech firms has been accompanied by increased interest in the marketing of high-tech products and services. Many authors argue that marketing high technology prodicts requires significant changes in the marketing approach of the company. Accepting this assertion leads one to expect that the marketing planning process of high-tech firms might also be significantly different. However, no research has specifically looked at this issue.

A marketing plan provides managers with a guide for their marketing activities, a reminder of the purpose and objectives of the company, a basis for evaluation of managerial and corporate performance and a tool for the brientation of new employees. The need for a marketing plan, however, is secondary to the need for the planning process. (Hopkins, 1981). It is the process that develops a clearer understanding of the market, the competition, and the various environments in which the firm operates. In this thesis, 'process' refers to the flow of activities and components involved in producing the end product - the marketing plan - rather than the interactions of the people conducting the planning. An examination of the latter process would be an interesting and theoretically valuable study, but the former process serves as the focus of this research.

There are two types of marketing plans and, correspondingly, two types of marketing planning processes. The first is the strategic marketing plan which is a macro-plan for a proquct, product line, division or company. The second is frequently called an annual marketing plan. This is narrower in nature because it is very detailed and is concerned with a one-year time span. By analyzing the literature on both of these types of plans, an understanding can be gained of how such plans are developed.

The research conducted for this thesis is concerned with the annual marketing plan development activities for high technology firms and their products. The firms in these technology-intensive industries are growing in number and size As part of the growth process, formal planning becomes increasingly important for effective management. It is not known whether the marketing planning process for high technology firms is similar to, slightly different from, or very different from the same process for other firms.

This thesis first examines the relevant literature on the marketing planning process and marketing in high technology industries. Next, it presents the specific research objectives and the methodology used to achievo these objectives, including the research process, and analysis procedures utilized. A discussion of the results is then presented. These are classified under Historical Planning Efforts at Techsys, Development of the 
Marketing Plan, Discussions of Anicipated and Unanticipated Difficulties and Anomalies. Finally, conclusions of the research and some of the implications for marketing practitioners and academicians are presented. 


\section{Literature Review}

\subsection{Marketing Planning Literature}

Marketing planning is defined as "a systematic process for developing and coordinating marketing decisions" (Guiltinan and Paul, 1985; p. 12). Stasch and Lanktre (1980), and McDonald (1982) have divided the literature in this area into four categories:

1. Empirically based materials not directly concerned with marketing plans but still relevant to marketing planning (e.g. business planning, market segmentation practices, international marketing);

2. Literature which is not empirically based but is directly concerned with marketing plans (e.g. normative models of the steps in marketing plan development);

3. Empirically based research directly concerned with marketing plans; and

4. Empirically based research which focuses on the individual responsible for the marketing plan.

The vastness and limited relevance of the first category to the marketing plan development process precludes it from a detailed analysis in this review. The second and third categories - the literature directly concerned with marketing plans and planning will be analyzed in detail. The fourth, and most specific area, will be briefly mentioned as it has tangential relevance to the development process.

The normative literature directly concerned with marketing plans identifies both strategic marketing plans and annual marketing plans. Strategic marketing planning:

"... includes the selection of targmarkets and the development of long-range programs for the major ingredients in the marketing mix - the product, the distribution, the pricing structure, and the promotional activities."

(Stanton, Sommers and Bames, 1985; p. 622)

Cravens and Lamb (1986) provide a typical example of the strategic marketing plan development processes found in the normative literature (see Figure 1). Steps 9 and 10 of Cravens and Lamb's process indicate that the annual or short-term marketing plan stems from the strategic planning process. Strategic planning must be completed before the annual plan bectuse it formalizes key issues such as target market(s), product positioning, and intex-product relationships that are used in developing the annual plan.

A key difference between the two types of plans is the time period for which they are intended. The strategic plan identifies the market and product decisions for the five $=$ to fifteen-year time horizon (Verschuur, 1984). The annual plan is narrower in scope and, as 
the name implies, is the part of the strategic planning process that applies to only the current year (Stanton, Sommers and Barnes, 1985).

\title{
Figure 1 .
}

\section{The Strategic Marketing Planning Process}

\author{
1. Understand the corporate strategic plan \\ 2. Select marketing planning and control units \\ 3. Analyze situation in product markets \\ 4. Choose market target strategy \\ 5. Set objectives for target markets \\ 6. Determine marketing program positioning strategy \\ 7. Design the marketing organization \\ 8. Prepare financial analyses for marketing strategy \\ 9. Translate strategy into short-term plans \\ 10. Implement, evaluate, and update annually \\ Source: Cravens, David W., and Charles W. Lamb, Jr., (1986). \\ Strategic Marketing Cases and Applications (2nd Edition). \\ Richard D. Irwin Inc., Ilomewood, Illinois, p. 8.
}

In smaller, single business organizations (rather than diveŕrified, multi-divisional companies), the two plans may be combined into one (Stanton, Sommers and Barnes, 1985). In such cases, the strategies would be carried for two or more planning periods with only minor modifications. The annual plans would be different each planning period. If the two plans are not combined in some way, the reconciliation of long term goals to short term objectives and plans may be a difficult process (Hopkins, 1981).

In contrast to strategic planning, annual planning is concerned more with specific actions than with strategies and theoretical concepts, such as product portfolio matrices and lifestyle segmentation.

"The [annual] marketing plan outlines the details of and rationale for the organization's total marketing effort. It may be prepared for a brand, a product line, a division, or even an entire organization."

$$
\text { (Wright, Winter, Zeigler, O'Dea, 1984; p. 515) }
$$

Discussion of annual marketing planning is most often normative with little empirical backing. Ipcluded in virtually every introductory marketing and marketing management textbook is a flowchart of the components of a marketing plan (See figure 2). Usually accompanying the diagram is a description of the components, perhaps making general references to the kinds of information that should be considered under each heading. An example of the type of normative explanation most often found in the literature is provided by Winer (1965): 
"Ideally ${ }_{z}$ the situation analysis should cover other firms in the industry, so that the company may benefit from their experiences, both successes and failures." (Winer, 1965; p. 4)

Winer does not discuss what aspects of the competition to 'cover', how to go about such an investigation or where to get the information. Most normative sources do not identify what

. firms are really doing when they plan their marketing.

\section{Figure 2 \\ Marketing Plan Components}

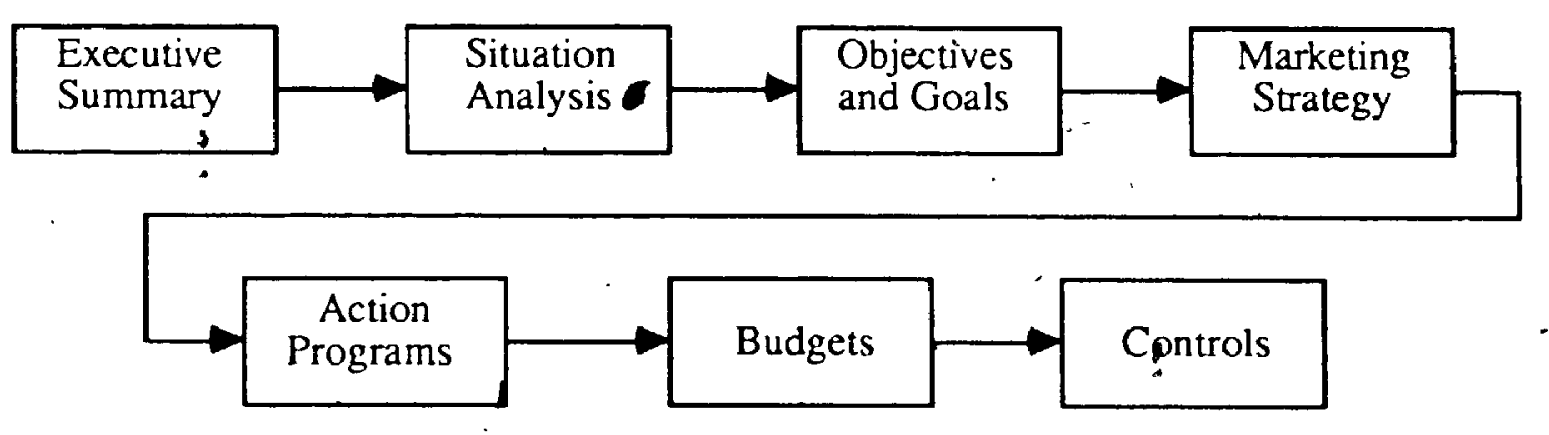

Source: Kotler, Philip, and Gordon G. McDougall, (1982)
Principles of Marketing, Prentice-llall Canada. Inc..
Scarborough. Ont.. 86.

Of greater use for the sludy of the marketing plan development process is empirically based research directly concerned with that topic. The next section outlines the findings of authors in this area.

\subsubsection{The Marketing Plan Development Process}

Several authors have outlined characteristics of good plan development or a good plan. Aylmer (1980), who drew on his experience at Domtar Inc., a large, diversified Canadian manufacturer of commodity type products, stressed the importance of using product specific and market segment specific figures. Stasch and Lanktree (1980), one of the few multi-case empirical research studies, used a convenience sample of six organizations, and outlined the planning characteristics that were common to the two 'very good' marketing planning organizations in their sample. These characteristics included a top-down orientation at the outset of the process (where upper management does the planning), the inclusion of senior managers' input at key points in the process, the use of 
staff specialists, frequent vertical communication, and an iterative writing process for the marketing plan.

John and Martin (1984) obtained organizational level results from a survey of marketing personnel in 53 companies in the Boston and New York areas. Their results allowed them to characterize a good marketing plan as one that is both credible to and utilized by a company's officers. They studied the effects of organizational structuring of marketing planning activities on the resulting credibility and utilization of the plan output. They found that four elements contributed to the development of a credible plan that would be utilized:

1. Clear rules and guidelines are utilized to executé relevant activities.

2. The personnel responsible for the execution of the action plan are separated organizationally to promote accountability and hence credibility.

3. Participation in the planning activities is as broad as possible.

4. The decision-making activities are decentralized among the personnel involved in the process.

Walker (1976) recommended that one executive have responsibility for the entire plan. Jaffe (1975) promoted the use of engineers in the development of marketing plans as they are the product experts and will be valuable at many stages of plan development, including the preparation of the advertising and sales literature. Finally, McDonald (1982) made several suggestions to prevent problems from arising in the plan development process: utilize common terminology, include only essential data, stress the narrative form rather than figures and purely financial data, develop a fully-integrated marketing function, obtain the support of the CEO and have a plan for the implementation of the plan. These recommendations resulted from data collected using in-depth interviews, postal questionnaries and attending marketing planning workshops. In total, 385 directors and senior executives in a spectrum of organizations were contacted over a three year period by McDonald.

In spite of the diversity of the opinions of these writers, there were some recurring themes that may be isolated.

- There is a need for the development of a good annual marketing plan (Jaffe, 1975; Walker, 1976; Stasch and Lanktree, 1980; John and Martin, 1984). 
- A sense of accountability or responsibility for the plans is needed for success (Walker, 1976; John and Martin,1984)..

- The commitment of top management helps ensure that the plans are well developed and implemented (Stasch and Lanktree, 1980; McDonald, 1982). .

- A bottom-up orientation is more successful when it comes to plan development (Jaffe, 1975; John and Martin, 1984).

The empirically based research directly concerned with marketing plan development is very limited (Stasch and Lanktree, 1980; Cosse and Swan, 1983; John and Martin, 1984). The primary example is by Hopkins who completed two studies for The U.S. Conference Board in which he surveyed 162 American manufacturing and service firms (1972) and then 267 manufacturing and service firms (1981). No details are given in the reports on sampling procedures or response rates. His purpose was not to study and report on the process nor to provide an overview report on methods or plan formats. Rather his report was practitioner oriented, and simply provided examples of plans and planning guidelines from which business practitioners could extract information that would be helpful in their own planning. These two studies, which yielded very similar results, described the marketing planning practices of the companies that responded and provided numerous examples of the development guidelines ufilized by these companies: They did not yield quantitative or summary data.

The more comprehensive of the two studies was the one published in 1981, using 267 American firms. The purpose of the report published from the study was as follows:

"... to describe the current practices of company managements in the preparation of marketing plans, and to show examples of company guidelines, forms and schedules actually employed for this purpose."

(Hopkins, 1981; p. vi)

In most of the 267 companies in the sample, the senior marketing management officer was surveyed. Unfortunately, Hopkins did not provide any more detail on the research methodology he utilized for his survey.

The importance of the study and its results should not be underestimated because of the lack of an explanation of Hopkins' research procedures. The study had several advantages that make it valuable to researchers of the marketing plan development process. It is an empirical investigation of 267 companies - the most of any study on the topic of marketing planning. . It provides many examples of maketing planning guidelines that allow the reader to extract information that Hopkins did not mention in his report. It is practitioner oriented which allows the results to be used for more than just theoretical discussion and examination. For example, it lends itself to the formulation of a marketing 
plan development guideline which may be used for such practical purposes as the development of a marketing plan.

The marketing planning literature has not developed to the point where the key concepts and practices are known so that specific hypotheses may be formed about variable relationships. On the contrary, very little is known about the planning activities of most types of companies. The Hopkins reports represent the most advanced research studief to date, yet they are descriptive in nature and do not provide detailed analysis of the data nor attempt to provide specific frameworks for future researchers of practitioners.

Furthermore, there is no description of the process or comparison across firms in different industries. This reflects the low development of knowledge and identifies the need for more exploratory empirical research.

\subsection{A Review of High Technology Marketing Planning}

There are few examples of marketing planning studies in the marketing high technology literature. The relative freshness of the topic does not encourage such advanced research of an entire process. One project by Moore (1981), used a case study of Porex Technologies, a plastics manufacturer, to show the importance of marketing planning in high technology industries. He concluded that it is absolutely necessary to launch a professional marketing effort before a crisis, such as the appearance of an even

- higher technology, strikes. He also recommended that the planning process be a continuous one and that the plan be given enough time to take effect. Updating the plan, in an attempt to keep it current and therefore useful would seem to be a necessity in an environment that is changing so quickly. This opposes the second recommendation of giving the plan enough time to take effect because there is the possibility that the plan could be rendered useless by a sudden change of events. Management must reconcile these two uncomplimentary goals so that the plan remains current yet is not changed before the valid recommendations have time to take effect.

Other authors such as Yeagar (1985) have examined strategies, such as a solution-oriented strategy versus a product-oriented strategy, when marketing high technology products. Yeagar found that a solutions orientation was a common success factor in cases such as Measurex, Tandem, Impact Systems, Zeiss and Hewlett Packard. Again, specific examples are given in the form of case studies. These reports do not, however, discuss marketing planning activities or plans explicitly.

Another area that must be considered when examining the marketing plan development for high technology products is the importance of marketing internationally. In many instances, the high-tech firm's product is so specialized that there are only a few

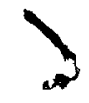


geographically dispersed, potential buyers. Marketing and selling the product internationally is often the only way for the company to achieve profitability. One study . found that over $50 \%$ of Canadian high-tech firms' sales come from outside of Canada (Barnhill, 1985).

The topic of international marketing planning has been given some consideration by those interested in international marketing. The work done, however, has not been specifically related to the marketing of high technology products. Nonetheless, because of the importance of marketing internationally for high-tech firms these studies do provide some valuable insights. Hulbert, Brandt and Richers (1980) described and compared the marketing planning practices of subsidiaries of Japanese, European, and U.S. firms using personal, structured interview data from the managers of 80 multinational corporations' subsidiaries operating in Brazil. These authors identified the following issues as problems for the multinational company marketing planner:

1. Information from subsidiaries may be difficult or impossible to retrieve.

2. Coordinating information flows within the company is difficult.

3. Planning is short-term only, or the long-term planning is inadequate.

4. There is a lack of trained manpower in the subsidiary's environment.

5. There is an overemphasis on plans as control devices leading to infighting and manipulations to meet projections.

Hulbert, Brandarld Richers recommended joint participation in objective-setting, the use of managers with field experience at the home-office, better management of planning and communications systems and the promotion of collaborative atpitudes as possible ways to alleviate the problems.

Lorange (1973), in discussing formal planning in multinational corporations, stated:
"The complexity of strategies and environments of a multinational makes the design creation process difficult. However, beyond this increase in complexity there is no fundamental difference in designing planning systems for multinational or national companies."

(Lorange, 1973; p. 83)

It would seem then, that the marketing planning function for an international marketer is more complex but not necessarily different from that of a domestic marketer. Any differences would arise from the information sources used and the timing elements, not the process or end result. 


\subsubsection{Marketing in High Technology Industries}

Since the focus of this thesis is specific to marketing planning in high technology firms, it is appropriate to review the relevant literature concerning high-tech marketing. This literature is limited because the marketing of high technology products and services is a relatively new topic for research. As a result there are few empirical studies but many articles utilizing experts' opinions and case studies.

An important consideration in this exploratory stage of theory development is a definition of the term "high technology". Many authors refer to "high technology" products and firms without offering a definition of the term (Barnhill, 1986; Boag and Munro, 1986; et al).

Shanklin and Ryans (1984a) have outlined three criteria which must be met for a product or firm to be labeled "high technology":

1. A strong scientific - technical bias 2. The new technology can quickly make an existing technology
obsolete

3. The applications of the products create or revolutionize markets and demand.

A particular industry would be labeled a high technology industry if the products, processes or services produced satisfied these three criteria.

A more general definition of high technology was suggested by the U.S. Department of Commerce:

"A product or process with an above average level of science and engineering skills and capabilities compared to other industries, or one in which there is a rapid rate of technological development."

(as quoted in Fauman and Weiss, 1986; p. 68)

This definition, although more general than Shanklin and Ryans', agrees with their overall notion of high technology.

The nefure of the products, as the definitions imply, has encouraged the assumption that marketing in a technology environmeat is significantly different than marketing in other environments. These differences are attributed to the fast moving nature of the products and markets stemming from such factors as frequent product improvements, unexpected technological breakthroughs, and the ease of entry into and exit out of the market which create ever changing competitive environments.

The majority of the literature about marketing in high technology firms deals with a single aspect of marketing at a time. Examples include the topics of segmentation (Shanklin and Ryans, 1984b; Johne, 1984), advertising (Sigel, 1984; Sigel, 1985; 
Shanklin and Ryans, 1984a, 1984c; Fuerst, 1986), distribution and channel relations (Kent, 1985; Petre, 1985; Finch, 1986), and marketing research (Cowell and Blois, 1977; New and Schlacter, 1979; Hauser, 1984). There are also several papers on the general use of marketing in high technology industries (Lamont, 1972; Shanklin and Ryans, 1984a, 1984d, 1984e; Barnhill, 1985; Barnhill, Gattiker and Lynn, 1986; Boag and Munro, 1986).

The information in this body of literature can be very helpul in identifying areas of the marketing planning function in a high-tech firpothat could be different from this function in other firms. These areas have been isolated and are presented below. Many of the anticipated differences in the marketing function are normative in nature but the points discussed do provide areas fór examination.

\section{Products}

Product Life Cycle - The stage of the product life cycle may be very difficult to determine because the growth of high-tech products is often very fast and different from that of other products. Several authors (Shanklin' and Ryans, 1984d,e; Ford and Ryan, 1981; Ryan, 1984) have suggested that a technology life cycle (TLC) which traces the sales of a technology rather than a product, may be more strategically useful (refer to Appendix 1 for a discussion of this concept).

Servicing - The products are complex and as a result there may be a greater chance that a functional problem will arise. This places a demand for servicing as part of the product which may not be present or as important for most products. The importance of this area has been outlined by Kent (1985) who asserted that servicing can enhance the chances for success for a high-tech company.

Timing of Obsolescence - The definition of high technology products indicates that a new product can quickly make an existing product obsolete (Shanklin and Ryans, 1984a). This puts a strain on management to estimate when the next version of a product should be marketed. It is suspected that this may be a factor in many areas when developing the marketing plan (especially the strategies section, which in turn affects all other sections).

\section{Research and Develópment}

Somewhere in the marketing plan should be a description of $R \& D$ activities and their implications for future marketing needs. This may not be a major concern for most firms, but is central to many other areas in the high-tech firm. It would most appropriately be incorporated into the "Internal Problems and Opportunities" section of the plan. 
Special attention should be paid to the R\&D - Marketing interface. A major problem in many high-tech companies is the strained relationship between personnel in the R\&D department and the marketing department. These problems stem from a lack of communications, lack of appreciation for the other's function and generally a difference in goals (Souder, 1980; Kiel 1984; Gupta, Raj and Wilemon, 1985).

An additional potential difference results from the fact that most high-tech executives have technical backgrounds (Bamhill, 1985). It may be necessary to monitor the terminology of the plan so that it is common to both R\&D and Marketing personnel (McDonald, 1982).

\section{Market Situation}

The anticipated changes-component of the "Market Situation" section may be very difficult to complete. It will be arduous to analyze the company's own technological future but it will be much more complex to analyze the anticipated changes for the entire market.

International market analysis will be quite cồmmon in high-tech firms' marketing plans. A company with a specialized product is forced to market internationally to achieve profitability. This multiplies the problems and opportunities that the company is exposed to in distribution, marketing communications and other areas. It would also make the competitive analysis larger becäuse it would include each country in which the company operates.

\section{Forecasts}

The major problem here is the difficulty in defining and measuring demand and sales. When a high-tech product is in the early stages of the product life cycle (or - technology life cycle), it is supposed to create the demand (Shanklin and Ryans, 1984a). If the demand must be created, then a quantitative measure of potential sales is not easily determined. Once again the technological forecasts will be difficult because of the unpredictability of many of the environments in which high-tech companies compete.

\section{Information Sources}

The literature contains mixed views on the extent to which high-tech firms utilize market research. Bamhill (1985) found that with some exceptions, little or no marketing research is done by companies in the high-tech industry in Canada. Shanklin and Ryans (1984e), on the other hand, found that high-tech managers are using fórmal marketing research such as focus groups and concept testing. There is the chance that marketing research reports will be a rare commodity for the high-tech firm as a source of information. 
There is the possibility that formal company records (such as sales meetings summaries) will not be available as a source of information. Internal record keeping, certainly in any well-developed form, is often a characteristif of an established company, not a young, fast-moving company (as most high-tech firms are).

Competitive literature may be very difficult to obtain due to the necessity of secrecy when introducing new products/strategies. It was found that $80 \%$ of high-tech executives considered trade shows to be their primary source of learning about competitors' new product development (Shanklin and Ryans, 1984a)., This indicates weak sources of information on the competitive environment for many firms because the information becomes 'public' at a trade show.

\subsection{Summary of Literature}

The research on and knowledge of marketing planning and marketing planning in high technology industries is still in the formative stages of development. The numerous prescriptive models that exist do not identify what is really involved in developing a marketing plan. It is one thing to know the headings of the sections of a marketing plan; it is quite another to understand all of the elements of each section, how to proceed to develop each section and where the information may be found. McDonald (1982) "summarizes the situation stating:

"... [the problem] is the inadequacy of the current literature in providing the practical guidance [that is] so essential.

- Whilst there can be no such thing as an off-the-peg, universally applicable system, because of the differing size, diversity, complexity and personality of companies, what is clearly needed is something more than the current literature provides."

(McDonald, 1982; p. 8)

The empirical research concerning marketing planning is a step in the right direction but the authors, such as Hopkins, have not identified the issues of importance for high-tech firms.

The theory of the marketing plan development process is underdeveloped. Even less is known about the process for high technology firms. There are suggestions in the literature that the marketing function in high-tech furms is significantly different from this function in other firms. These differences suggest that the marketing planning function for most firms will be inappropriate for high-tech firms. This possibility was investigated and is discussed in the following chapters. 


\section{Research Objectives}

The research examined the annual marketing plan development process in high technology firms using a case study approach. Specifically, the objectives were as follows:

1. Develop a marketing planning schema from the marketing planning literature. .

2. Determine the applicability of the schema to a high technology firm.

3. Identify anomalies in the application of the schema attributable to the high technology environment in which the planning is conducted.

4. Propose amendments to the schema which incorporate the anomalies identified, making it more suitable for the firm studied and perhaps other firms with similar characteristics. 


\section{Research Methodology}

The methodology used in this research may be described using a number of classification techniques. On the broadest scale, this'thesis is exploratory because it is concerned with discovering the general nature of marketing plan development in a high technology environment, and identifying the variables that relate to it (Tull and Hawkins, 1984). The study may also be described as field research since the observations are taking place in the natural decision-making setting - the company (Babbie, 1979).

The data collection methods utilized were a mixture of passive and active. Passive data collection involved the observation of characteristics of the elements under study while active data collection required the querying of respondents (Davis and Cosenza, 1985). Both structured and unstructured observations were made. Structured observations were used to gather information on certain prespecified characteristics such as the use of market research and the R\&D-Marketing interface (Stone, 1978). Observations were unstructured because the researcher actively sought unspecified, salient aspects of the plan development process (Davis and Cosenza, 1985).

The study is also classified as participant observation because the researcher participated in the activities of the system under study (Stone, 1978). The term "participant observation" takes into account several research methods such as observation, informant interviewing, document analysis, respondent interviewing, and participation with self-analysis (McCall and Simmons, 1969). In conducting participant observation research, the researcher can play one of several roles. In this case, the researcher might best be described as 'participant-as-observer' (Gold, 1969). In this role, the researcher participated fully in the activities under observation but made it clear that he was doing research (Babbie, 1979).

The participant observation technique offered significant advantages that other research methods did not. It allowed the researcher to be more responsive to data than other methods. The researcher did not need to rely on the memories of respondents, and as such the method was particularly useful for the study of the marketing plan development process (McCall and Simmons, 1969). Participant observation, in general, allows the researcher to study a complex situation in great depth, providing the opportunity to gain insights that may not be possible using other methods.

A disadvantage of employing the participant observation technique is the lack of standardized procedures (McCall and Simmons, 1969). Specific techniques of data collection and analysis must be developed for eacti study done. In this case, the application of the marketing plan schema, to be described later, Was the procedure used to 
provide structure to the areas that were examined. In addition, the researcher was familiar with the work of other researchers who used similar techniques and/or studied related topics. A second disadvantage is that the researcher may over-identify with the group under study and lose the research perspective (Miller, 1969). Regular discussions with the thesis advisory committee members, who were external to the firm under study yet sensitive to the research, served to maintain the researcher's objectivity. Thirdly, there is selective perception and interpretation on the observer's part (Miller, 1969). Careful documentation (tape recorded interviews and written observational summaries) allowed the advisory committee to monitor the data collection and interpretation and therefore check for biases. Finally, there are reactive effects of the researcher's presence on the organization (Babbie, 1979). Babbie explained that there is no complete protection against this effect, but sensitivity to the issue may provide partial protection.

Another classification of the research study is case research. This method of data collection is appropriate when the researcher wishes to gain a rich, in-depth knowledge of the situation in question. It may be differentiated from case studies used for teaching purposes in that it has a research focus to structure the data collection activities.

Furthermore, a case history or case study enumerates a sequence of ev " ts while case research requires an understanding and analysis of these events. It may concluded then, that case research follows a process, stemming from the research purpose and objectives, that will aid data analysis (Bonoma, 1985).

Bonema (1985) provided this description of xhy case research should be utilized:

"...the goal of data collection in case research is not quantification or even enumeration, but rather

(1) description (2) classification (typology development) (3) theory development and

- (4) limited theory testing. In a word, the goal is understanding."

(Bonoma, 1985; p. 206)

The research goal in this instance was to gain an understanding of the marketing plan development process in a high technology firm.

Bonoma (1985) also suggested three instances in which case research is useful.

1. When the theory development is low,

2. When the subject is of a complex nature, and

3. When there is a need for the subject to be studied in a natural context.

The study of marketing plan development exhibited all three of the characteristics 
suggested by Bonoma.

Whenever the selection of a data collection technique is made, there is a trade-off between data integrity (error and bias factors) and currency (real-world applicability or external validity) (Bonoma, 1985). Case research rates very high on 'currency' but low on 'data integrity' (as defined by Bonoma).

Hirschman (1986) takes a much more positive view on the value of case research in marketing. She feels that this method and others which stem from the humanist philosophy can-provide complete and effective-approaches of theory construction, testing and revision when they are used competently. She suggests that Bonoma's classification of such methods as primarily hypothesis-generating devices underestimates the power of these research techniques. Both authors, however, agree that case research is appropriate in an area where the level of theory development is low, such as is the case regarding marketing planning in high technology firms.

The use of a case study was supported by the use of cases in several of the studies mentioned in the review of the literature (for example Aylmer, 1980; Stasch and Lanktree, 1980; Helmeke, 1984; Yeagar, 1985). Other authors, Hopkins (1981) being the prime example, have used survey techniques to examine the marketing plan development topic. These examples are few in comparison with the total sum of literature. If this thesis were concerned only with the literature on marketing plans and not with the marketing plan development process, a survey might have been a viable alternative. The current research, however, went beyond the Hopkins study to examine marketing planning in a firm that was operating in a high technology environment. This is an area that has very little theory development and would not be as efficiently studied through survey techniques at this stage as it can be through case research.

\subsection{The Research Process}

The stages in the research process were:

1. A schema for marketing plan development was prepared from the relevant literature using Hopkins' (1981) study as the framework on which to build. The schema was compiled using the information contained in the Hopkins report (including the many forms, tables and exhibits provided as examples of actual planning guidelines utilized by the companies surveyed), as well as the guidelines of the other authors refenced. The plan divisions (i.e., the section headings) were those proposed by Hopkins. This schema provided a composite of the components of a marketing plan, the development processes . that were followed, and the relevant information sources needed. The end product was a general step-by-step procedure for marketing plan development that was much more 
comprehensive than any of the individual research sources alone could have provided.

Although the schema is formally an uutcome of the research and, therefore, might more usually appear later in the thësis, it has been included in this section to facilitate understanding of the research process and analysis procedures. Also, a glossary of key terms and names is provided to avoid difficulties in comprehension of the following sections. The glossary is presented in Appendix 2. The schema is shown in condensed form in Figure 3 and in its entirety. in Appendix 3.

- The schema outlines a sequence of development for the marketing plan starting with an analysis of the situation, and leading to forecasts, objectives and strategies, action programs, monitoring procedures for the programs and, finally, contingency plans. Also provided is a description of the process to follow in the development of each section, the components that each section should contain, and a listing of potentially appropriate information sources for the development of each section.

2. A firm was selected as the site for the case study. The choice of an appropriate firm was affected by several factors. The exploratory nature of the research stemming from the low theory development, the time requirements of developing a marketing plan for a firm, and the nature of the thesis context all served to limit the size of the sample. In particular, the decision to actually develop a marketing plan for the company required, for the purposes of this thesis, that only one firm be examined.

The decision to conduct this research using one firm naturally led to the question of which one to study. One of the companies that was approached as meeting important criteria and that agreed to participate was Techsys Electronics. An important factor in the firm selection was that the company faced situations that other companies operating in high technology environments also faced. Some of the situations that Techsys faced which were representative of other high-tech firms were:

(i) The firm was competing in a high technology industry (as defined by Shanklin and Ryans). (Refer to Appendix 4 for a description of Techsys Electronics Inc.). The bubble memory technology that Techsys incorporated into its products may be labeled high-tech, allowing the categorization of the products and the firm as high-tech.

(ii) It was located in Ottawa but competed in both the domestic and international markets. Many interviews and on-sight observations were required in this research. It was therefore necessary for the firm to be located close to the 


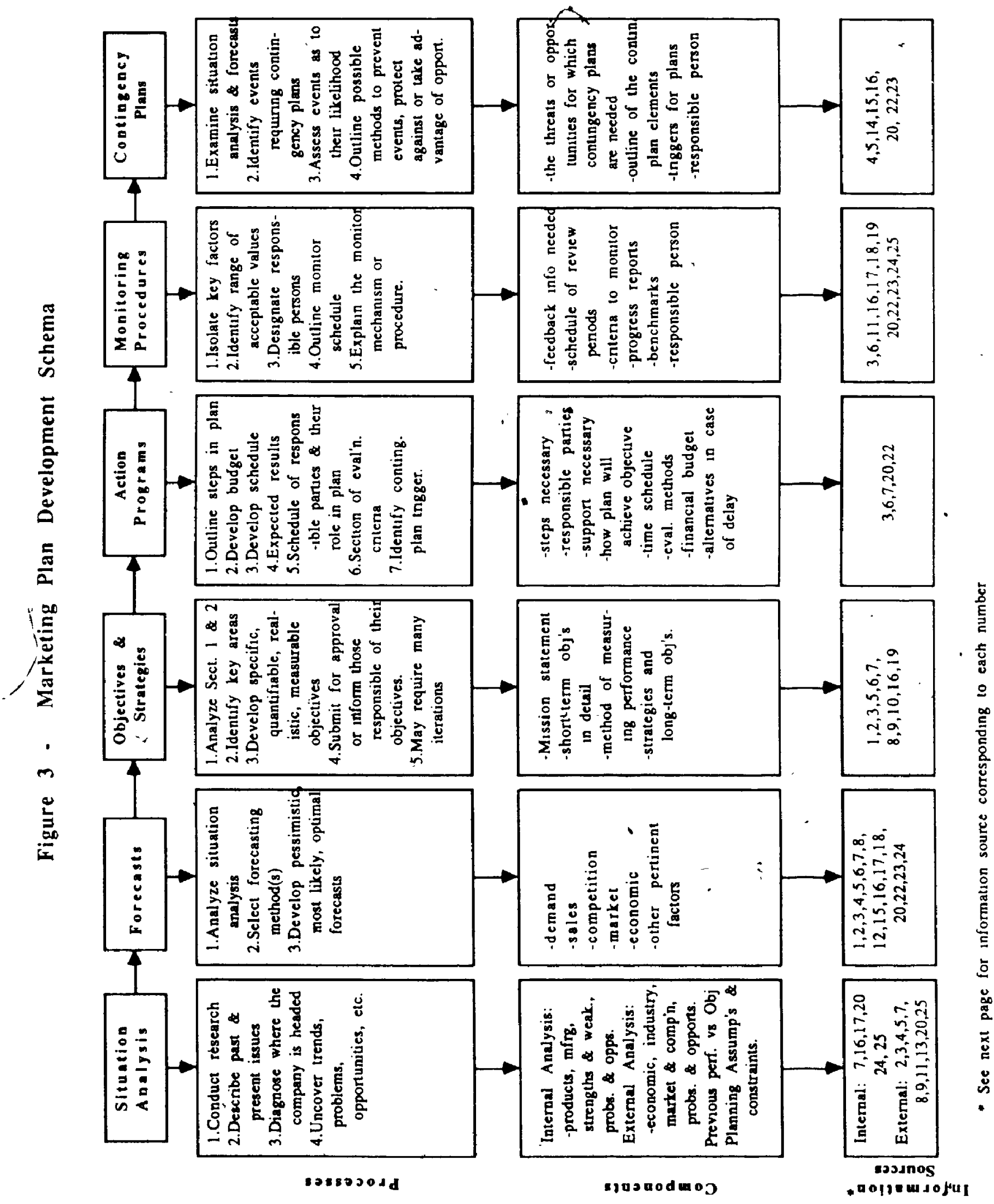




\section{Figure 3 - Continued}

Sources of Information

Qutside the Company

1. Customers

2. Competitive Literature

3. Suppliers, Distributors, Wholesalers

4. Trade Magazines

5. Trade Associations

6. Professional Organizations

7. Consultants

8. Embassies, Consulates

9. Libraries - Government, National, Universities

\section{Government}

10. Census Data

11. Patent Reviews

12. Federal Publications, Local Publications

13. Specific Government Departments/Officials

14. Industrial Sector Reports

15. Statistics Canada Publications

\section{Inside the Company}

16. Market Research Reports

17. Sales Call Reports

18. Orders

19. Complaints .

20. Informed Persons - Employees 6 Other Managers

21. Past Year's Customer Correspondence

22. Sales Meeting Summaries

23. Technical Reports

24. Financial Statements/Records

25. Other Company Records (e.g. Personnel Files, Production Reports) $\therefore$ 
researcher. This situation was not unlike that of many other Canadian high-tech firms, however, as there are many such firms located in the Ottawa area. An international element is also characteristic of most high-tech firms in Canada.

(iii) The firm needed to develop a marketing plan. If the marketing plan was not needed then the development process would have been a low priority to the firm's officers, would have been unrealistic and the quality of the information obtained and the plan itself might have suffered. Techsys had experienced stalling markets (as shown by a decrease in sales in the past year) after a period of rapid growth. This indicated the need for more marketing input into the management of the firm.

(iv) The company had a supportive staff and Chief Executive Officer. The commitment of top management has been found to improve the marketing plan development process and promote plan utilization (Stasch and Lanktree, 1980; McDonald, 1982). Strong managerial support was also necessary for the type of research proposed.

(v) The company had been in existence for more than one year with little likelihood of ceasing operations in the current year. The development of the marketing plan took approximately three months. If the selected firm had gone out of business in that time, the research may have been lost and a new firm would have been needed.

(vi) The firm was small (i.e., small sales volume and few employees). This was an important theoretical point because most high-tech firms are small. It was also of

- practical importance because a larger firm's marketing plan development may have been too large a task given the time and resource constraints of this thesis.

(vii) At the time of selection, the company was felt to have one distinct product line. A single marketing plan for the entire company, therefore, seemed to be appropriate. The theoretical support for this situation comes from the fact that most high-tech firms are formed on one product idea (Zarecor, 1975). Most, . then; fall into this "one product line" category at the beginning of their development. Once the planning was started, however, it was discovered that Techsys really had two closely related lines and was developing a new product 
line that was unrelated to the other two. This complicated the planning process because it meant more analyses and more strategies had to be developed. However, the need to develop a new line of products added another realistic factor to the plan development process.

(viii) Techsys was operating in a difficult, highly competitive, risky environment typical of high-tech firms. The company was in the middle position between component suppliers on the one side and Original Equipment Manufacturers (OEMs) and Value Added Resellers (VARs) on the other. If the suppliers ceased operations or stopped supplying Techsys, the firm would have had to look for other suppliers of bubble memories (which were few in number). The search and negotiation period would be very costly to Techsys. Similarly, if their customers were to produce the products themselves, Techsys would lose a large part of their business. This situation is similar to one faced by many high-tech firms and many industrial firms in general. -

3. Initial semi-structured, in-depth interviews were conducted (and tape recorded) with key personnel of the oase firm. These interviews acted as familiarization sessions for the researcher and the company personnel. They also provided a starting point for the marketing plan development by examining the employees' personal histories, their responsibilities in the company, their exposure to planning and their knowledge of marketing planning in particular. (See Appendix 5 for the questions used to guide these interviews).

4. The schema was utilized to develop a marketing plan for the case firm selected. The researcher's role in the development of the plan was to advise the President and Marketing Manager as to what could go into each section of the plan (as determined by following the schema) and then to develop the plan based on their input. If the researcher felt that management should pursue or not pursue some action, a recommendation was made. It was left to management as to whether they wanted to follow this advice or not.

In order to promote input from the executives a photocopy of each section of the schema was given to them at different points in time (to correspond to the section being developed at the time) so that they could quickly provide their comments and suggestions. The researcher utilized these point-form comments to guide the development of the planning. This, combined with oral comments, allowed management to provide the most input with the least investment in time. 
5. Throughout the marketing plan formulation process, an observation journal was kep't in which relevant or potentially relevant observations and comments were recorded. (See literature review for the areas of observation).

The observation journal was composed of both structured and unstructured elements. As soon as possible after any interaction with company officials, an "interaction summary sheet" was completed. (Refer to Appendix 6 for an example sheet). These records provided structured observational data, recorded at the time of the interaction, or shortly after, that were available for analysis upon completion of the marketing plan. The unstructured elements were an essential part of the data collection process dealing with unanticipated, yet pertinent, information, elaborations on the structured material, and key. points that served as guideposts for future observations.

Regular progress reports were given to the thesis supervisor and supervisory committee. These informal oral updates were normally held every two weeks but were more frequent when the necessity arose. In addition to these regular informal sessions, the supervisory committee reviewed and critiqued preliminary drafts of the marketing plan. These two review procedures ensured that sufficient, appropriate data were collected in the proper manner. When the marketing plan was completed, it was felt to be too long and detailed for the firm's employees to use as an operational guide for marketing operations. A second, condensed marketing plan was created to solve this problem. The majority of the reduction came from a drastically condensed situation analysis. The remainder was the result of reduced description and decision explanations and the replacement of many time schedules with only one master schedule that was put into an Appendix. Both plans were given to the President as he felt that both were valuable for different purposes.

6. The marketing plan was then presented to management and semi-structured interviews were conducted with key personnel to obtain their opinions on the plan's. apparent usefulness, clarity, areas for improvement and so on. (Refer to Appendix 7 for interview format)

7. Anomalies in the process were identified and an attempt was made to assess their source and the effect that they might have on the marketing of the case firm.

\subsection{Analysis Procedures}

One of the most serious obstacles of qualitative data analysis techniques is that the methods of analysis are not well formulated (Miles, 1979). In participant observation, for example, the research design is intentionally unstructured so as to maximize discovery and 
description rather than systematic hypothesis testing (McCall and Simmons, 1969). In this research, however, there was an attempt to formalize certain aspects of the analysis. The predetermined questions for the two semi-structured interviews (one at the beginning of the marketing plan development process and one at the end, presented in Appendices 5 and $7)$, serve as examples. The majority of the structure came from the schema that was -developed and tested (presented in Appendix 3), and the observational journal.

Barton and Lazarsfield (1969) found that four types of analysis were used when qualitative data were collected using participant observation. These methods of analysis were as follows:

1. Outlining surprising observations

2. Putting observations into descriptive systems

3. Suggesting relationships, causes and effects

4. Formulating concepts which sum up a great wealth of observations in a single formula.

While this thesis utilized all four analysis techniques, the predominant method was outlining surprising observations because of the expressed interest in discovering anomalies in the marketing plan development process.

By analyzing the marketing of high technology literature, it was possible to isolate areas of the marketing plan and its development process which could potentially differ significantly from those observed in a non-high technology company. For the purposes of this thesis, a significant difference referred to an instance when the schema was incapable of describing or explaining a component in the company's marketing plan development process or marketing plan. The difference could have been in the form of an additional aspect that must be included, a variation of an existing component or a deletion from the schema because of its inappropriateness for the high-tech firm studied. These areas were the key points for observation and analysis in the marketing plan development process.

The areas discovered in the literature were concerned with the products (the product life cycle theory, servicing as a component of the product, timing of obsolescence), research and development, market situation, forecasts, and information sources. There were, of course, many previously unidentified areas where significant events were observed and recorded, but these topics represented differences which had already been identified and suggested in the literature review as potential sources of variances and so were specifically sought out in the plan development process.

\subsection{Limitations of the Research}

This research study has two main limitations. The first is its lack of 
generalizability. This characteristic is generic to the case research methodology which was discussed previously. The lack of generalizability may be described more specifically as weak external validity due to selection interaction and low reliability (Davis and Cosenza, 1985). "Selection interaction refers to the effects that the type of respondent or subject has on the study's results. The similarities between Techsys' situation and those faced by other high-tech firms have been outlined. A characteristic that might make Techsys unusual is a $23 \%$ decline in sales for the last fiscal year after several years of very large sales increases. The research also rates low on reliability because the data collection and analysis were dependent on the researcher's personal observations, interview skills and ability to interpret qualitative data accurately. Again, these are problems with the case study methodology that have been discussed in an earlier section along with methods for decreasing their impact.

The second limitation of the research is that it does not include consideration of the implementation of the plan developed. The implementation of the plan was outside the scope of this research of the plan development process, but it does limit the amount of exposure to potential problems and information. There will be many anomalous situations concerning the implementation of the marketing plan that could be attributed to the high technology environment. These differences could be recorded and then incorporated into the marketing plan development schema. Future researchers may wish to examine such anomalies. This issue does not necessarily represent a weakness in the research, only a limitation.

In an effort to mitigate this second limitation, semi-structured interviews were conducted with the key personnel after they had examined the finished marketing plan. They were asked to identify any weaknesses that could inhibit implementation and generally judge the plan's apparent usefulness. There were few 'surprises' from these interviews as the same two company officials who had significant input throughout the development stages were also the ones interviewed.

It is important to note that the firm's positive evaluation and implementation of the marketing plan that was developed is not an issue in judging the success of this research. The firm's emphasis could have changed during the course of the plan development process, the plan may not be as the company's officers had envisioned it or the plan may not be implemented for several other-reasons. These situations do not reflect upon the value of the data collected on the development process of the marketing plan. 


\section{Discussion of Results}

The remaining sections of this document present and discuss the resilts of the research. The chapter is divided into five sections beginning with an examination of the previous marketing planning efforts of Techsys. The information in this segment provides a clear understanding of the environment in which the research took place and allows for a better conceptualization of the value added by this research and the researcher's role in the plan development process.

The second section, 5.2, overviews the development of the marketing plan. It provides a step-by-step description of the process and information sources used.

The third section deals with the difficulties that were anticipated from a review of the literature. These prespecified difficulties were outlined in Section 2.2.1, the review of the "marketing in high technology industries" literature, and were specifically examined in the case study. Thie same headings of Products, Research and Development, Market Situation, Forecasts and Information Sources, as used in Section 2.2.1, are used in section 5.3 to simplify the comparison. 4

Section 5.4 analyzes those difficulties experienced during the marketing plan development that were not anticipated from an analysis of the literature.

Finally, 5.5 utilizes the information and knowledge gained from the first four sections to classify anomalies discovered in the application of the schema. These anomalies are grouped and attribution judgments are made as to their source - either the technology environment or other factors. The progression adopted for this discussion of the results is a logical method of presenting the many detailed and complex observations that were provided by the case study.

\subsection{Historical Marketing Planning Efforts}

The marketing planning activities that Techsys engaged in before this research commenced were primarily of an informal nature. Although the President had created several versions of a business plan which contained sections on marketing strategies, a marketing plan had never been developed. A difference between the types of documents was that the business plan did not contain all of the important marketing elements that the marketing plan did. Also, the business plans had been general in nature with their main purpose to attract investors. In contrast, the marketing plan déveloped for this research was meant to be a detailed operational document to be used by Techsys employees but also adaptable to act as an investment-raising tool.

Planning activities such as uncovering and analyzing trends in the marketplace, 
soliciting opinions on strategies from salesmen, customers and distributors, and designating persons responsible for carrying out actions to achieve goals had been done, but had never been documented in any form for future reference. Other planning activities such as developing monitoring procedures, consciously selecting forecasting techniques and formulating contingency' plans had never beeñ done at all.

The company had not formally analyzed their situation in the five years since the firm's formation. This absence of historical tracking is likely not uncommon in high-tech companies in general. Completing a situation analysis allowed the company's management to examine the progression of events that had led up to their current situation, document where the firm had succeeded and failed, and identify objectives for the future. It also formulated situations in marketing frameworks using such concepts as benefits sought and market positioning where none existed previously.

By developing a marketing plan for Techsys, which outlined the company's strengths and weaknesses and documented previous marketing activities, management could learn from the experiences of the company to become more successful in the future. Documenting the plans for the coming year, would allow management-orcompare objectives, analyze variances, and develop new strategies with greater authority in following years.

\subsection{Development of the Marketing Plan}

As discussed in the research methodology section the researcher's role in this study was to document the application of the marketing plan development schema as utilized by the case firm. The schema was provided to the firm's management along with an explanation of the various sections. The researcher then wrote the plan utilizing management's oral and written comments on each section as guidelines in the development. Many other sources were needed to complete the plan, but management's input was the primary influence on the plan's direction and substance.

The scherra's comprehensive nature meant that management probably would not need to complete every component of every section for their marketing plan to be complete. This was the case at Techsys, where, because of the company's specific environment and/or management's personal preferences, evory section of the schema was not included in the resulting document. The section that was most notably brief was the Economic Analysis'. Management felt that the company's financial situation moved with general economic indicators and certain industry sectors' profitability. They did not feel that a detailed analysis of such general indicators would add significantly to their planning efforts. Not surprisingly then, an economic forecast was omitted from the plan. 
The process of developing the marketing plan is best described by discussing the development of each section of the marketing plan individually.

The situation analysis section of the plan was done predominantly by the researcher with explanations, discussions and input from company personnel as needed. It . was felt that an objective viewpoint on the situation would be most beneficial to the firm. The President reviewed this analysis and made minor modifications before the rest of the plan was developed. Much of the information used to write this section was contained on the premises of Techsys (e.g., competitive brochures, financial'statements, sales call reports, existing business plans). Many outside sources such as Statistics Canada reports, Dun and Bradstreet reports, distributors, customers opinions were also used where needed.

The forecasts section of the plan was done in part by the President and in part by the researcher. The sources that were utilized for the sales forecasts were company records of past sales, trade journal articles, distributor opinions and customer input. Using the information gained from these sources, the President was able to develop five-year forecasts for the PLD line (a.new product line in the development stages at Techsys) that satisfied his standards. The President relied heavily on one distributor for many elements of the PLD planning. This source was accessible and the President felt him to be very reliable. The problem with this relationship was that the President would rely on this source to the exclusion of seeking information elsewhere. This exposed the company to the risk of having a very narrow view of marketing opportunities, customer viewpoints and so on. The sales forecasts for the company as a whole were developed by the researcher, in conjunction with the President. These were based on the past year's fiscal performance, the sales and expenses for the 1986-87 year and judgmental estimates of the company's expected change for the coming year. Other members of management found it very difficult, if not impossible, to suggest sales forecasts for the company. The demand forecasts, like the market size estimation, were judgmental in nature and supplied by the President. The other forecasts were the result of several discussions with the President and Marketing Manager and minor interpretation by the researcher.

A satisfactory mission statement already existed in the company. The objectives were developed by the President and after a discussion with the researcher, were modified slightly to improve their measurability and realism. Strategies were taken from the most current business plan and from conversations with the President and Marketing Manager. The strategies were not given an entire section of their own, but were scattered throughout the marketing plan as the researcher felt this to be a more logical format.

The action programs were developed by the researcher in consultation with the 
President and the Marketing Manager. The activities and time schedules were revised several times because of input from these executives. The primary information sources for these programs were the preceding section of the marketing plan as well as conversations with the marketing personnel.

The monitoring procedures and contingency plans were formulated by the researcher and reviewed by the company representatives. The case company had conducted some monitoring procedures in the past but had never documented the procedures. Weekly management meetings to monitor all facets of the organization and weekly sales and marketing meetings were the key activities done in the past. New procedures were added to these ones for the action programs that were developed. Contingency plans had never before been developed so management had no existing method for their creation.

The marketing plan developed for Techsys was approximately fifty pages in length (see Appendix 8). Four factors were responsible for making the marketing plan so lengthy. The first was that the researcher had little knowledge of either Techsys or its products before the research began. This unfamiliarity promoted lengthy explanations of concepts which may have been obvious to Techsys employees. Related to this was the anticipated lack of technical and situation-specific knowledge of users of the plan outside of the Techsys organization (e.g. those reading this thesis as a research document). The third factor was that Techsys had never developed a marketing plan before and, therefore, required a comprehensive situation analysis, which accounted for about one-third of the length of the plan. Finally, the schema used as a guide was developed from a report which included the planning guidelines from many companies (as presented in Hopkins, 1981). Hopkins' intent was to ensure all possible components and information sources relevant to a broad spectrum of industries be included in this comprehensive report. This completeness lent itself to the creation of a very detailed schema.

Because this marketing plan was too detailed to act as an operational guide for management, a condensed plan was written (see Appendix 9). The President felt that this fifteen-page format was more appropriate for Techsys employees than the one used in the first document which included the theory behind and reasoning for the decisions made. Both plans were presented to Techsys as the President wanted all of the information from the first and the succinctness of the second.

When the marketing plan was completed, it was presented to the President and Marketing Manager of Techsys for a critical review. Their comments were examined and utilized to modify the plan. The changes were predominantly concerned with the accuracy of historical and factual statements and not with the strategies developed. In general, they 
were pleased with the plan and felt that it would be useful to the company. In addition to the operational guidance that the two versions of the plan could offer, they felt that additional value would come from using the documents as tools to educate new employees and to obtain funding. Their critical analyses of the plans were very helpul in formulating the sources of anomalies to be discussed in Section 5.5.

The literature on marketing planning contained many suggestions to insure the quality of the planning activity and the plan jtself. The recommendations followed in this research included: senior management input at key points, an iterative writing process, frequent vertical communication, use of staff specialists. (Stasch and Lanktree, 1980); one person responsible for the entire plan (Walker, 1976); use of engineers in the development (Jaffe, 1975); utilization of common terminology, inclusion of essential data only, a narrative form rather than figures and purely financial data, the support of the CEO (McDonald, 1982); and clear rules and guidelines to execute actions (John and Martin, 1984). Other recommendations could not be followed because of circumstances at Techsys such as the lack of marketing planning experience of management, the small number of employees and the researchers's absence of control over the implementation of the plan. The suggestions that could not be followed because of the above reasons include a top-down orientation at the beginning of the process (Stasch and Lanktree, 1980); organizationally separate the personnel responsible to promote accountability and credibility, promote broad participation in planning, decentralize décision-making activities (John and Martin, 1984); develop a fully-integrated marketing function and a plan for the implementation of the plan (McDonald, 1982).

\subsection{Discussion of Anticipated Difficulties}

The discussion in this section compares the issues suggested in the literature to cause difficulties in the marketing of high-tech products to the experience with the case firm. These areas were especially examined in a structured way because they were anticipated to be a source of problems in the schema application. The arguments put forth by various researchers were described in the literature review and are described under the same sub-headings in this section. The headings are Products, Research and Development, Marketing Situation, Forecasts, and Information Sources.

\section{Broducts}

Product Life Cycle - The application of the product life cycle theory has been questioned for high-tech firms and so it was expected to cause problems in its application to Techsys. In fact, the classical product life cycle theory did not explain the Techsys 
situation well, but through a revised model, some strategic information was obtained. The sales aspect of the product life cycle model applied, as evidenced by the three years of rapid sales growth followed by two years of sales decline shown in Figure 4. The profit figures are incongruous with the product life cycle model, however, as the company has never made a profit and the amount of loss has varied from year to year. The traditional sales curve could not be constructed because Techsys did not keep sales figures broken down by product. Because the company's two main product lines were so similar (the Stortite and Stortite 1 or S and S1), the combined totals were felt to provide the most appropriate substitute. With this modification, the sales curve could be drawn and did indeed fit the expected curve.

\section{Figure 4}

Historical Sales and Profits (Losses)

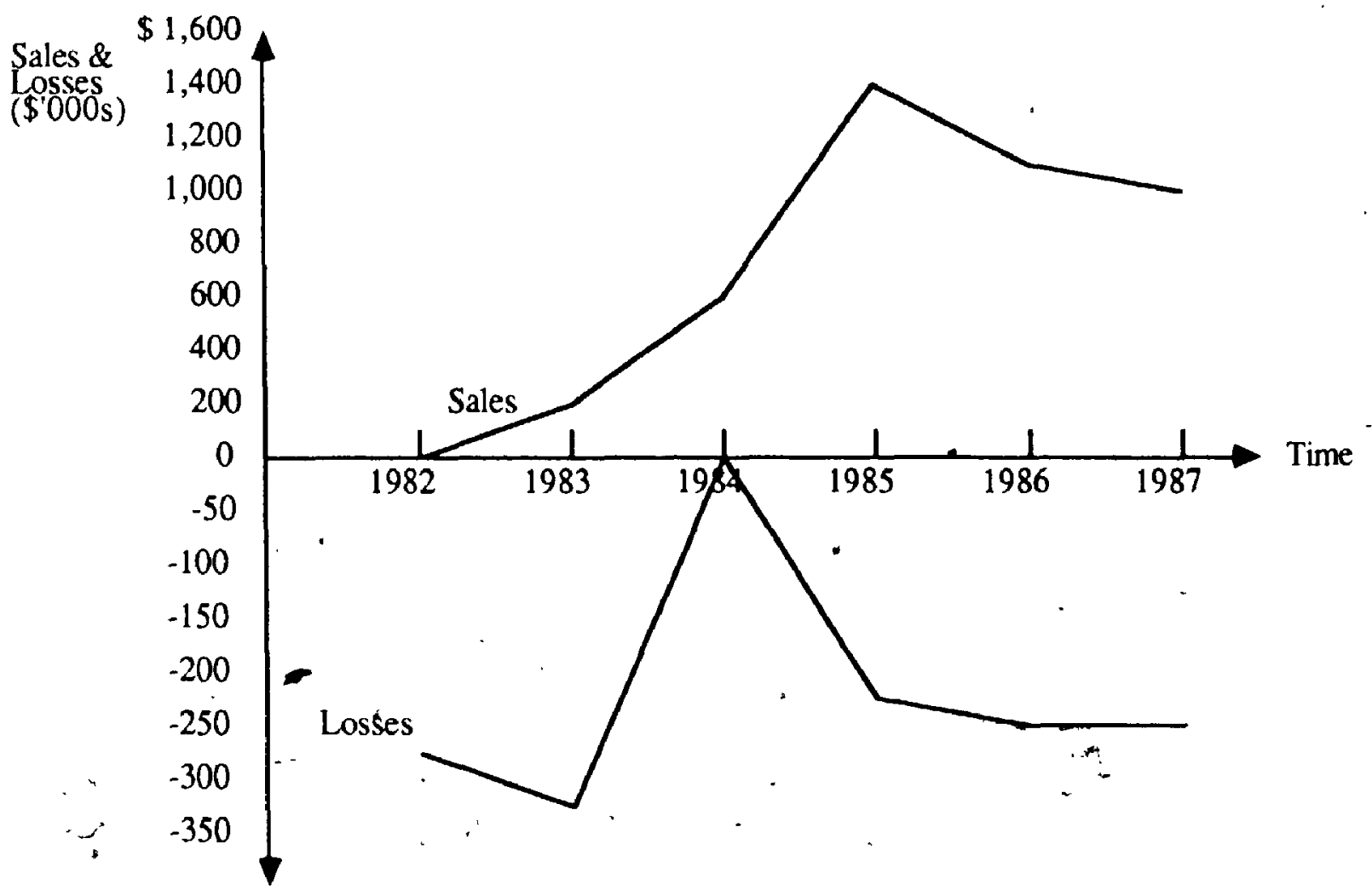

A factor that complicates the interpretation of the sales and profit figures is the inconsistent marketing and particularly the advertising efforts devoted to the products by Techsys. Upon analysis of the advertising expenditures and sales per period overthe last five years, the President found that the most consistent sales came when magazine 
advertising space was purchased exty period. In contrast, when advertising space was not purchased, the sales per periód varied enormously. Therefore, it is difficult to determine if the demonstrated product life cycle is dugio normal market interest in the product or lack of promotion.

The technology life cycle theory appears to solve some of the problems of the product life cyete theory. However, the model only provides a partial fit to the situation at Techers. This theory contends that sales of a technology, such as bubble memory, are a more informative measure for a high technology company to trace for strategic purposes than product sales. Like the product life cycle theory, sales are traced through a series of development stages. Instead of product sales, however, the company's technology sales, production cycles, and technology application are traced. At Techsys the "company technology sales" and "company production cycle" curves seemed to be representative. However, the bubble memory technology never matured to fit the "major technological application" curve. In general, Ford and Ryans' (1981) technology life cycle theory appears to fit the situation better than the product life cycle and consequently seems to give the planner more useful insights into the situation of the company and its high-tech products. This finding concurs with Shanklin and Ryans' (1984d,e) recommendation for the use of the TLC in high-tech industries.

Servicing - Kent (1985) argued that manufacturer support was so important to a high-tech firm's success that it could be the difference between which companies survive and which ones do not. This is not to say that superior servicing ensures success in the marketplace, but it is a necessary component of a successful product offering. There were several occasions when a customer contacted Techsys with regards to a functional problem with one of their products or an inquiry as to a product's capabilities. These were allgiven high priority and attended to by the personnel necessary to solve the problem or answer the question quickly. In one, instance a customer who had been using a Stortite I Data Recorder (one of the firm's products) for several years was given an up-to-date version of the product at no charge. The several hundred dollars spent by Techsys for the upgrade was felt by manayement to be a good investment because the customer,was a regular, large purchaser of the company's products. This example of the typical behavior of the company personnel illustrates the importance placed on the servicing function at Techsys.

Operating in a price sensitive market and selling a premium-priced product, Techsys had to provide superior servicing as part of their product offering or customers would purchase elsewhere. The servicing aspect is particularly importamt when the buying process involves a trial period in which the customer, after purchasing one or two units, 
decides whether to purchase more. If the company sends an engineer to help install the product, is quick to reply to telephone inquiries, and contacts the customer after installation to see how the product is performing, the customer should form a favourable opinion.

The sale of the company's high-tech product does not end when payment is received. This marks the beginning of what is hoped to be a long-term relationship between the two entities. This is certainly different from many consumer product sales bet is similar to most industrial and service sales.

Timing of Obsolescence - Shanklin and Ryans (1984a) felt that the obsolescence topic was important enough to include it in their definition of high technology. Phasing products out was a particularly important consideration for Techsys at the time that the plan was being developed. The products using bubble memories had been available for over five years and had not been successful in terms of profit contribution to the company. The only profitably viable market for the bubble products appeared to be the military sector. There were several reasons why Techsys was not in a position to sell to this market segment. Some of these reasons are the large amount of human resource and capital investment that are necessary to become a military qualified supplier which is a necessary designation for many contracts; lengthy negotiation periods which require continued selling manpower are standard buying practice; and long periods of continued marketing investment for advertising, promotions and sales calls with no return are expected.

The company was in the process of developing the new PLD line which management hoped would someday replace the established bubble memory and CMQS RAM storage systems produced. The problem confronting management was the limited engineering and marketing resources with which to develop and introduce the new line. An uncertain introduction date made the decisions of when to announce the new line and stop promoting the $S$ and $S 1$ lines very difficult. Announcing too soon could cut off the $S$ and S1 sales, leaving Techsys with a period of no revenues while the PLD line's awareness built. Announcing too late would give the competition time to develop similar products and lose potential sales for the new line.

In the case of Techsys, the decision became even more important because Futuro, a very large, established manufacturer of PLCs (programmable logic controllers) and other industrial equipment, was rumoured to be introducing a lap top computer - a replacement product for their tape loader that would compete with Techsys' portable PLD. The introduction date for the lap top was unknown but was expected to be within a few months. The threat of this introduction was enough to make the President reconsider his desire to phase out the current lines. He feared introducing the PLD line into a marketplace 
that had already or would soon become enamoured with the Futuro product. Having phased out the S and S1 lines he would have no "fall back" position and could very easily end up out of business. Shanklin and Ryans' (1984a) high technology criterion of new technologies making existing ones obsolete was certainly appropriate for the situation at Techsys.

\section{Research and Development}

Research and development of new and improved products was vital to the firm's survival. Creating customized versions of their existing lines took up a great deal of time. The recent loss of the Director of Engineering and his replacement, and two draftsmen had severely constrained R\&D as it left only one experienced engineer and a new part-time engineer. The manpower shortage had made a vital aspect of the business even more of a strategic concern. This issue was not dealt with specifically in any detail in the marketing plan although it did affect the objectives and therefore the action programs, monitoring procedures and contingency plans.

Another predetermined area for observation during the plan development process . was the possible problem area of the Marketing-R\&D interface. Suggested by Kiel (1984), Souder (1980), Gupta, Raj and Wilemon (1985) and others, this did not prove to be a problem for two reasons. The first reason was that Techsys was such a small company (about 11 employees) and so informal, that it was difficult to not communicate with other employees on a regular basis. There were only two marketing personnel and two R\&D personnel operating in the same office. Second, the President, the Marketing Manager, the new Assistant Marketer and the Salesman were all engineers. This was expected as Barnhill (1985) found that most high-tech executives have technology backgrounds. Coming from technical backgrounds, it was much easier for them to discuss their problems and needs with the other employees.

Hiring marketers with technical backgrounds was one conflict-reducing strategy for the marketing-R\&D interface but it also raised a problem. The marketing planning had to be sensitive to the lack of marketing backgrounds with regards to descriptive. frameworks and terminology used in the plan (McDonald, 1982). If a Techsys employee had developed the marketing plan instead of the researcher, then the terminology might not have been a problem. However, the marketing plan would have probably had a 'technical' or 'product capabilities' slant to it - taking away from its usefulness as a document for guiding marketing efforts. The extreme case would have been the development of a document that was not a marketing plan at all, but rather an operations plan. 
Market Situation

The international analysis that was expected was not a major concern while developing the plan. Management did not look at the international markets any differently from the domestic market. Although located in Ottawa, Canada, the company was a global marketer in the sense that they were willing to sell their products wherever there was a need for them. Techsys put most of their marketing efforts into the United States market as $75 \%$ of their sales had been made there (of a total of $90 \%$ in North America). The sales that came from Europe and elsewhere were usually "spillovers" from U.S. trade journals (containing press releases or advertisements from Techsys) that were sold in foreign countries.

The areas of the plan where the U.S. situation was analyzed included the economic and industrial analyses, the competitive analysis (because most of the direct competitors were located in the U.S., particularly, California) and the action plans. When designing communications and distribution strategies for both the $S$ and $S 1$ lines and the new PLD line, the U.S. was the market of concern. Being so small and limited in resources, Techsys could not expend a great deal of effort on many international markets. The large size and close proximity of the U.S. market, in addition to the concentration of potential customers, led management to pursue only the U.S. in eamest, and just service any other interested foreign customers on an ad hoc basis,

The comp'ny's strategy for the next fiscal year was to concentrate on the United States market as that is where their best success had been. Their financial situation did not allow for the pursuit of foreign markets in a serious way. If the short range strategy had included a target market in other countries and related objectives for the 1987-88 fiscal year, then an analysis of the plans to sell to these markets would have been warranted in the marketing plan. As no objectives existed for these overseas markets, no such analysis was conducted.

Eorecasts

As expected, the sales forecasts section of the marketing plan was the most difficult one to do. Two factors were expected to contribute to the complexity of the forecasting activity. First is that Shanklin and Ryans (1984a) wamed that a product in the early stages of the product life cycle must create its own demand. If the Stortite and Stortite I lines were in the early stages of their life cycle, then quantifying their future sales would have been difficult. Second, the sales in the past had been so erratic, and the future looked so uncertain that any estimate of sales was felt to be a guess at best. The second factor turned out to be the reason for the difficulties experienced in forecasting sales 
because the products were not creating their own demand. The problem was a rapidly changing situation in which there was a lack of accurate market information and a lack of management (expert) time to assist in the development. It,would have been misleading to use previous year's figures for an extrapolated estimate of sales because of the great amount of fluctuation from year to year. They were taken into account in a qualitative manner by the researcher.

Market information, as input for the forecasts, was limited. Management would develop a forecast for the next three periods based on what they saw as identified prospects and the likelihood of their buying in that period. They could also expect to get an average of $\$ 20,000$ per month of "bluebirds" (unexpected sales). These estimates would then be updated as new information came to light. The long, unpredictable sales cycle made it difficult to do forecasts with any accuracy for periods of longer than three months. Although they did develop sales forecasts, management did not seem to have considered developing technology or competitive forecasts. It would appear that management was so entrenched in the technologies and markets that the near future seemed obvious and therefole did not require documenting.

The President was not very concerned with the total size of the market or his estimate of it. His opinion of any type of forecast was that, if it is within a factor of three (i.e. one-third to three times as large) of the actual size, then the estimate is useful. A contributing factor to this belief was the small size of the company in terms of sales (about $\$ 1$ Million per year) and the historical volatility of the monthly and yearly sales. These characteristi- meant that the sales forecast for any given month could go from very accurate to totally inappropriate with the receipt of one large order. In spite of this, a range estimate of such dimensions would seem to provide figures of very little strategic use. An accurate forecast may be quite difficult to obtain but it would allow for measures of market share, future sales potential, and informed decision-making. These are figures that affect . the objectives of the company, and, therefore the action programs, monitoring procedures and contingency plans. These factors make the development of an accurate forecast a worthwhile exercise even if the task is a complex one.

Accurate and detailed technological and competitive forecasts were expected to be difficult as well because of the lack of market information. They were quite simple to develop, however, because the executive judgment method was used once again. The corresponding problem was that the forecasts were not detailed and their accuracy was questionable. No estimates of sales, promotions or prices for the future were provided for the competition and various technologies. These technological and competitive forecasts sections represent the President's and Marketing Manager's opinions on the future of the 
technologies and competition. Their value in the marketing plan was to document management's opinion of the situation at Techsys relative to other companies and other technologies so that the action plans could be developed in the proper context. Without some detailed quantitative data and analysis, however, these forecasts have very limited value.

\section{Information Sources}

Market Research - Very little use was made of marketing research at Techsys, supporting Barnhill's (1985) finding that little or no marketing research is done by high-tech firms in Canada and contrasting Shanklin and Ryans (1984e) finding that formal marketing research such as focus groups and concept testing is done. Limited concept testing was done for the wall-mount PLD after a contract with a major automotive manufacturer to develop the wall mount PLD was received (i.e. after the fact). This research consisted of telephone conversations with some potential users. The researcher recommended conducting a formalized survey of potential users with the objective of quantifying demand for the PLD line (wall-mount, portable and networking). The suggestion was not followed because the President felt that the investment of time and money would not be worth the return.

Other members of Techsys did not seem to share the President's opinion that only minimal marketresearch was needed. The following quotes from two engineers at Techsys reveal the need for customer information.

"We can get running off in one direction or the other, building stuff that either won't sell or there is no high volume potential or whatever, and I figure it could run us down pretty quick."

"We can't go out and start developing all sorts of products which will sit on the shetf. We need a lot of customer input to find out what the customers want, and based on that, develop the products they want."

The President was the classic entrepreneur in the sense that he found a product idea that he believed in and became its "champion". The tenacity that accompanied his belief in the product, and his ability to communicate this confidence to others, were often the only things that kept the company from receivership. Unfortunately, these same qualities also seemed to encourage the avoidance of dissonance-causing information such as potentially negative market research results. The Marketing Manager felt that the PLD . line might not have been the company-saving product that the President anticipated.

Although he was not prepared to say that a formal market survey was the required action, he did feel that more knowledge of the market and petential of the product would be 
helpful.

Company Records - The formal company records were found to be acceptable for analysis purposes except in one area. Performance figures (sales, expenses) were not broken down by product line or by market as Aylmer (1980) recommeded. Per period sales, orders, expenses, management meeting minutes, and business trip reports were all documented. It may be unreasonable to expect that a company with such limited administrative resources (a receptionist/typist and accounting clerk) in any industry, not just a high technology industry, could provide much more detailed records.

Competitive Literature - The final structured observation was the expectation that competitive literature would be scarce. Two files containing information on the competition were held by the President and Marketing Manager. These files, in addition to conversations with various personnel, were used to develop a competition summary table in the marketing plan. The information sources used to gather this information included: manufacturers' representatives, distributors, trade journals (articles, press releases, advertisements), trade shows and telephone inquiries (posing as a potential customer for the competition). While a detailed profile of each company could not be formulated, the information did identify Techsys' main competitors, their product forms, and competitive strengths. Detailed information such as the price of their products, their financial situation and new product developments was scarce.

Whether the amount of information available to Techsys was significantly less than other industrial companies is difficult to say. The newness of the industry (non-volatile computer data storage) may also account for the lack of market knowledge. In addition, Techsys was entering a second industry (PLC backup systems) in which they had very little experience. It is suspected that any company entering a new industry/market would have limited competitive knowledge, and Techsys was no exception. The effects of the technology environment should not be discounted as a cause for the lack of competitive information altogether. The short life cycle of high-tech products is certainly caused, in part, by the highly competitive nature of the technology enyironment. This short life cycle, in turn, means that no current industry statistics are available.

\subsection{Discussion of Unanticipated Difficulties}

The areas discussed in the preceding section served as guideposts for the observations made during the data collection period. In addition to these prespecified issues, there were many difficulties in the schema application that were unanticipated. The 
unanticipated topics fell into two categories. The first category contained general difficulties. These subjects were seen over and over again during the course of the marketing plan development. The second category included several specific problems that occurred during data collection. In addition to the 'general versus specific' distinction that can be made, there is also a 'process versus components' separation. The general difficulties are process oriented by nature while the specific difficulties are more closely related to components of the marketing plan. The following discussion is presented in light of these distinctions.

\section{General Difficulties}

Rapid Changes and Crises - There were three recurring difficulties throughout the process. The most serious of the three to the planning efforts was the speed with which the operating situation changed at Techsys during the plan development period. Because the firm was operating in a high technology environment, a certain amount of change was expected during the course of the plan development. The pace of the changest and the crises that resulted were not expected. Some of the changes that took place from May 4 to July 31, when the marketing plan was being developed, were the following:

1. Financial - Techsys almost ceased operations due to a lack of orders and hence

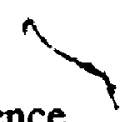
operating funds. The lack of backorders also made it impossible for the company to secure funding from other sources such as venture capitalists or banking institutions. Interestingly, the company was having a profitable year up until the eighth period of

' their fiscal year (Techsys divides their fiscal year into thirteen, twenty-eight day periods). Three successive periods of very low sales were sufficient to almost bankrupt the company. A sale on all products was needed to boost revenue in periods 11 and 12 to a point where Techsys could look further than the next week for their planning.

2. Personnel - The Marketing Manager, Managing Engineer and countant quit in the three month development period. Previous to this, but still in the 1986-87 fiscal year, the Director of Engineering, a Sales Secretary and two Draftsmen left the company. It was clear that the firm could not keep qualified personnel in such an unstable environment. An Assistant Marketer, an Accounting Clerk and new Receptionist were hired in the development period to balance the losses. Recruiting was being conducted for an Engineer and a Sales Representative to start immediately. 
3. New Product Development - A new product line became the emphasis for the future as the bubble memory products were perceived to be unprofitable in the industrial market in the near future. The product line was in the development stages. In addition to the PLD line, a variation of the Stortite line (using a different type of memory technology) was developed. These product innovations were not in development when the planning was started but were felt to be necessary for future success in existing and new markets.

4. Competition - After the first draft of the marketing plan was completed, one of Techsys' distributors told the President that Futuro (who produces the PLCs for which Techsys' PLDs are compatible) was going to introduce a competitive lap top computer that would perform many more functions than Techsys' PLD products. This new Futuro product was going to replace their existing competitive alternative on the market and take away Techsys' competitive size advantage. Management expected Futuro to make a competitive move but not at such an earl $f$ date. This piece of information indicated that the objectives, forecasts, competitive analysis and action programs had to be changed.

5. Existing Product Lines - When the news of Futuro's new product was analyzed, the President indicated that he did not want to de-emphasize the Stortite 1 and Stortite products any longer. In fact he was considering strengthening Techsys' relationship with the current manufacturers" representative in light of the change in the competitive environment. If the President had been sure that this retrenchment strategy was going to be implemented then it could have been documented through an action program developed as part of the marketing plan. The strategy, however, was uncertain. In any case, the President was very reluctant to plan for the obsolescence of the $S$ and $S 1$ lines when the potential success of the PLD line was dubious.

During the research period when these events were taking place, the researcher was assured by various members of the organization that such financial swings were irregular but frequent occurances for the company. These swings sometimes necessitated drastic strategic changes, but the company had always survived the crises. While three months may be an average amount of time for marketing plan development (Hopkins, 1981), it appeared to be too long a period for Techsys' situation to remain relatively stable. 
Lack of Timely Information - The second recurring difficulty encountered was a lack of timely, relevant information for planning (e.g. market, industry, competitive, economic and company information). Company records were satisfactory for most needs but limited for detailed analysis purposes. For example, sales figures were available on a per period basis but were not broken down by product, customer type or geographic area. A reason for this is that virtually all (over $90 \%$ ) of Techsys' sales were made by the one direct sales representative, which reduced the need for such breakdowns. In a strategic sense, however, such breakdowns could be very valuable for communications planning, new product ideas or positioning decisions. It was found that no market research was documented although some was done (mostly small numbers of unstructured conversations and interviews with potential customers or distributors).

Shortage of Senior Management Time - The third recurring difficulty was that the President and Marketing Manager had only a limited amount of time that could be devoted to the marketing plan development. As in most small companies, each employee at Techsys had many responsibilities which were integral to the company's operation. This situation meant that management did not have the time to conduct planning, although planning was needed and the value of planning was realized. When two members of Techsys' management left, about $20 \%$ of the firm's human resources was lost. This meant that the President and the Marketing Manager, as the only personnel qualified to fill the vacant positions in the period while new management was being hired, had to assume many new responsibilities. This limited the amount of time that they could allocate to the plan development. If the company were very successful, management's time would probably be just as constrained but for different reasons. The small size of the company, rather than the financial situation, was probably the cause of the limited time that management could contribute to the plan development. This problem was overcome by obtaining their input on each section orally, rather than making them write their comments as this would have taken significantly more time. In addition to these unstructured interviews, both the Marketing Manager and President read and critiqued a completed version of the marketing plan. This allowed for their input while making the minimum demand on their time.

It is suspected that these three difficulties in the marketing plan development process are symptomatic of the stage of development of the firm. Techsys was formed on the strength of a contract with a Federal government department which funded the development of the initial product lines. The firm grew very rapidly in the first few years 
as more contracts were received and products were sold to many different customers. In order to sustain such growth, new capital had to be received so that new products could be developed and new markets pursued. An overestimated market size and the surprisingly slow development of bubble memories limited the firm's profit potential and hence the ability to raise new capital. The deprivation of new capital made the development of new products and markets impossible and hence impeded Techsys in its move to the next stage of development. These factors, in turn, drove many of the upwardly mobile employees to seek employment elsewhere which placed severe time pressures on management.

Although these changes were taking place, the firm seemed to be stuck at a stage in its development without the resources to move forward and refusing to slide backwards. These seemingly contradictory situations may be characteristic of small, relatively new, high-tech firms.

Techsys' dependence on government funding and tax breaks may have contributed to the firm's inability to move forward in its development. These financial incentives were received because of the nature of the business at Techsys, and in particular the research and development activities that were conducted on an ongoing basis. They are most often . received in the early stages of an organization's development and decrease as the company progresses. The firm, therefore, became accustomed to receiving such benefits only to have the amount and frequency decline when the firm was older, but still in need of financial assistance.

\section{Specific Difficulties}

Industry Definition - On the broadest level, the industry and market that Techsys competed in was difficult to define. Because the products were so specialized - catering to the specific needs of small niches in the data storage market = most industry labels did not seem appropriate.

Two sources were utilized to try to label the industry in which Techsys competed. The first was the Standard Industrial Classification (SIC) which yielded "Electronic Computing and Peripheral Equipment Industries" (SIC 3361), and "Other Communications and Electronic Equipment Industries" (SIC 3259). The latter classification represented a close match for Techsys' new line of Programmable Logic Controller (PLC) backup systems, tentatively called Program Loäding Devices (PLDs) as it specifically mentioned companies that manufacture electronic process control equipment. The President felt that the former classification was not that close a match as it included such companies as IBM. He felt that the companies within the classification must be very similar to his own or the categories would be of very limited use. 
Bonoma and Shapiro (1983) provided support for Techsys management's reluctance to use the SIC classification when they expłained that the classification makes two assumptions that create difficulties when trying to use the SIC for segmenting purposes. First, is that all establishments in the same code classifications engage in the same kinds of activities. The second assumption is that establishments belonging to a given category account for a large proportion of the total activity included in that category. Techsys was not using SIC's for segmenting however, only for comparison purposes in an industry analysis. A wider latitude on industry classification should be acceptable to the planner for this use as it would still result in informative analyses.

The second source was Dun and Bradstreet, which produces a listing of key business ratios for Canadian corporations. The most applicable categories were "Electrical Equipment Industrial" and "Electrical Equipment - Miscellaneous". Dun and Bradstreet does not define these industry sectors in any more detail, making a more specific classification of Techsys difficult. These classifications were so broad that management felt them to be of limited value for their needs.

Without an accepted industry definition, a quantitative industrial analysis was not feasible without a great deal of primary research because figures to compare Techsys to other companies in the same industry were not publicly available (from Statistics Canada, Dun and Bradstreet etc). Without such an analysis, market shares were diffictlt, if not impossible to determine, industry leaders could not be identified, and industry standards of profits, wages and growth could only be approximated.

To resolve this problem, all of the classifications described above were used to provide approximate figures for comparisons. Also, a very narrow industry definition was adopted implicitly so that qualitative comparisons could be made. The industry may be labeled "non-volatile data storage system manufacturers". This definition made the market analysis somewhat easier as well, although the same problem of insufficient quantitative comparisons was experienced.

Performance Review - The "Previous Performance VS Objectives" section of the situation analysis also posed a problem. Techsys prepared yearly budgets and monitored the actual-versus- budget discrepency but did not formally try to isolate or document the causes of the variance. As a result the only statement that could be made in this section - was that Techsys had never met the projected income, profit or growth levels that were anticipated in any year. This statement does not help future planning activities. Reasons could have included poor forecasts, unexpected economic downtums, ineffective or insufficient marketing efforts and many others. It is likely that some combination of these 
and other factors were responsible for the variance. These issues were analyzed in detail in the marketing plan (Refer to the Situation Analysis section of the marketing plan in Appendix 8).

Target Market Analysis - The "Market Situation" heading of the schema (in the Situation Analysis) called for a description and analysis of the company's major market segments. This was not possible in Techsys' case as they did not segment the market nor choose a target market. Management did not seem to plan in terms of their customers, rather they were far more concerned with the products. For example, when asked to describe their target market, both the Marketing Manager and the President outlined the many uses of the company's products in almost any industry. An engineer confessed to this product, rather than customer, orientation when he said: "In the past we've built products that were great products but nobody wanted them". Because of the many potential uses of the product, and the small size of any one application, the company, perhaps naively did not select a target market. The opportunities were never prioritized so that some structure could be applied to the marketing efforts. Shanklin and Ryans (1984d) identified this problem as one of the ten characteristics of high-tech market behavior. As a result of this characteristic, neither quantitative nor qualitative analyses of market segments could be done.

After selling the products for five years, it was possible to develop a classification system for Techsys' customers based on benefit sought, geographic location, customers' user status and industry sector. This classification demonstrated that market segments did exist if they could have been identified. Whether this was only possible because of the experience gained over a long period of trying to sell the products, or if primary research could have been conducted prior to start-up, is not known.

The way that Techsys' management focused their efforts was to try and reach the engineers who would be confronted with a data storage problem that Techsys' products could resolve. They reached them through trade shows, and press releases and advertisements in general electrical engineering journals. By doing this, management seemed to have implicitly selected a target audience without having a target market.

It should be noted that the line of PLD products did have a target market - owners of Futuro PLC-2s and PLC-3s in the automotive industry in North America. Having selected this target before the products were introduced, the company should be able to focus their marketing efforts in the future. 


\subsection{Anomalies}

The previous discussion of the anticipated difficulties and unanticipated difficulties of developing a marketing plan for a high technology firm provides the raw material for an identification and analysis of the aromalies. Webster's New World Dictionary (1979 edition) defines an anomaly as "a departure from the usual; an abnormality". For this research the "usual" was represented as the schema for marketing plan development. There were many instances when the marketing plan development process departed from the schema for Techsys. These anomalies, caused by the difficulties experienced in applying the schema, may be divided into those that seemed not to be attributable to the high technology environment in which the planning was conducted and those that were attributable to this environment.

\subsubsection{Anomalies Not Attributed to the Téchnology Environment}

The anomalies that were not attributed to the high technology environment were difficulties that caused a departure from the schema but were due to factors such as a poorly developed or redundant part of the schema, firm specific situations or preference? of the President or Researcher. These anomalies were felt to be significant enough to warrant changes to the schema. They are discussed under headings that reflect their causes and are labeled as follows: Schema Organization, a Shift in Emphasis and Stage of Organizational Development.

\section{Schema Organization}

There were a few problems with the scbema that made certain sections of the marketing plan redundant and in part accounted for the excessive length of the first plan. There were several sections in the schema that called for a description and analysis of a particular topic. After applying the schema it became obvious that a brief'analysis alone was more appropriate than both a description and analysis because the main users were already familiar with the product or concept being described. There were also areas in the schema where the same description or analysis was required more than once so that different sections of the plan could be examined independently without a loss of continuity. An example is the examination of the product life cycle stage for the products in the "Internal Analysis", "Market Forecasts" and "Strategies" section.

Another factor promoting some corffusion in the șchema's application to Techsys was the combination of both industrial and consumer companies' planning guidelines that were contained in Hopkins' report and hence in the schema. The mixture allowed the inclusion of such components as values and lifestyles which, for an industrial company, 
has limited use, if any. The consumer elements also took attention away from such components as the distribution channels used, manufacturer's servicing of products sold, timing of obsolescence, and technological forecasts which were of much greater importance to Techsys as a manufacturer of industrial products. These factors are common to industrial firms in general rather than just high-tech firms, although their importance may be augmented in a technology environment.

\section{A Shiff in Emphasis}

The topics discussed under this heading concerned subject areas that were mentioned in the schema but were either given too much attention or not enough attention for the situation at Techsys. Since they required changes, in some cases relatively minor changes, they were labeled anomalies.

The "Strategies" component of the "Objectives" section was not given a separate subsection in the marketing plan. It was felt that the topics had been covered to a certain extent in the situation analysis and would be examined in detail in the action programs. This does not reflect the high-tech environment as much as it do the purpose of an annual marketing plan. Such strategies should be incorporated throughơt the plan, holding it together and guiding the direction of the action programs, not placed in a separate section where they will only be mentioned briefly in an incomplete form. This would certainly. have been the case if the firm had a strategic marketing plan.

If planning were an established activity at Techsys, the company would have had a formal strategic marketing plan outlining strategies for the next two to five or more years. The company did not have such a document, although there were several business plans which provided the necessary strategic background for the development of the annual marketing plan.

A further modification was the use of only a sales forecast rather than both a sales and demand forecast. The distinction between the two sections was not felt to provide sufficient information for the inclusion of both in Techsys' case.

An issue which was covered to some extent in the schema but which deserves greater emphasis at Techsys was management's reluctance to change the distribution channels when there was clear dissatisfaction with the channel members' performance. As in industrial sales, one of the major criteria for the selection of a representative for Techlys was a perceived similarity between the representative's existing product line and the company's ownn product. Unfortunately, Techsys' products were quite uncommon, complex, and not as similar to any of the representatives' lines as originally felt. These representatives were the closest that management felt that they could come, however, to a 
complementary distribution channel with salesmen who had some product expertise. In spite of their poor performance, then, the President was very hesitant to release the old representatives and recruit new ones. He felt that the likelihood of finding representatives with more complementary product lines was remote.

The same reasoning was responsible for the continued employment of a salesman whom management felt was less than effective in several areas. He was kept because his product knowledge was substantial and he was very familiar with the company and its customers. The company could not afford to keep two salesmen on the payroll for any length of time, so,the first salesman would have to have been dismissed before a new saleșman could have been hired. The time necessary to train the new salesman, in which no sales would be made, and the expense of the salesman's salary would be more than Techsys could afford. The company was therefore caught in a distribution dilemma, from which management felt there was no financially acceptable solution. It should be noted that the salesman felt that a technical education was not a necessity to sell Techsys' products: "There's nothing more than awareness [of electronics] needed in sales of this type of product".

\section{Stage of Organizational Development}

Other aspects of the schema resulted in anomalies that seemed to relate to the company's age. Age refers not only to the number of years that Techsys has been in existence (five) but also to the small size of the firm in terms of sales (about $\$ 1,000,000$ per year) and the firm's stage of organizational development. The schema was developed from marketing planning guidelines of companies that were much larger than Techsys and had progressed far enough in their marketing plan development documentatipn to have "established guidelines. The first anomaly this characteristic arose from was the difficulty of trying to develop a marketing plan when the President was required to make most of the marketing decisions. His time was severely limited because he was doing much of the work of several employees in the firm who had left previously and had not been replaced. The schema implied that significant manpower was available for the research, analysis and decision making.

Part of the President's time was taken up in trying to obtain funding through debt or equity sources. A search for investors is usually done by new or growing companies. In Techsys' case, the funding was required to develop the PLD line and get the products to market quickly. The timely introduction of the PLD line, in turn, was an assumption in the development of the action programs. In order to be competitive, and in Techsys' case survive, the PLD line and other new products had to be developed. These funding and 
product development issues were not covered sufficiently in the schema for Techsys.

The "Previous Performance vs Objectives" section of the plan was comprised of comparisons of the expected revenues and expenses for the year on a period-by-period basis. This was made possible because the contany had kept annual budgets for several years. The conclusions made were that the expected levels of profit, sales and growth had not been met. The section could not be completed in more detail because Techsys did not keep records of their objectives or their relative achievement of those objectives. No marketing objectives related to goals other than sales, profits and growth were documented.

The lack of documentation and effort given to the analysis of budget-versus-actual discrepancies prevented that section of the schema from applying to Techsys. This anomaly cannot be attributed to the technology environment, however, as any company can be a poor record keeper. A company with very few employees and with a relatively short history in which to develop advanced record keeping procedures is particularly susceptible to such difficulties. This anomaly is more likely caused by the early stage of development of the company than the technological characteristics of the products or environment.

a The anomalies discussed in the above section were felt to be significant enough to merit modifying the schema. The next section identifies anomalies that were felt to arise out of the technology environment in which Techsys operates and also required changes in the schema.

\subsubsection{Anomalies Atributed to the Technology Environment}

2 The anomalies in this section have also been classified according to their cause. This format was felt to group homogeneous difficulties into more meaningful subsets.

\section{East Changing Situation}

The cause of several anomalies that was most evident because it was reinforced by events throughout the planning process was the speed with which the situation at Techsys changed. In Section 5.4, Discussion of Unanticipated Difficulties, five examples were given to describe how the situation changed significantly in the areas of financial stability, personnel, new product development, competition and management strategy. These changes required that sections be added to the situation analysis, the objectives be modified (pertaining to sales and product introduction dates), and the action programs revised to reflect the new information. A series of statements made by the President reveal his opinion of the planning function for such a small company operating in such a fast moving 
environment.

"Things change so damn fast that chances are we'll end up on one or another of the contingency plans or some other contingency, unanticipated by the plan."

"We've lost an engineer in the meantime, [since the marketing plan and in particular the schedule of activities were completed] now we've hired another one but he's got to get up to speed ... When one person quits, that's $10 \%$ of the company that has quit ... half of our research and development department gave two weeks notice."

"You cannot develop enough contingency plans for that kind of thing."

Significant changes made the planning function more complex than if Techsys was operating in a stable environment. A consistent progression of events would have allowed for the confident use of extrapolation forecasting techniques. Stability would have also made a longer plannirg period possible because the plans made three months ago would be valid today. With Techsys, the planner had to be ready to modify several areas of the plan at any time. It was also necessary to observe a cutoff point in time, after which no changes would be made. This brought with it the problem that if a serious event that would otherwise necessitate major revisions had occured after the cutoff date, the plan's value to the firm would have been limited. It is suspected that these problofms are present in non-technology firms as well, but they would probably not manifest themselves to nearly the same extent. They may therefore be attributed to the technology environment.

\section{Lack of an Accurate Existing Industry Definition}

Management was reluctant to classify Techsys into any of the existing industry categories proposed in the Standard Industrial Classification. The President's opinion that the products were unique affected the way in which Techsys marketed. Until the researcher developed their marketing plan, management had never positioned their products in the marketplace. They felt that the market was knowledgeable enough and the product differences were obvious enough that awareness building was all that was necessary. That is, if they told the audience that a product with features $X, Y$, and $Z$ was available at Techsys, then the audience would react and purchase the product if it was peeded. This approach will be discussed in greater detail under the "Management's Product Orientation" heading later in this section of the thesis. The point to consider here is how their perception of uniqueness affected their marketing strategies and planning, perhaps inhibiting the effectiveness of the marketing activities. Management was correct in 
assuming that the potential purchasers of their products are technically knowledgeable and even that the product differences are obvious to a certain extent. These facts do not replace the need to tell the customer about the benefits that are available upon purchase and to persuade that customer to purchase Techsys' products rather than a competitor's (i.e., to position and market the product).

In designing a schema for the marketing plan development in a high technology environment, it may be useful to consider similar industries when making comparisons. It would also be useful to propose a new industry classification and conduct qualitative analyses sach as how the companies differ from those in other industries and how these differences affect income, profit, growth and other variables.

\section{Lack of Information Sources}

The availability and utilization of relevant information sources for the development of Techsys' marketing plan were limited. This was expected from research conducted by Cowell and Blois (1977). Part of the lack of availability was due to the problems discussed under the industry definition issue. Also contributing to the problem was the fact that Techsys did not have a target market identified and, therefore, it could not be analyzed through primary research. This was an important constraint because little secondary information was available.

This anomaly has been attributed to the technological environment in which Techsys operates for two reasons. First, the speed with which the situation changed made finding timely, relevant secondary information sources difficult. Second, Techsys' products were only desired for very specific applications where no other data storage system would function so the niche markets were a direct result of the-technology used in the products. These niches were so small that gevernment agencies such as Statistics Canada or private market research firms like Frost and Sullivan would find it unnecessary and unprofitable respectively to produce market information for companies like Techsys.

There was a definite need for primary research at Techsys Electronics. Support for this assertion came from the fact that management was having difficulties in quantifying demand for the new PLD line for planning purposes. This is a common problem for any new product, not just electronics or high-tech products. The PLD line is not a high-tech product in the sense that it must create a demand for itself, but may be called a technological innovation in that it uses available technology to make an existing product (the standard tape loader being used for PLC backups) more effective or efficient. The PLD line had an identifiable target market that could have been analyzed in great detail. Instead, the President talked to a few of the engineers in the General Motors company 
while trying to formalize the product specifications (a form of concept testing) and relied heavily on the opinion of one distributor who sold Futuro PLCs to the target market. While these two activities were extremely helpful, the information could have been supported or rejected through a larger survey of the target. The President's efforts were useful because he was obtaining strategic information from members of the target automobile manufacturers segment, but it is contended that the amount of data gathered was insufficient to reach, an informed decision.

Management did not conduct such research because the President felt that the input of funds and management time to carry out such a study would not be worth the return of a more accurate demand estimation. The schema should be changed to mention the types of research that could be applicable and where to apply them. As it stands, "marketing research reports" is listed as one of the many information sources. For the technology manager, more specific references are probably necessary.

\section{Management's Product Orientation}

At Techsys, the President, Marketing Manager, Salesman, Engineering Manager, Production Manager and Director of Operations (the members of the management team) all had technical educations. This affected the marketing planning because a great deal of emphasis was placed on the product's capabilities rather than the market's needs and wants. The Marketing Manager realized this fact as a problem when he statèd:

"Included among the mistakes that we've made in this company is the fact that we haven't really been careful or paid enough attention to what the market wants. I think we have been technology-driven from time to time and that's going to get you in trouble if your technology drivers don't happen to coincide with the needs of the market."

The example. in the previous section demonstrated how management was willing to conduct research to determine the product specifications that some customers wanted but not to estimate demand, use statistically significant sample sizes where possible or formalize the research techniques. The President felt that he did not have the necessary resources for such research. With true entrepreneurial spirit, he was willing to change the direction of the company to pursue the programmable logic controller backup system market with which he had very little experience, with a prototype that had not yet been tested,-and a product line that had not yet been developed. The risks that he was subjecting the company to might have been avoided or mitigated if he had been willing to conduct some in-depth market research before the strategies were developed.

Another issue which was presented in an earlier section but deserves expansion 
here is the failure to select a target market. When asked who the target market for the Stortite and Stortite 1 products were, both the Marketing Manager and the President described the many possible applications of the products. Chisnall (1985) identified this situation where products have many applications over many markets in different industries as horizontal demand. Techsys never progressed to the point of narrowing down the application possibilities to the largest ones and aggressively marketing to those segments, which is the next step in the decision process (Shanklin and Ryans, 1984d).

The product orientation was accompanied by, and perhaps partially caused by, a generalized lack of marketing knowledge. The two persons responsible for the marketing function at Techsys, the President and Marketing Manager, were both electrical engineers with years of engineering experience. It appears to be a lengthy process to modify a manager's way of thinking so that he considers what the customer wants before he thinks of what he can design or manufacture. The situation at Techsys was one where concepts such as competitive positioning, unique selling propositions and benefits sought were understood (although not necessarily under these names) but the concepts were not practiced in day-to-day management as they must be to derive any benefit.

The schema for developing a marketing plan assumes familiarity with these concepts but more importantly it assumes that such concepts have been utilized in the past and will be in the future. A brief explanation of such concepts and the benefit of their use, along with less frequent use of marketing terminology, may make the application of the schema less troublesome for the technically oriented marketing manager. Such changes may also promote the use of such concepts.

\section{Competitive Analysis Complexity}

The competitive analysis was difficult because the products with which the $S$ and S1 lines competed were not well known. The companies that Techsys competed with were easily identified but product information, particularly price, was not abundant. Even if the price of one product configuration was known, the differing storage capacities, speeds and other-specifications of the products made comparisons complex; if not impossible.

Because no research had ever been done, management did not know which features customers wanted most or what the tradeoffs between the three factors of cost per bit, speed and density were.

The schema required an identification of who the competition was, along with their strengths and weaknesses and the marketing strategies they employed for competing products. The importance of competition to Techsys was not captured by this discussion. A greater emphasis was felt to be appropriate so "Competition" was separated from 
"Market Situation" in the "External Analysis" of the marketing plan.

Another aspect of the competition that the schema did not cover adequately was the distinction between competitive technologies and competitive products. For example, a bubble memory system from another company, Compco, was a competitive product for Techsys' $\mathrm{S}$ and $\mathrm{S} 1$ bubble memory storage systems. A storage system using CMOS RAM, or a Winchester or floppy disk from any company represented a competitive technology. This distinction has implications for how the product is positioned in the market. If, as is the case when a new technology is marketed, there is little or no product competition then the company will stress the benefits of the technology. In the case of Techsys, the advantage of an ultra-reliable bubble memory storage system over the Winchester disk would be promoted. If, however, there are many product competitors (all built with the same technology) then you would stress the benefit of buying your particular product configuration. Techsys had both types of competition and up until the marketing plan, was spending most of their resources competing against technology competitors. This emphasis was switched so that Techsys could better defend against their main competitor, Compco, who was competing against other technologies as well. This allowed Techsys to differentiate itself from the competition.

The idea of separating the competitors into categories is not a new one in marketing theory. Desire, generic, product form and brand competition are the more traditional breakdowns for a product's or company's competitors. The technology and product competition distinction may just be considered a corollary of this theory. This notion of two stages of competition fits with Shanklin and Ryans' (1984a) concept of supply side marketing where a product creates its own demand in the initial stages of product development. The technological competition would play the major role in the early stages of product development while the product competition would play a relatively minor role. When competitive products using the same technology are introduced, the roles played by the two types of competition are reversed. This is when demand side marketing concepts dominate according to Shanklin and Ryans.

The schema should be amended to reflect this fundamental difference in the types of competition. An examination of where the company's real competition is should be conducted and the competitive strategies should be developed around such an analysis.

\section{The Value of the Product Life Cycle}

In-the case of Techsys, the technology life cycle proved to be of greater value than the product life cycle. The fact that it considers technology sales rather than product sales (Ford and Ryan, 1981) fits in with the way that management viewed their products. The $S$ 
and $\mathrm{S} 1$ lines were considered different lines but both used bubble or CMOS RAM memory technologies. The technological separation made more sense than the product line separation because the price and speed differences between the technologies were more important than the "ruggedness" or reliability differences that separated the two lines. The group of CMOS products and bubble products were more homogeneous than were the Stortite products or the Stortite $I$ products.

Neither life cycle was used at Techsys during the planning process because management wanted to de-emphasize the $S$ and $S 1$ lines and was just developing the PLD line. Such an analysis would not have yielded any benefit. It would'have been useful two years ago when the actual sales trend followed the theoretical trend quite closely and management could have anticipated the demise of the bubble memory. It may not be useful in the future because the PLD line does not utilize a new technology as did the bubble memory products. It uses 3.5 inch floppy diskettes and existing electronic components to provide an innovative package but not one which may be labeled a high-tech product. The product life cycle may therefore be more appropriate for this line. Management may be able to gauge their strategic marketing efforts better if they follow the sales of PLC backup systems and fit these figures into the product life cycle curve to determine the stage of product development.

The schema should provide for the use of both the technology and product life cycles in marketing planning. The planner will have to determine which theory is more appropriate for his products. He can do this by examining the technology used to produce the product and assess the growth and expected replacement pattern through the sales history. If the technology is one where new generations are developed frequently, then the technology cycle would seem to be indicated. If many years pass before each technological leap then the product cycle would be of greater utility to the manager.

\section{Market to Technology Shift}

The final anomaly is felt to represent a significant change in thinking for marketing plan development. This anomaly was not as obvious as some of the others were but was quite subtle in the manner in which it manifested itself. The components of the "Market Forecasts" séction were separated into the existing "Situation Analysis" and a new section entitled "Technological Forecasts". In its original form, the schema did not place enough emphasis on the technological forecasts but did allow for predictions of other less pertinent subjects to Techsys. A shift in emphasis from market to technology forecasts was therefore felt to represent an improvement of the schema for Techsys' situation. Most of the same information would be provided in a different configuration in other sections of the 
plan.

This minor shift in the "Forecasts" section is felt to be representative of a greater movement to management's technology concerns rather than market concerns. A complete shift from one to the other would have been very detrimental to the firm. However, an increase in the importance of the technology and all the other components that this. parameter affects was worthy of increasing the attention given to it in the schema. Market considerations, on the other hand, took on a less significant role, with the technology minded managers giving it almost no attention. This is obviously too extreme, but a slight reduction in importance seemed necessary to the researcher.

\section{Summary of Changes to the Schema}

The major changes that were made in the amended schema include more explanation of marketing concepts and terminology, replacement of description and analysis with only analysis, separation of the market siturith apd competitive . environment, more information sources, technology rather than market forecasts and other, smaller changes in the components.

The changes suggested by the discussion of the anomalies have been implemented in the amended schema shown in Appendix 10. This revised version will be of greater use to Techsys Electronics than the original version. No drastic changes were made to the schema because of the anomalies found. The original schema provided an adequate base guide to follow for marketing plan development. With the changes discussed in the previous sections, the schema is now better suited to Techsys' situation. The cause of most of the anomalies was the fast changing environment which was something that could not be remedied by making changes in the schema structure. It is advisable to have a master plan, such as the one developed for Techsys as part of this research, that can be be modified as needed or perhaps at regular intervals (for example every three months). Such a revision would only require one or two afternoons of management's time so that the present situation could be taken into account and changes in the objectives and action plans made. This suggestion was also presented by Moore (1981) who recommended that the planning process be a continuous one. Activities such as keeping each section brief, making the sections flexible by utilizing ranges for figures and dates where possible, and building in many contingency plans with a significant amoum of detail could promote easy and time efficient updates. These activities could only serve to provide more relevant plans to guide the fifm's operations.

Overall, the ohianges that were required to amend the schema so that it would be more applicable to Techsys were not that drastie. A summary of the amended schema (in 
the same format as the flowchart of Figure 3) was attempted. The changes that were made to the schema, however, occurred at lower levels than the headings and subheadings that would have appeared in the flowchart. Therefore, the diagram would have looked . essentially the same as the original. The differences were left in the full-scale amended schema in Appendix 10 and were highlighted for easy comparisons to the original. 


\section{Conclusions}

This research examined the marketing plan development process in a high technology firm using a case research methodology. The relevant literature was reviewed and analyzed in order to develop a schema for marketing plan development. This schema was applied to Techsys Electronics, a technology firm in the Ottawa-Carleton area. Anomalies in the application of this schema were identified and their hypothesized origin discussed. Finally an amended schema was developed which was more applicable to Techsys and perhaps other firms operating in similar high-tech environments.

The general conclusion is that the schema was a useful guide to follow in the preparation of the marketing plan for the case firm. Some of the anomalies discovered did not require that the schema be changed. They just represented difficulties in the planning process. About half of the anomalies discovered were attributed to reasons other than the technology environment in which the planning was conducted. Such factors as the smali number of employees, the early stage of organizational development that the company was in, and the industrial nature of the products were believed to be responsible for these departures from the schema. Many of the differences did not require changes to the components of the schema but were more effectively amended by reducing or jicreasing the emphasis of a particular element. Examples are the separation of "Competitive Analysis" from "Market Situation", the addition of technology as well as produat. competition and the dissipation of the "Strategies" component to other areas of the plan.

The other anomalies were attributed to the technology environment. That is, characteristics attributed to technology firms were felt to provide the most likely reasons as to why the application of the schema was made difficult. Of these seven anomalies, it was felt that six were likely to apply to other small-medium sized technology firms. The industry definition anomaly is related to the technology environment but is likely attributable to-Techsys' management and their perception of their industry's classification. Industry classification is not vital to a company's marketing planning if management is willing to accept loose definitions for comparison purposes only.

The cause of many of the anomalies was the rate at which the companyis situation changed. The literature (e.g. Shanklin and Ryans 1984d, Boag and Munro, 1986) discussed the turbulence of high-tech markets, and the case example certainly demonstrated this characteristic. In order to mitigate the effects of such rapid changes, two or three people should work on the plan's development to complete it in perhaps one month. After the initial, comprehensive plan is developed, updates should be performed quarterly or as needed to keep the document current. Such updates should only require one or two 
afternoons of the Marketing Manager's time each quarter.

The second most important anomaly category was the result of management's product, rather than market, orientation on the plan development. With the suspected large "percentage of technically-educated marketers in high technology companies, the use of marketing concepts and terminology is probably not as prevalent as in other companies' plans. Brief explanations of these issues in the schema and either marketing education for technically-oriented managers or input from marketing-oriented personnel could improve the marketing plan development. Not only would the development proces be smoother but the marketing plan would be a more effective document to guide marketing activities.

The amount of information available to develop the marketing plan was limited. The fast pace of the environmental changes was responsible for much of the lack of relevant information. In addition, the avenues open to management to gain more market information, namely primary market research, were not followed. This was attributed to management's lack of exposure to and acceptance of marketing principles and avoidance of dissonance-causing stimuli such as negative market research results.

The competitive analysis suggested in the original schema was found to be inadequate for a technology firm because it did not specifically discuss technology as opposed to product or organizational competition. This was an easily amended anomaly; Any company that develops a product that uses a technology not before used for such a purpose must consider the competition that it gets from other products that provide the same benefit using a different technology.

Management considered the technology used in the manufacture of the products to be more important in many instances than the market in which the products were sold. It is recognized that a high-tech firm must be very concerned with the technology of a product, especially at the early stages of the technology's development. The importance given to the market, however, should never be at the low level witnessed in the case firm and should be expected to increase over time. This shift from a technology driven firm to a market driven one coincides with Shanklin and Ryans' (1984a) suggested strategic progression from supply to demand side marketing.

The last of the six generalized anomalies was the use of the technology life cycle rather than the product life cycle. It is hypothesized that other companies producing multiple products with the same technology would find the technology of greater value than the product life cycle. If the product uses a commonplace technology, such as a - floppy disk storage system, then the product life cycle may be of greater strategic value. Indirectly related to the marketing planning but having a major impact on the irrm was the stage of development of the organization. In Section 4.1, Techsys was described 
as a firm that had many characteristics that were shared by other high-tech firms. Through the course of this research it was discovered that Techsys also suffered from many of the ills that afflict small high technology firms. Their constant problem of undercapitalization and the severe time pressure put on management are twoexamples. The firm seemed to be at a point in their organizational development where significant change was needed, but because of the circumstances, change was impossible. This is Memonstrated by the need for new products to be developed in order for the firm to survive when Techsys had neither the capital nor human resources for such development. 


\section{Value and Implications of Research}

$\checkmark$

The value of this research and the implications of the results are adoquately described under three headings according to the groups who will benefit. These groupings are presented below.

\subsection{Techsys Electronics Inc.}

Techsys, as the case organization, received the most direct and immediate benefits from the research. The final versions of the two marketing plans can be used to guide the marketing operations in the coming fiscal year and, with some revisions, act as investment-raising tools.

Techsys' benefits do not depend directly on their implementation of the marketing plan. In the schema they have a guideline for the development of future marketing plans. They have a detailed situation analysis to summarize where the company has been and where it is headed. The documentation of the firm's strengths, weaknesses, mistakes and successes will help current and future management to develop marketing strategies. The situation analysis can also serve as an orientation document for new employees.

By having someone outside of the company develop the plan, fresh jeas and new approaches to old situations were formulated. In addition, the information apalyzed was put into a marketing framework. This gave management the opportunity to examine a new style of looking at the planning function and the raw materials to utilize a similar style in the future.

\subsection{Marketing Practitioners and Other. High-Tech Managers •}

The research also presents some benefits to marketing managers outside of the case organization. The schema developed from the marketing planning literature can be used as an initial guide to marketing plan development in non-technology based companies. After an initial application to a firm the schema can be amended and customized to meet the specific needs of that organization. The amended version of the schema that resulted from this research is expected to be more appropriate for high technology firms than the original schema. This guideline, which has been applied to one company already, should provide some useful planning insights for marketing managers.

The results of the research and a.study of the anomalies identified will also be a valuable exercise to marketing managers. A comparison of the schema and resulting marketing plan will provide a useful lesson on how and how not to develop a marketing plan. These managers can rejject any portion that they feel does not apply to their situation 
and keep the remaining elements of the guideline. Again the schema can act as a starting point for a high technology firm inexperienced in marketing planning or dissatisfied with current methods.

This case study has suggested several areas where the marketing planning function car be improved. First must be the realization that marketing planning is needed within the company. If the support of upper management is not present then the planning efforts will probably not receive the resources needed to develop a complete, useful rarketing plan.

The research showed that marketing planning activities yield such benefits as a better understanding of the market, competition and company strengths and weaknesses. It also forces management to document strategic decisions so that they are easily examined and communicated to interested parties within the firm and outside the firm. This not only clarifies decision making activities for company personnel but also presents a more organized image to the current shareholders, potential investors, debtors, and so on.

The research suggests that the planning period should be brief and that several planning periods are necessary each year. The speed with which the situation chariges dictates that the planning process be a continuous one. If the plans are kept brief and flexible as well as current, the probability that management will implement and adhere to the plan increases. It is important to keep the plan functional and actionable so that planning is not looked upon as an academic exercise.

The application of a schema to a high-teçh firm suggests that traditional marketing planning concepts can be applied in a high technology environment. Executives in high-tech firms should take this into account when hiring marketing managers. It would be wise to employ managers with a marketing background in addition to those with technical backgrounds. Such a mix would balance the product and customer orientations 'of the marketing department and yield more effective marketing plans.' The orientation of the marketing department and the firm itself should evolve to be customer-oriented with extensive product input from R\&D and manufacturing departments.

There are several recommendations that can be made about the management of small high-tech firms. These suggestion lead to solme general policy considerations for managers and shareholders.

The executives of high-tech firms cannot allow themselves to think that their business situation is so unique that it cannot be compared to other situations. This type of parochial thinking eliminates the benefits that can be obtained by leaming from firms in other similar industries. This attitude can also lead to the impression that a firm's current, trained perșonnel are irreplaceable. In the case.pf Techsys, this was manifested by the fact that management felt trapped into using its current distribution channel members when 
replacements would have been more fective. By overestimating the value of these channel members to the firm, management was not being as effective as possible.

Another potential problem for small high-tech firms is the perception that the firm is committed to the use of one technology only. This attitude can put "blinders" on management such that they do not see opportunities using similar, related, or even completely different technologies. The avoidance of this problem may be accomplished by defining the business in which the firm operates in broad terms. The best place to document this is in the firm's mission statement. The best way to ensure that the attitude remains throughout the firm's operations is to implement a broad scope in the strategic planning process.

There are several characteristics of the marketing planning function that would indicate a high-tech firm is approaching the activity in a responsible manner. If the firm is not already doing these actions then they represent ways of improving the marketing function. One is the existence of a marketing segmentation strategy and evidence of the selection of one or two viable target markets. In a high technology environment it is very easy to assume that the product or technology's characteristics have determined the appropriate target market through the process of elimination. The selection of a target market should never be assumed because the result of the segmentation exercise should drive the entire marketing strategy.

The existence of a formalized forecasting strategy for sales, competition, technology and other areas is also an indication of responsible management in high-tech firms. This area is very easy to neglect with a sweeping generalization that the future is so volatile that accurate forecasts are impossible. Even if this is true, the exercise of trying to develop forecasts gives management a much better understanding of the markets, products, strengths and weaknesses than if no attempt was made at all. The existence of a forecasting strategy, then, is a sign of managerial maturity.

A preliminary exercise that can assist in selecting a target market and developing forecasts is primary market research. The fast changing situation has been used as a crutch for managers in high-tech companies that do not conduct research. They do not see the value in trying to estimate the size of a market or assess a sample of potential customers' purchase intent. Market research should be embraced by high-tech marketers as a method of avoiding costly development of unmarketable products. Perhaps large, time consuming surveys are impractical for the high-tech firm, but focus groups, concept testing and small sample surveys can be done quickly and can yield results that will help management. If the research results are negative, new areas can be considered. If the research results are positive, then greater resources can be invested and capital will be easier to raise. 


\subsection{Researchers}

The research has empirically tested a schema for the development of a marketing plan. Both the formation of a schema and its test on a case company have taken the marketing planning theory further than was found in the literature. This exploratory study has raised several interesting areas for further research.

The schema developed from Hopkins' research on marketing planning provides a subject for criticism and testing. A detailed guideline for marketing planning had not been developed before because one model was not believed to be applicable to all types of firms. As was shown in this research, such a model could act as a starting point for a marketing planner. Before, during or after its first application, the schema could be modified for the specific company's needs. Researchers could use several case studies to test the applicability of the schema over a range of companies. In this way the possibility of developing a generalized schema suitable to most companies could be tested.

The next step in developing the theory of marketing planning in technology firms would be a multiple case study. This would probably require that the researcher utilize a data collection technique other than actually developing a marketing plan for each firm. A questionnaire/interview combination, where a respondent can think about the topic independently, or among co-workers and answer a questionnaire, and then discuss the schema with the reseacher may be a possible technique. Allowing the case firms to develop the plans themselves while the researcher divides his observation time among them is also a possibility. It is also feasible that a totally new approach, not considered would yield more stimulating and thought provoking results for future researchers. A survey utilizing semi-structured questionnaires may be such a method in the future. It is suspected that more theory development would be required before the concepts were concrete enough to develop a structured questionnaire.

The research suggèsted that the marketing plan development process in high-tech companies wás not drastically different from the process in other firms. There were some anomalies, but they were not significant enough to suggest that traditional marketing principles would not apply. This finding suggests the hypothesis that the anomalies found reflect only a difference in emphasis on the various components of the planning process not a difference in the planning process itself.

An area that this research did not explore but which seems to be a logical extension of the study of the plan development process is an examination of the plan implementation process. The implementation of a plan that was developed by utilizing the schema for technology-based firms may reveal many differences in the marketing function due to the high-tech environment. On the other hand, such a study may support the contention that 
the marketing function in technology firms is not drastically different from other firms. A case research methodology would again seem to be an effective way to begin to study the implementation subject.

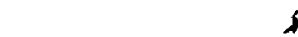




\section{References}

Aylmer, Richard J., (1980). "Strategic Marketing Planning", Managerial Planning. 28 (January), 8-11.

Babbie, Earl, R., (1979). The Practice of Social Research (second edition): Wadsworth Publishing Company Inc., California.

Barnhill, A., (1985). "High Technology Marketing: The Performance and Practices of Canadian Companies", in The Proceedings of the Annual Conference of ASAC Marketing Division. L.C. Chebat, ed., 6 (May 27-29), Part 3, 59-68.

Barnhill, A., V.E. Gattiker and D. Lynn, (1986). "Marketing and Market Development Activities of High Technology Companies in Canada", in The Proceedings of the Annual Conference of ASAC - Marketing Division. T.E. Muller, ed., 7 (June 1-3), Part 3, 59-68.

Barton, Allen H., and Paul Lazarsfeld, (1969). "Some Functions of Qualitative Analysis

- in Social Research", in Issues in Participant Observation: A Text and Reader. George J. McCall and J.L. Simmons, eds. Addison-Wesley Publishing Company, Don Mills, 163-196.

Boag, D.A., and H.J. Munro, (1986). "Analysis of Marketing Acitivities in High Technology Manufacturing Companies", in The Proceedings of the Annual Confefence of ASAC - Marketing Division. T.E. Muller, ed., 7 (June 1-3), Part 3, 69-78.

Bonoma, Thomas V., and Benson P. Shapiro, (1983). Segmenting the Industrial Market. Lexington Books, Toronto.

Bonoma, Thomas V., (1985). "Case Research in Marketing: Opportunities, Problems, and a Process", Journal of Marketing Research. XXII (May), 199-208.

Chisnell, Peter M., (1985). Strategic Industrial Marketing. Prentice-Hall International, Toronto.

Cosse, Thomas J., and John E. Swan, (1983). "Strategic Marketing Planning by Product Managers - Room for Improvement?', Journal of Marketing. 47 (Summer), 92-102.

Cowell, D.W., and K.J. Blois, (1977). "Conducting Marketing Research for High Technology Products", Industrial Marketing Management. 6, No. 5, 329-336.

Cravens, David W., and Charles W. Lamb, Jr., (1986). Strategic Marketing Cases and Applications (2nd edition). Richard D. Irwin Inc., Homewood, Illjentis.

Davis, Duane and Robert M. Cosenza, (1985). Business Research for Decision Making. Kent Publishing Company, Boston, Massachusetts.

Fauman, Bruce C., and Doyle L. Weiss, (1986). "What High Technology Managers Can Learn from the Soap Marketers", in Managing High Technology. George H. Haines, Jr., and John R. Callahan, eds., Ottawa, Ont., 68. 
Finch, P., (1986). "Getting Serious at Comdex/Fall '85", Businéss Marketing. 71 (January), No. 1, 88-92.

Ford, D., and Ryan C.,(1981). "Taking Technology to Market", Harvard Business Review. 59 (March-April), No. 2, 117-126.

Fuerst, I., (1986). "Behind the Faces", Datamation. 32 (February 15); No. 4, $37-44$.

Gold, Raymond L., (1969). "Roles in Sociological Field Observation", in Issues in Participant Observation. George J. McCall and J.L. Simmons, eds.. Addison-Wesley, Reading, Mass., 30-39.

Guiltinan, Joseph P., and Gordon W. Paul, (1985). Marketing Management Strategies and Programs. McGraw-Hill Book Company, Toronto.

Gupta, A.K., S.P. Raj and D. Wilemon, (1985). "The R\&D-Marketing Interface in High Technology Firms", Journal of Product Innovation Management. 2 (March) No. 1, 12-24.

Hauser, J. R., (1984). "Consumer Research to Focus R\&D Projects", Journal of Product Innovation Management. 1 (March) No, 2 70-84.

Helmeke, T.M. (1984). "Strategic Business Unit Market Planning: An Industrial Case History", Business Marketing. 49 (November), 42-43+.

Hirschman, Elizabeth C., (1986). "Humanistic Inquiry in Marketing Research: Philosophy, Method, and Criteria", Journal of Marketing Research. XXIII (August), 237-249.

Hopkins, David S., (1972). The Short-Term Marketing Plan, Conference Board Report No. 565, New York.

Hopkins, David S., (1981). The Marketing Plan, Conference Board Report No. 801, New York.

Hulbert, James M., William K. Brandt and Raimar Richers, (1980). "Marketing Planning in the Multinational Subsidiary: Practices and Problems", Journal of Marketing. 44 (Summer), 7-15.

Jaffe, Heinz A., (1975). "Involve Engineers in Marketing Plans: Their Aid Can Boost Profit Potential", Industrial Marketing. 60 (August), 53.

John, George, and John Martin, (1984). "Effects of Organizational Structure of Marketing Planning on Credibility and Utilization of Plan Output", Journal of Marketing Research. XXI (May), 170-183.

Johne, F.A., (1984). "Segmenting High Technology Adopters", Industrial Marketing Management. 13, 59-63.

Kiel, Geoffrey, (1984). "Technology and Marketing: The Magic Mix?", Business Horizons. 27 (May-June), No. 3, 14.

Kent, Debra, (1985). "Computer Retailers Clamor for Manufacturers' Support", Datamation. 70 (June), No. 6, 61-68. 
Kotler, Philip, and Gordon H.G. McDougall, (1982). Principles of Marketing. Prentice-Hall Canada Inc., Scarborough, Ont..

Lamont, L.M. (1972). "Marketing Industrial Technology in Small Businesses", Industrial Marketing Management. 1 (July), No. 4, 387-396.

Lorange, Peter, (1973). "Formal Planning in Multinational Corporations", Columbia Journal of World Business. XXII (May), 199-208.

McCall, George J. and J.L. Simmons (eds), (1969). Issues in Participant Observation: $A$ Text and Reader. Addison-Wesley Publishing Company, Don Mills.

McDonald, Malcolm H.B., (1982). "International Marketing Planning", European Journal of Marketing. 16, No. 2, 1-32.

Miles, Matthew B., (1979). "Qualitative Data as an Attractive Nuisance: The Problem of Analysis", Administrative Science Quarterly. 24 (December), 590-601.

Miller, S.M. (1969). "The Participant Observer and 'Over-Rapport' ", in Issues in Participant Observation: A Fext and Reader. George J. McCall and J.L. Simmons eds. Addison-Wesley Publishing Company. Don Mills, 87-89.

Moore, Gerald, (1981). "How Determined Market Planning Protects a Maturing Product Technology", Industrial Marketing. 66 (May), 72-74.

New, D.E., and J.L. Schlacter, (1979). "Abandon Bad R\&D Projects with Earlier Marketing Appraisals", Industrial Marketing Management. 8 (November) No. 4, 274-280.

Petre, Peter, (1985). "Computer Marts: A New Way to Hawk High Tech", Forrune. February 4, 64.

Ryan, C.G., (1984). The Marketing of Technology. Peter Peregrinus Ltd., London, U.K.

Shank, John K., Edward G. Niblock and William T. Sandalì, Jr., (1973). "Balance 'Creativity' and 'Practicality' in Formal Planning", Harvard Business Review. (January-February), 87-95.

Shanklin, William L., and John K. Ryans, Jr., (1984a). Marketing High Technology. Lexington Books, Toronto.

Shanklin, William L., and John K. Ryans, Jr., (1984b). "Positioning and Selecting Target Markets", Research Management. 27 (September-October), No. 5, 28-32.

Shanklin, William L., and John K. Ryans, Jr., (1984c). "On Marketing Communications: The High Tech'ers are Consistent, But... ", Business Marketing. 69 (September), No. 9, 105.

Shanklin, William L., and John K. Ryans, Jr., (1984d). "10 Principles of High Technology Market Behavior", Business Marketing. 69 (September) No. 9, 100-106. 
Shanklin, William L., and John K. Ryans, Jr., (1984e). "Organizing for High-Tech Marketing", Harvard Business Review. 62 (November-December) No. 6, 164-171.

Sigel, Efrem, (1984). "The Selling of Software", Datamation. April 15, 125-128.

Sigel, Efrem, (1985). "Computer Advertising, 1985: The \$2.1 Billion Prize", Datamation. 31 (July 31) No. 13, 147-152.

Souder, W.E., (1980). "Promoting an Effective R\&D/Marketing Interface", Research Management. 23 (July) No. 4, 10-15.

Stanton, William J., Montrose S. Sommers and James G. Barnes, (1985). Fundamentals of Marketing. McGraw-Hill Ryerson Limited, Toronto.

Stasch, Stanley F., and Patricia Lanktree, (1980). "Can Your Marketing Planning Procedures be Improved?", Journal of Marketing. 44 (Summer), 79-90.

Stone, Eugene F., (1978). Research Models in Organizational Behavior. Goodyear Publishing Company Inc., Santa Monica, California.

Stoner, James A.F., (1982). Management. Prentice-Hall Inc., Englewood Cliffs, New Jersey.

Tull, Donald S., and Del I. Hawkins, (1984). Marketing Research Measurement and .Method (Third Edition). MacMillan Publishing Company, New York.

Verschuur, J.J. (1984). Technologies and Markets. Peter Perengrinus Ltd., London, U.K.

Walker, K.R. (1976). "How to Draw Up a Marketing Plan That Will Keep You on the Track", Industrial Marketing. 60 (August), 53.

Winer, Leon, (1965). "Are Your Really Planning Your Marketing", Journal of Marketing. 29 (January), 1-8.

Wright, John S., Willis L'. Winter, Jr., Sherilyn K. Zeigler, and P. Noel O'Dea, (1984). Advertising. McGraw-Hill Ryerson Limited, Toronto.

Yeagar, Robert L., (1985). "Engineering the Customer-Oriented Marketing Strategy", Business Marketing. 70 (November), 60-76.

Zarecor, William D., (1975). "High Technology Product Planning", Harvard Business Review. 53 (January-February), No. 1, 108-115. 


\section{Appendices}

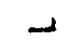

$s$ 


\section{Appendix 1}

\section{The Technology Life Cycle}

The technology life cycle (TLC) was proposed by Ford and Ryan (1981) as an alternative to the product life cycle (PLC).

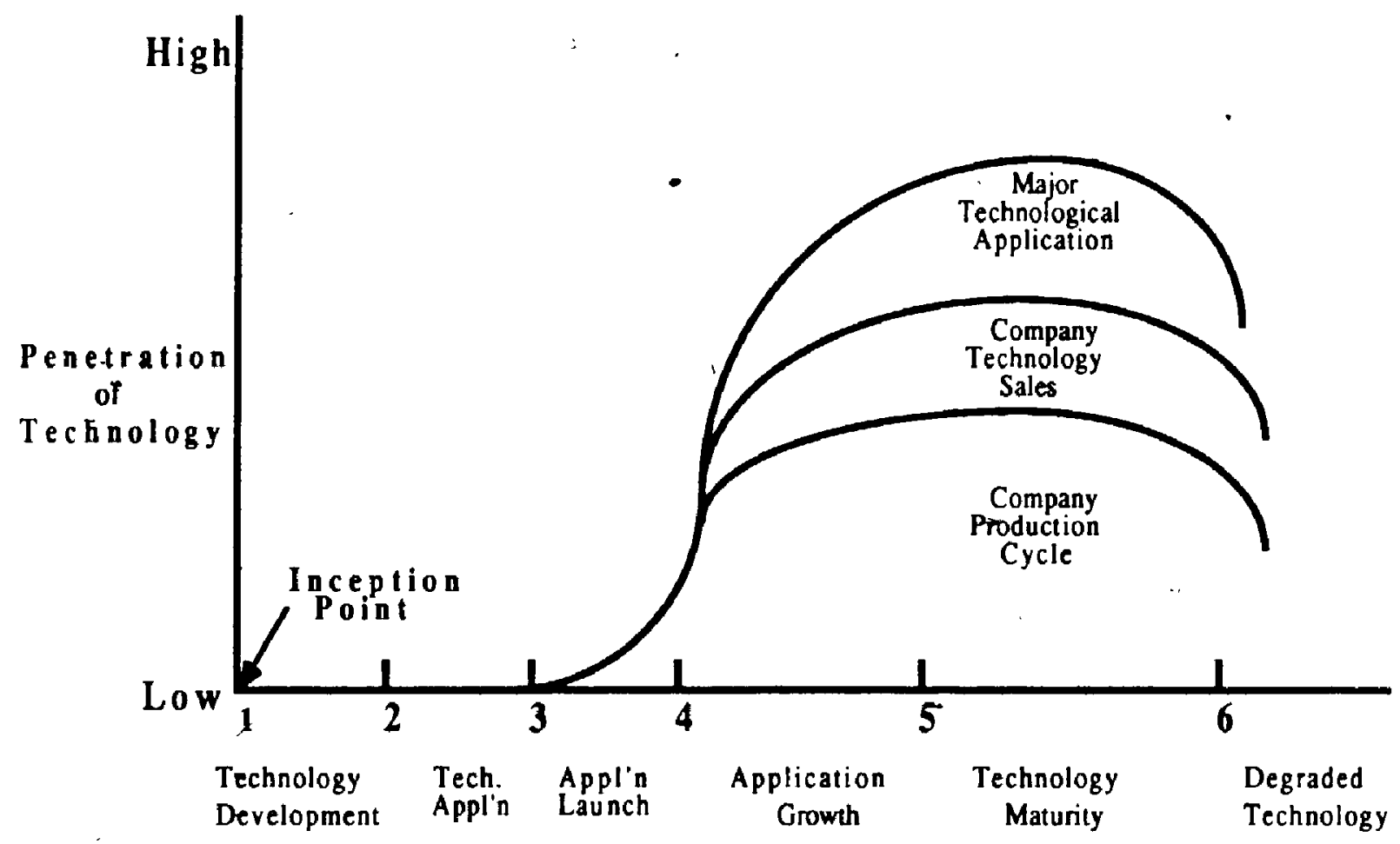

As can be seen, the curve increases, levels, and then decreases; and the technology passes through various stages - similar to the product life cycle. The focal point is a technology, however, not a product.

This curve is more appropriate for strategic marketing because it has a longer span of development than a product is likely to have. For instance, one researcher found that a five year product life cycle was considered to be a reasonable expectation in the high-tech industry (Barnhill, 1985).

For a low technology product, the life cycle is likely to be long enough for the PLC to be a valuable strategic tool while the TLC will have limited value because of the length of the technology's life. 


\section{Appendix 2}

\section{Glossary of Important Names and Concepts}

Bubble Memory - The memory technology used in both the Stortite 1 and Stortite lines. It is the most reliable menfory technology available but also the most expensive. Unique

- because the magnetic media does not move as it does with magnetic tape and disks.

CMOS RAM - A memory technology that also serves as an ultra-reliable data storage medium. The only end-use difference between CMOS RAM and bubble memory is that CMOS needs a battery to act as a backup in case the power supply is disrupted. It is therefore not a truly non-volatile system but may be adapted with the use of a supplementary independent power supply.

Compco - A new company in the ultra-reliable data storage system market, operating out of California. They had a very well financed start-up which utilized advertising to a large degree and, as a result, overshadowed Techsys. They are trying to attract the same customers as Techsys but are offering much lower prices in most cases because they manufacture the bubble memory devices themselves while Techsys must buy them from another company.

Control Engineering, EDN, Programmable Controls - The trade journals that are read by Techsys' customers and in which Techsys is particularly concerned.

Data Recorder - A member of the Stortite 1 line of products that is unique because it can be sold to an end user and function independently whereas the rest of the line must be incorporated into a larger system.

Dissonance-causing Stimuli - Information obtained after a decision has been made that is likely to make the decision-maker regret the action taken as a result of the decision.

I rmware - The software that is included in the electronic data storage system for all three of Techsys' lines. This is a generic term used by all companies in similar fields.

Frost and Sullivan - A professional market research firm in the U.S. which produces and sells various reports on a multitude of industry sectors. These very detailed reports sell for several thousands of dollars on average but are very useful for understanding a market and/or an industry.

Futuro - The market leader in programmable logic controllers for industrial use in North America. Their two major products in this line are the PLC-2 and PLC-3 which the Techsys' Programmable Loading Device is meant to backup.

Lap Top Computer - A small computer terminal with a keyboard and viewscreen which Futuro plans to utilize for their new PLC backup offering in the industrial market. It will be a direct competitor of Techsys' PLD.

Memco - Techsys' distributor of the Stortite and Stortite I product lines in Michigan. This firm is also the largest distributor of Futuro PLCs in North America. Representatives of this company provided a great deal of market information on the PLC backup market and strategic information on Futuro. The company will distribute Techsys' PLD product line when it is introduced. 
Military Qualified or MIL QUAL or MIL SPEC - A company becomes a Military Qualified (MIIL QUAL) supplier if it meets certain requirements established by the military purchasing body for product specifications and quality control criteria. If the company is a MIL QUAL supplier it is capable of supplying MIL SPEC products for military purchase. This is a very desirable designation because of the attractiveness of the lucrative military market.

Networking PLD - A product in Techsys' proposed PLD line that will interface with the computer network of a company and offer it data storage backup and potentially other services in the future.

Non-volatile,-A data storage system is said to be non-volatile if it maintains its integrity (stores the data contained on the storage medium) when the power supply is terminated.

PLC-2, RLC-3 - Futuro's two major product offerings in the PLC market. The PLC-2 is about one-fifth the price of the PLC- 3 and has about five times the sales.

Product Life Cycle - A theory used for strategic product analysis which stipulates that a product moves through various 'stages' as part of its development. The stages which are determined by the sales and profit growth of the product are: product development, introduction, growth, maturity and decline.

Program Loading Device or PLD or PLC Backup System - A computer storage system that serves to backup a Programmable Logic Controller.

Programmable Logic Controller or PLC or Process Controller - A computer used in many industrial applications to control a mechanical process on an assembly line or independently.

Ruggedness/Ruggedized - An adjective used to describe the storage systems and how reliable they are under adverse conditions of extreme temperature, dust, or vibration.

Stortite - One of Techsys' product lines of ultra-reliable data storage $\$$ stems. Includes a group of products which may be customized according to different computer interfaces, storage media and storage capacities.

$$
\text { s. }
$$

Stortite I - A line of data storage systems that is more reliable than the Stortite line but which serves the same purpose. It was the first of Techsys' products ever developed.

Tape Loader - A device which has been used for backing up a PLC. They are currently provided by Futuro and other leaders in the.PLC industry. This method of loading programs and making backups is slower than Techsys' PLD and Futuro's lap top

- computer which both use microfloppy diskettes.

Technology Life Cycle - A theory, similar to the product life cycle in that it considers various stages of development but different bocause it follows a technology and its sales, and application growth rather than a product's

Unique Selling Proposition - A marketing concept which refers to the combination of a selling feature of a product, and a promise or benefit for the user in a unique way for selling purposes.

Winchester Disk - Also known as a 'hard disk'. This storage medium is faster than the microfloppy diskettes but is also more expensive and not as transportable. 


\section{STEP 1 - Process}

Qbjectives: Obtain an understanding of where the company is, how it got there, and what factors are affecting its products and operations.

Uncover trends, problems or opportunities so that they may in the following sections of the marketing plan.

The main activity in this section will be research including secondary sources, interviews with company personnel, company documents and external sources etc. A thorough understanding must be gained so that it may be transmitted to the users of the marketing plan.

Following the preliminary research must be an analysis of the data uncovered, (economic, industry, company sales, profits etc.) and an effort to detect any trends. There are therefore two areas which must be developed:

1. A description of past and present issues, and

2. A diagnosis of where the company and its products are headed in the next year or more.

In summiary, information gathering, analysis and reporting.

\section{STEP 2 - Componenits}

\section{Internal Analysis}

Products:

-description of product, main features, benefits, selling points,

history, quality, breadth, price etc.

-product life cycle stage

-product sales, bookings, expenses, profits

-market share of product

-major target markets for product

-pobitioning, reputation

-patent position

-marketing strategy utilized - 4P's

-figures by product line, product, market segment, size, model, type etc.

,Manufacturing/Production:

-description of key processes, factors, history and development

-future developmants (i.e. new equipment, retooling, aging equipment)

-timing of obsolescence of products

-capacity of plants (source of product)

-flexibility of manufacturing

-location of major plants

efficiency ratings on major processes

t

Company strengths and weaknesses:

-financial - ratios (ex. current ratio, retum on assets), cash availability

- technology - automation of production, R\&D department

-goodwill/badwill - reputation in customers' and competitors' minds

-vertical integration - ability to control production and distribution of products

-personnel - turnovèr rate, expertise, unionization

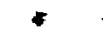


-Internal problems and opportunities:

-marketing - existence of formal marketing function

-R\&D - extent of use, need, availability

-manufacturing - efficiency, lead times, control over, capacity

-financial - stability

-personnel - turnover rate, unused capacity, skilled vs unskilled

-new products - opportunity for development

-situation specific problems and opportunities

\section{External Analysis}

Econopic Analysis:

-key factors affecting company

-GNP, exchange rates, unemployment, interest rates, disposable income etc.

Industry Analysis:

-industry standards of profit, wages, growth

-description of industry (SIC), what types of firms, products operating practices

-leader in the industry, role played

-barriers to entry

-capacity utilization

-geographic diversity or concentration

Market Situation and Competitive Environment:

-size of total market, major segments, characteristics

-descriptión of market segments - demographics, geography, benefits sought, buying behavior, preferences, motivations to purchase

-marketplace dynamics - trends, shifts, patterns or behavior

-market shares of major players

-positioning of products in the market

-level of technology of products

-anticipated changes in the market - social, technological, political, legal

-marketing strategies employed by competition - 4P's, segmèntation

-competition's strengths and weaknesses.

External problems and opportunities:

-market - trend of decreasing/increasing consumption.

-specific segments - unmet demand in certain segments

-competition - increasing/decreasing competitive pressures

-regulation - industry specific, market specific, company specific

-conomic- inflation, interest rates, disposable income, consumption patterns

-political - changes in government bodies, regulation, opinions

-social - values and lifestyle trends, shifts

-international - new markets appear, old markets decline, regulations, tariffs, quotas, new governments, agreements etc.

Previous Performance VS Objectives

Explain Variances

Planning Assumptions and Constraints

Any assumptions necessary for the development of this plan that the user may find relevant

- e.g. no new products. within the next fiscal year, no technological improvements for 2 years.

Any constraints that limit the marketing activitiog and hence the plan development, ex. government regulations regarding advertising, sales quotas etc. 


\section{STEP 3 - Information Sources}

For the Internal Analysis:

-market research reports

-financial statements

-sales and production reports

-informed persons within the company (ex. department heads, salesmen)

-consultants (knowledgeable persons outside the company)

For the External Analysis:

-market research reports

-Statistics Canada püblications/government documents

-trade association

-trade magazines

-consultants

$b$

-embassies

-libraries

-patent reviews

-government agencies/officials

-informed persons

-Bank of Canada

-company records

-suppliers, distributors, wholesalers

-newspapers

-competitive literature

\section{SECTION 2 - FORECASTS}

\section{STEP 1 - Process}

Objective:

Using the analysis from the first section, along with other sources of

- information, project where the company is headed in the short and long term.

There are several ways to forecast including test markets, surveys of buyer intentions and sales force composites (bottom-up approach). More sophisticated techniques such as

- regression or correlation analysis are also available. Smaller firms may use trend analysis (the projection of past data into the future) or executive judgement with great success. The problem with trend analysis is the a priori assumption that the past is.indicative of the future. There are methods available (e.g. exponential smoothing) to avoid some of the pitfalls of this method but the basic assumption remains the same. Executive judgement may be the simplest method but it relies solely on the executive's ability to assimilate all relevant information and develop forecasts independently. The use of any particular method will depend on the specific industry and company characteristics, company resources as well as the forecaster's preferences.

It is recommended that the forecaster identify pessimistic, most likely and optimistic forecasts for such factors as sales, profits, and the economic indicators. This will help improve the monitoring procedures.

\section{STEP 2 - Components}

Demand:

estimation of the size of the industry, market, and segments demand -broken down by product, segment or even customer if appropriate -growth rates of each unit of analysis -any market changes 
Sales:

-company, product, segment

-in units and dollars

-profits and contribution margin figures

Competitive:

-sales, prices, product introductions, promotion, distribution

Market:

-purchasing patterns.

-how will they buy and what will they buy, who buys, why they buy (i.e., the industrial buying process)

-customer preferences

-market shares

-social, technological, legal, political

-cyclicality or seasonality factors

-Product Life Cycle of product classes

Economic:

-Inflation, GNP, exchange rates, income $\sim$

Other:

-situation specific occurances that will affect the company or market or industry in some significant way.

\section{STEP 3 - Information Sources}

-marketing research reports

-sales call reports

-orders

-informed persons

-sales meeting summaries

-technical reports

-financial statements/records

-federal and local government publications

-Statistics Canada reports

-customers

-competitive literature

-suppliers, distributors, wholesalers

-trade magazines

-trade association

-professional organizations

-consultants

-embassies/foreign governments

\section{SECTION 3 - OBJECTIVES}

\section{STEP 1 - Process}

Objective:

Establish quantifiable, measurable and realistic statements of the dosired results of the company's operations in areas of strategic importance.

The objectives are not what one expects to happen in the future (as were the forecasts), but rather what the company will strive for. They must be realistically attainable so that they 
are motivationuer thether than demotivational for the personnel responsible for their attainment. They must be quantifiable and measurable if possible.This allows for monitoring to take place and a measures of success to be developed.

There are two basic ways that the objectives will be set: top-down and bottom-up:

In the top-down approach, top management interprets economic, industry and market trends and forecasts (sections 1 and 2 of the plan) and translates them into objectives. Instead of this interpretation they may also use test market or survey results as a guide. Whatever method, they must take the company's available resources (capital, personnel, financial) into account.

In the bottom-up approach, top management solicits the opinions of the line personnel (ex. sales representatives) for their sales, profit, and other objectives. These lower level personnel set the objectives which they, themselves must meet, and submit them to upper management for approval. $-\infty$

In both cases, the objectives should be set in consultation with any relevant outside groups such as advertising or public relations agencies, consultants, accountants etc.

\section{STEP 2 - Components}

Mission Statement: -definition of the company's business -purpose, motives -scope of activities

Objectives:

-relatively few (perhaps 6 - 8), divided into short, medium and long term -potential objectives pertain to:

1. profit margin

2. field sales effort

3. new product development

4. sales to major accounts

5. pricing policy

6 . inventories/distribution ,

7. sales promotion

8. márketing research
9. advertising themes

10. customer/product service

11. export sales

12. advertising expenditures

13. dealer relations

14. sales training

15. other marketing overseas

16. packaging

-other objectives may be related to financial measures such as Return on investment (ROI), Return on assets (ROA), inventory türnover. -how each objective will be measured should also be specified.

Strategies:

-market segmentation

-target market evaluation and selection

-market share strategies (e.g. market leadership, dominance)

-product development strategies - Product Life Cycle analysis

-e.g. stimulate primary/selective demand

-product porfolio analysis -decisions to add or drop products at specifig times, (planned obsolescence)

-markel penetration, diversification, concentration etc.

-competitive strategies - head-on, product differentiation

-competitive counterplanning

-5 year statements, budgets, long range marketing mix 
-these are the longer term elements of the marketing plan (assumes there is no separate strategic marketing plan)

STEP 3 - Information Sources

-sections 1 and 2 - situation analysis and forecasts

-ad agencies

-consultants

-complaints from cus pmers and personnel

-market research reports

-informed persons

-past year's customer correspondence

-sales meeting summaries

-technical reports

-financial statements

-other company records

-competitive literature

-suppliers, distributors, wholesalers

-customers

\section{SECTION 4 - ACTION PROGRAMS}

\section{STEP 1 - Process}

Objective:

Develop step-by-step procedures that individuals will follow in order to achieve the objectives for the coming year and beyond.

These action plans stem directly from the objectives and necessarily must take the situation analysis and forecasts into account.

Once again this can be done using the top-down or bottom-up approach. Using the top-down approach, top management would develop the programs and merely inform the responsible individuals of their responsibilities. In the bottom-up approach, the flanner would develop the programs in conjuction with the parties who will be responsible. An agreed upon program would be developed to be carried out by the lower-level persormel.

The steps in each action plan development are as follows:

(i) outline the necessary steps

(ii) develop a financial budget for the plan

(iii) develop a timing schedule

(iv) outline expected results of the program

(v) compose a schedule of responsible departments (or individuals) along with their role or duty in the implementation

(vi) include a section on evaluation criteria while the plan is in progress and upon completion to judge success

(vii) identify a contingency plan trigger (i.e. if market share drops betow $5 \%$ then contingency plan $B$ will be implemented).

These programs may be developed in conjunction with or by an ad agency, PR agency on other intornal or external, knowledgable bodies for acceptance by upper management. The programs may be very detailed (as an advertising plan would be) or very brief.

\section{STEP 2 - Components}

- the steps necessary to achieve the objectives set

- who is responsible for each step (individual, department, task force etc.)

-when each step must be started and completed 
-available alternatives in the event of a delay

-methods of evaluation

-support necessary (by division, individual)

-financial budgets for each plan

-explanation of how the action plan will help achieve the objective(s)

-the estimated impact of the completion of the action plan on sales, profits, expenditures, etc.

accompanying tables and schedules where appropriate or necessary

Possible action programs may be in the following areas:

1. product line plans

2. advertising plans

3. sales promotion and display plans

4. major packaging plans

5. trade selling plans

6. special market research projects

7. pricing

8. special cost reduction plans

9. market segments selected and targeted

10. positioning

11. distribution plans

12. after sales - service and warranties

13. co-relationships - joint ventures, licensing

STEP 3 - Information Sources

-suppliers, distributors, wholesalers

-professional organizations

-consultants

-informed persons

-sales meetings summaries

\section{SECTION 5 - MONITORING PROCEDURES}

\section{STEP 1 - Process}

Objective:

Develop a set of procedures that allow management to keep abreast of the progress of the various programs, isolate any deviations from the plan, and attempt to

understand the variances and make any modifications deemed necessary.

The steps in the process would be as follows:

1. Isolate the key factors in the program (they are probably directly related to the objective that the program was developed to achieve).

2. Identify the range of acceptable values of these key factors.

3. Designate an individual responsible for monitoring the program. This individual should be someone with knowledge of the plan but not the person responsible for it's implementation.

4. Identify periods when structured monitoring will take place (e.g. monthly), and

5. Identify the procedure to be followed.

e.g. Compare sales figures of Product $X$ in February with the objective sales level for February. Identify any significant variances and try to isolate their cause. Classify the cause according to these criteria: (i) Internal cause (ii) External cause (iii) Controllable (iv) Uncontrollable 
STEP 2 - Components

- what kind of feedback information will be needed

-a schedule of review periods

-criteria for measuring effectiveness of action plans

-performance reports which allow for isolation and analysis of variance

- benchmarks for succéss

-identification of person responsible for monitoring each plan

STEP 3 - Information Sources

-suppliers, distributors, wholesalers

-professional organizations

-consultants

-patent reviews

-market research reports

-sales call reports

-orders

-complaints

-informed persons

-sales meeting summaries

-technical reports

Éfinancial statements

-other company records

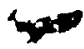

\section{SECTION 6 - CONTINGENCY PLANNING}

STEP 1 - Process

Objective:

Identify possible future crises or drastic improvements in the situation and develop plans that will outline the actions to be followed should the activities take place.

Top management would examine the situation analysis and forecasts in an attempt to identify possible future crises or drastic improvements that may develop. These events are isolated and assessed according to 1 . their likelihood and 2. the benefits or damage that would accrue should they occur.

Possible ways to prevent, couriteract or protect from the crises and exploit the opportunities should be identified. These plans are then outlined with the actions to be taken and key factors specified.

\section{STEP 2 - Components}

-list of major threats and opportunities for which contingency plans are needed

-afew plans that can be activated should drastic unexpected events occur

-perhaps 1 or 2 options for a downturn and 1 or 2 for an improved situation -events that will act as triggers for the contingency plans ex. sales level, profit leveh, machinery breakdown, strike

- -who will implement the contingency plan

-an outline of the major elements of the plans

STEP 3 - Information Sources

-trade magazines

-trade associations

-industrial sector reports

-market research reports

-informed persons 
-technical reports

-sales meeting summaries

-Statistics Canada publications

-the first 5 sections of the Marketing Plan

) 


\section{Appendix 4}

\section{Background on Techsys Electronics Inc.}

The company was formed in 1981 and sold its first product in December, 1982. Until recently, they were in the business of manufacturing ultra-reliable data storage systems using bubble memories only. They now utilize CMOS RAM memories with a battery backup in their Stortite and Stortite 1 product lines. In addition to their two main product lines they are developing a new line of programmable logic controller (factory floor computers used to control processes) backup systems. This line is tentatively referred to as the Program Loading Device or PLD line (reflecting their main functions to load, backup and store PLC programs).

Techsys is a very small company with annual sales of approximately $\$ 1$ million and eleven or twelve employees at any point in time. The President and Marketing Manager are the only two who are involved in marketing. Although the facilities are located in Ottawa, Canada, the company estimates that only about $10-15 \%$ of their sales are to Canadian customers. The majority of their sales are made to American companies but they have had customers from all over the world.

The Stortite and Stortite. 1 lines are sold to companies operating in any industry that requires the operation of computerized equipment in areas that are subjected to high levels of dust, grease, oil, vibration, rough handling, or chemical vapours. The PLD line will be sold to automobile manufacturers in the short term as they are the largest purchasers of PLCs. 


\section{Appendix 5 .}

Semi-Structured Interview Questions

\section{Familiarization Session}

\section{Objectives:}

1. Familiarize researcher with the company employees and environment

2. Familiarize employees with researcher and research to be conducted

3. Determine the information sources available for marketing plan development within the company. $\sim$

Date:

Name:

Position:

Time with Company:

Phone Number:

\section{*Explanation of Purpose of Interview*}

1. Please describe your professional background.

2. What is your personal history? How did you come to work at Techsys?

3. What are your main responsibilities with the company?

4. Who is your direct superior? What is his/her position?

5. Who are the people within the company that you deal with most of ten?

6. Are you involved in any planning or budgeting?

(a) Can you describe the plans/budgets?

(b) Can you describe the planning/budgeting activities?

7. What are your areas of expertise within the company?

8. How important is a marketing plan?

9. What should a marketing plan be used for?

10. What do you think should be in a marketing plan? 


\section{Appendix 6 \\ Sample Interaction Summary Sheet}

1. Person Interviewed: Marketing Manager

2. Time: 30 minutes

3. Place of Interaction: My office

4. Date: Friday May 15, 1987; 9:45 a.m.

5. Other Contributors: None

6. Topics for Discussion: Situation Analysis

\section{Content of Discussion:}

-He identified the specific thade shows that fechsys attends, their approximate cost, where they are located and who attends.

-Press Release results anonitored by the trade magazines and given to the company.

These results (in the form of number of inquiries) act as data when advertising rates for the company are set by the magazine.

- Techsys has tried direct mail efforts in the past (one to traffic and transportation departments in the U.S. based on a sale to one such department in Idaho for road analysis). These efforts have been dismal failures.

-I mentioned the possibility of using telemarketing. He was diplomatic in his response (as usual) but I think he would have to be convinced of its potential value. He pinpointed one of the main difficalties of its use - getting a good mail/telephone list.

-We discussed, in some detail the difficulty of segmenting the market into meaningful segments. He thinks that an initial breakdown of: 1. Mobile Environments (protection from vibration and shock) and 2 . Industrial data storage (protection from temperature extremes and contamination) is $\mathrm{OK}$ for a start. It would need to be broken down further however to be meaningful.

-He wonders whether it would be better to concentrate on the new PLC system backup rather than the older products

9. Decisions: None made

10. Other Meetings Scheduled: None 


\section{Appendix 7 \\ Semi-Structured Interview Questions \\ For Evaluation Purposes}

Date:

Name:

Position:

1. Do you think that the marketing plan will be used? Why? Why not? How? What parts in particular?

2. Do you see any limitations to using the plan?

3. What problems do you see in trying to implement the action plans? Do you see any ways to avoid these problems?

4. Is there anything that you would like to see in next year's plan that was not in this plan?

5. Is there anything that you would change next year about how the plan was developed? Why?

6. Would you change the layout of the plan next year? The content? How would you change it? Why?

7. Would you likestosee more, less or about the same amount of detail in next year's plan? In which areas? How much more or less? Why? 


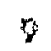

Appendix 8
$\quad$ Marketing Plan for Techs Electronics Inc.

3

-

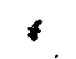
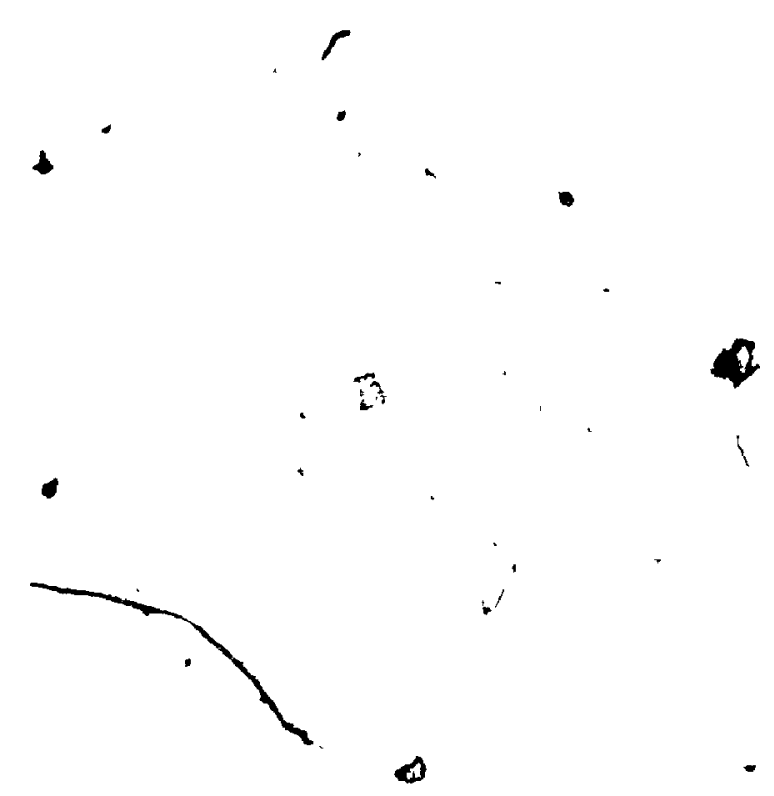

$-$
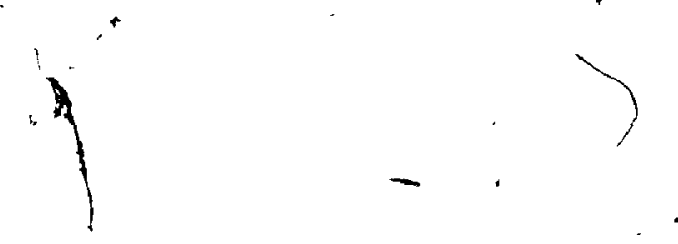

$s:$ 


$$
2^{\text {of } / \mathrm{de}} 2
$$




\section{Executive Summary}

This document is Techsys' first annual marketting plan since the Company's formation in 1982. It contains a detailed analysis of the sifuation in which Techsys operates, outlining both the strengths and weaknesses discovered. It also contains the objectives for the coming and future years and outlines action plans designed to achieve these objectives. Monitoring procedures and contingency plans are also provided as methods to maintain the plan throughout the year and deal with improbable events.

$$
\lambda
$$

The situation analysis revealed that the industrial market for bubble memory data storage systems is not viable for Techsys in the near future. Some potential does exist in the military market for military qualified manufacturers. It is unlikely that the Company could become such a manufacturer during the 1987-88 fiscal year.

Realizing that bubble memory products are too expensive for the industrial market, management is changing the Company's direction by modifying current products and developing new ones. To make the Stortite 1 and Stortite product lines more price competitive with Compco and other competitiors, CMOS RAM (with a battery backup) memories are used instead of the bubble memories. Using this technology, the price of the CMOS cartridges is about $60 \%$ of the bubble memory cartridges of similar capacity. This, combined with a speed advantage, should attract industrial buyers to Techsys' products in the coming year.

A new product line of Programmable Logic Controller (PLC) backup systems is in the design and development stages. This line of program loading devices (PLDs) will have a wall-mount version (to be fastened to the wall beside a PLC), a portable version (to be carried from PLC to PLC), and a networking wall-mount (to backup various components of the computer network of a factory). Initially these PLDs will only be compatible with Futuro PLC-2s and PLC-3s (as they are the market leaders with a 45\% market share). Once the Futuro compatible PLDs are commercialized, PLDs will be designed to operate with PLCs from Gould, General Electric and Texas Instruments. In the coming year, the automobile manufacturers in North America will be targeted. This industry is the largest PLC purchaser to date.

The distributors used by Futuro to sell their PLCs were selected as the most suitable for Techsys' PLD line. Their knowledge of the technology, the market and the customers needs will be very valuable to the Company. Designing a support system for the 10 or 11 distributors who cover $90 \%$ of the target market is a primary objective of this plan.

A comprehensive communication plan has been developed to support the Stortite 1, Stortite and PLD product lines. Magazine advertising will be the consistent core throughout the year and will be complimented by direct mailings, press releases, promotions and one trade show. These activities will focus on the Stortite 1 and Stortite lines in the first six months of the year but the emphas is will switch to the PLD line in the latter six months as the products are developed. Total cost of the communications is under $\$ 50,000$. The entire marketing plan has a budget of approximately $\$ 73,000$. 


\section{Table of Contents}

Section

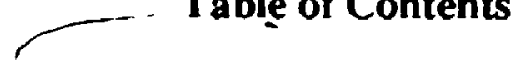

1. Situation Analysis $\quad 88$

1.1 Internal Analysis . $\quad 88$

1.1.1 Market Segmentation and Target Markets $\quad 88$

1.1.2 Products 89

+. 1.1.3 S and S1 Marketing Strategies 91

1.1.4 Manufacturing and Production 92

1.1 .5 New Products 93

1.1.6 Internal Problems and Weaknesses . 93

1.1.7 Internal Strengths and Opportunities 96

1.2 External Analysis

97

1.2.1 Economic Analysis $\quad$. 97

1.2.2 Industry Analysis 97

1.2.3 Market Situation and Competitive Environment 99

- 1.2.4 External Threats 104

- 1.2.5 Past Performance VS. Objectives 104

1.2.6 Planning Constraint : 105

2. Forecasts

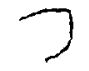

2.1 Demand Forecast

2.2 Sales Forecast

2.3 Competitive Forecast

2.4 Technological Forecast

106

106

106

107

108

3. Objectives

110

3.1 Mission Statement

110

3.2 Short-Term Objectives

110

3.3 Medium-Term Objectives

110

3.4 Long-Term Objectives

$-110$

4. Action Plans

111

4.1 S and S1 Product Lines Plan 111

4.2 PLD Development and Introduction Plan 113

4.2.1 The Product Line 115

4.2.2 Price $\quad 116$

4.2.3 Distribution - 117

4.2.4 Promotion 118

- 4.2.5 PLD Plan Overview . 118

4.3 Communications Plan - • 119

4.3.1 Trade Shows 121

4.3.2 Advertising - 121

4.3.3 Promotion 122

4.3.4 Direct Mailing 124

4.3.5 Publicity $\quad .124$

4.3.6 Communications Plan Overview 125

4.4 Distribution Plan for the PLD Line 126

4.4.1 Method of Distribution $\quad 126$

4.4.2 Why Carry . Techsys' PLD Line? 127

4.4.3 Why Not Carry Techsys' PLD Line? 128

4.4.4 Schedule of Activities 129

4.4.5 Distribution Plan Overview 129 
5. Monitoring Procedures 131

5.1 S and S1 Product Lines Plan Monitors 131

5.2 PLD Development and Introduction Plan Monitors 131

5.3 Communications Plan Monitors 132

5.4 Distribution Plan Monitors . 133

6. Contingency Plans $\quad .134$

6.1 Plans to Counteract Threatening Situations 134

6.2 Plans to Take Advantage of Opportunities . 135

Eigures

1. Market Classification $\quad 89$

2. Positioning of Memóry Technologies 90

3. Historical Sales and Profits 93

4. 1987 Orders per Period 93

5. Industry Structure ' 98

6. The Market for Techsys' Rugged Data Storage Products 99

7. Hierarchy of Effects $\quad 120$

Tables

1. Industry Comparison of Techsys - Key Business Ratios 98

2. Competitive Summary for the S and S1 Products 101

3. Techsys Budgeted Income Statement - 1987/88 106

4. PLD-Optimistic Sales 107

5. PLD-Most Likely Sales 107

6. PLD-Pessimistic Sales 107

7. S and S1 Action.Plan - Schedule of Activities - 113

8. PLD Plan - Schedule of Activities 114

9. PLD Line Price List 116

10. PLD' Discount Structure 117

11. Techsys' Contribution Margins 117

12. Advertising and Promotion Schedule 120

13. Communications Budget 125

14. Distributors' Gross Margins 127

15. Distributor Plan - Schedule of Activities . $\quad 129$

\section{Appendices :}

8-1. Assumptions to Market Demand Forecasts $\quad$. . 137

8.2. Schedule of Áctivities for Marketing Plan 138

-8-3. Financial Budget and Cash Flow Requirements for Marketing Plan 139 


\subsection{Internal Analysis}

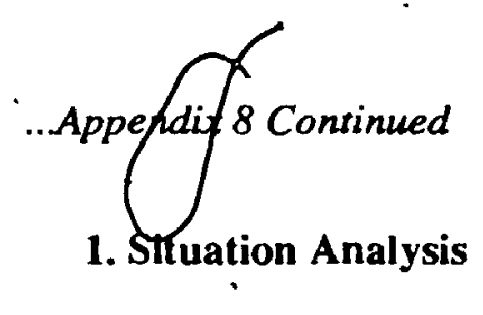

\subsubsection{Market Segmentation and Target Markets}

A market segmentation excercise, usually done in order to choose one or more target markets and then pursue those targets through a marketing strategy, was not conducted at the outset of operations. Instead, many applications in a multitude of industries were observed - clouding the target market decision. Adding to the difficulty of which market to target was the small perceived sales potential of any one segment. Choosing any one could have meant that the Company was confined to being a very small operation indefinitely and possibly never making a significant retum for the investors. It was decided, therefore, not to target.

Through experience and an analysis of the Compàny's cusfomer base, some appropriate market segments can be identified. They may be descrifted by using a multi-stage classification procedure. The first stage uses the benefits sought by those needing data storage systems as the basis for segmenting the market. This criterion identifies only the companies needing rugged and reliable data storage systems. It omits anyone whose prime concerns are low price or media density or who is not operating in a very rugged environment. The dotted line shows the speed benefit which Techsys intends to pursue with the CMOS products.

A second stage utilizes geographic segmentation to reveal the North American market (and predominantly the U.S.) as the most profitable. Although some sales have

i been made in Europe, Asia and elsewhere, over $90 \%$ of the Company's sales have come from American-based firms.

The third stage limits the customer class to which the target market belongs. "Original equipment manufacturers", "system integrators", and "vătué added resellers" all provide viable markets for Techsys. The "end user" segment must not be included as a target market because the $S$ and $S 1$ lines are not designed for this group. The products are designed to be the data storage component of a larger computer system. The exception to this is the data recorder products which can be sold to the end user group as well.

Onçe these three stages have been considered the fourth and final stage of "industry sector" must be utilized to break the market into even smaller segments. Four sectors have expressed a desire for Techsys' products more than any others. Those companies extsaged in mobile instrumentation, non-tactical defense and aerospace (not requiring MIL SPEC products), resource industry automation and manufacturing and plant automation have been consistent product purchasers. Figure 1 presents this classification process.

This classification, representing consistent custemer groups for the $S$ and $S 1$ lines, wâs only made possible after the Company had been in uusiness for several years. In light of this experience it seems feasible that a segmentationcould be done before operations begin for such products. Research would bo required however to identify the groups with the greatest need or desire for the product in questiond 
Figure 1

Market Classification

Staoe:

1. Benefit

Sought

2. Geographic Location

4. $\quad$ 3. Customer Classification

4. Industry

Sector

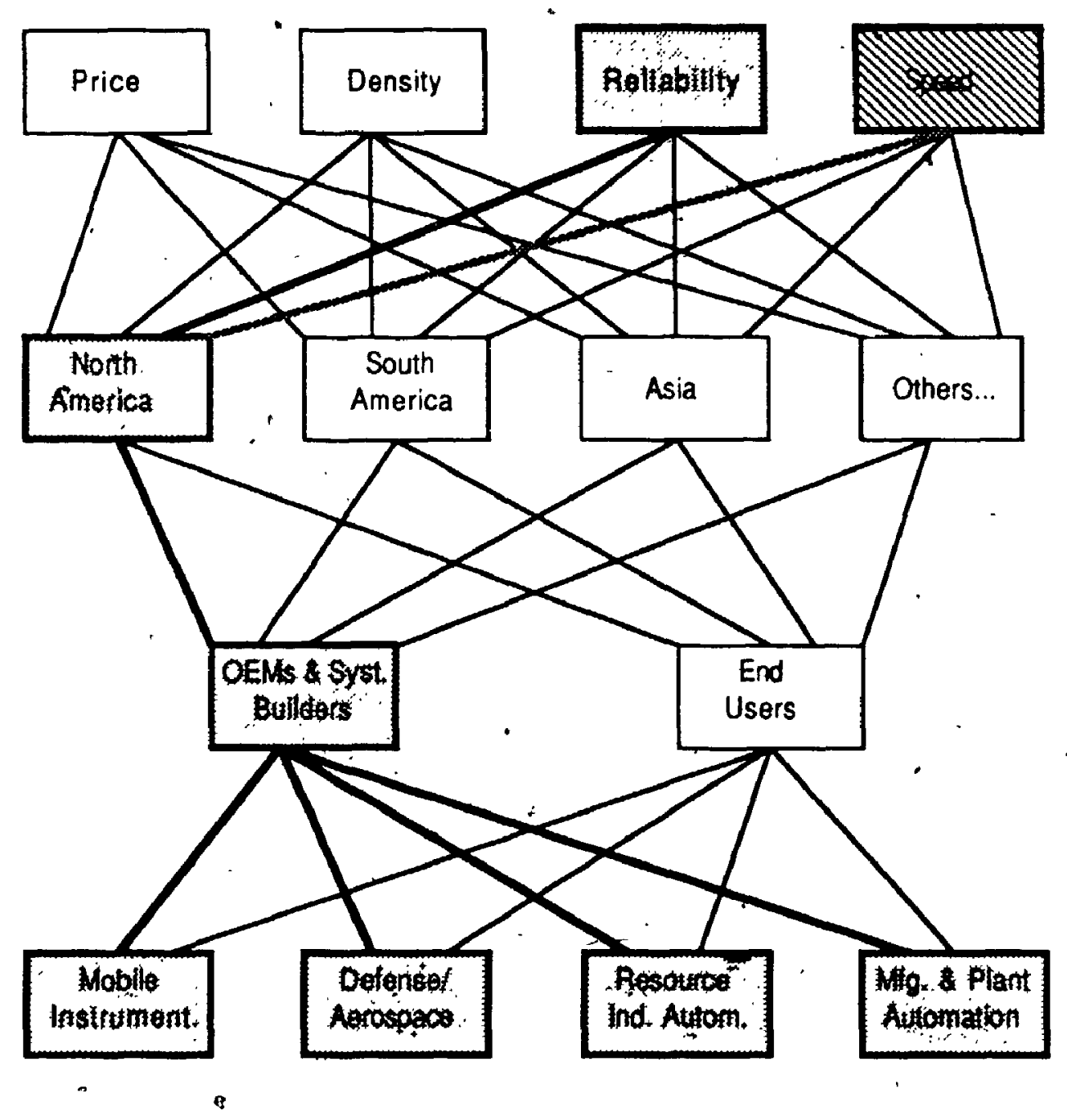

\subsubsection{Products}

When customers evaluate data storage system alternatives they focus on the three product attributes of cost per bit, speed and density (a memory capacity/unit size measurement). Techsys' Stortite and Stortite 1 (S and S1) product lines using bubble and CMOS RAM memory technologies are more expensive but as fast or faster than the three most used altematives - Winchester disks, floppy disks and tape. Both bubble memories and battery-backed CMOS RAM have lower densities than the other three alternatives. Figure 2 shows two positioning maps that identify management's opinion of how the various memory technologies are perceived by the market as of August 1987.

Techsys is in a non-competitive position when compared to the lower priced, higher density technologies. The Compeny has tried to avoid such comparisons from the beginning, choosing to differentiate the $S$ and $S 1$ lines by stressing other product characteristics. In most situations reliability and the ability to operate in rugged environments are not considerations in the customer's purchase decision. In other 
instances, the ones that Techsys attempts to discover, these two factors are the overriding purchase considerations. The S and S1 lines compete in this "harsh environment data storage" market along with a handful of other companies' products. The marketing and selling strategies for all of these products stress the "reliability in rugged environmants" selling point. The Company is now trying to appeal to those potential customers who require speed as the key feature for their system. The CMOS products will be suitable for this segment of the market.

Figure 2

Positioning of Memory Technologies
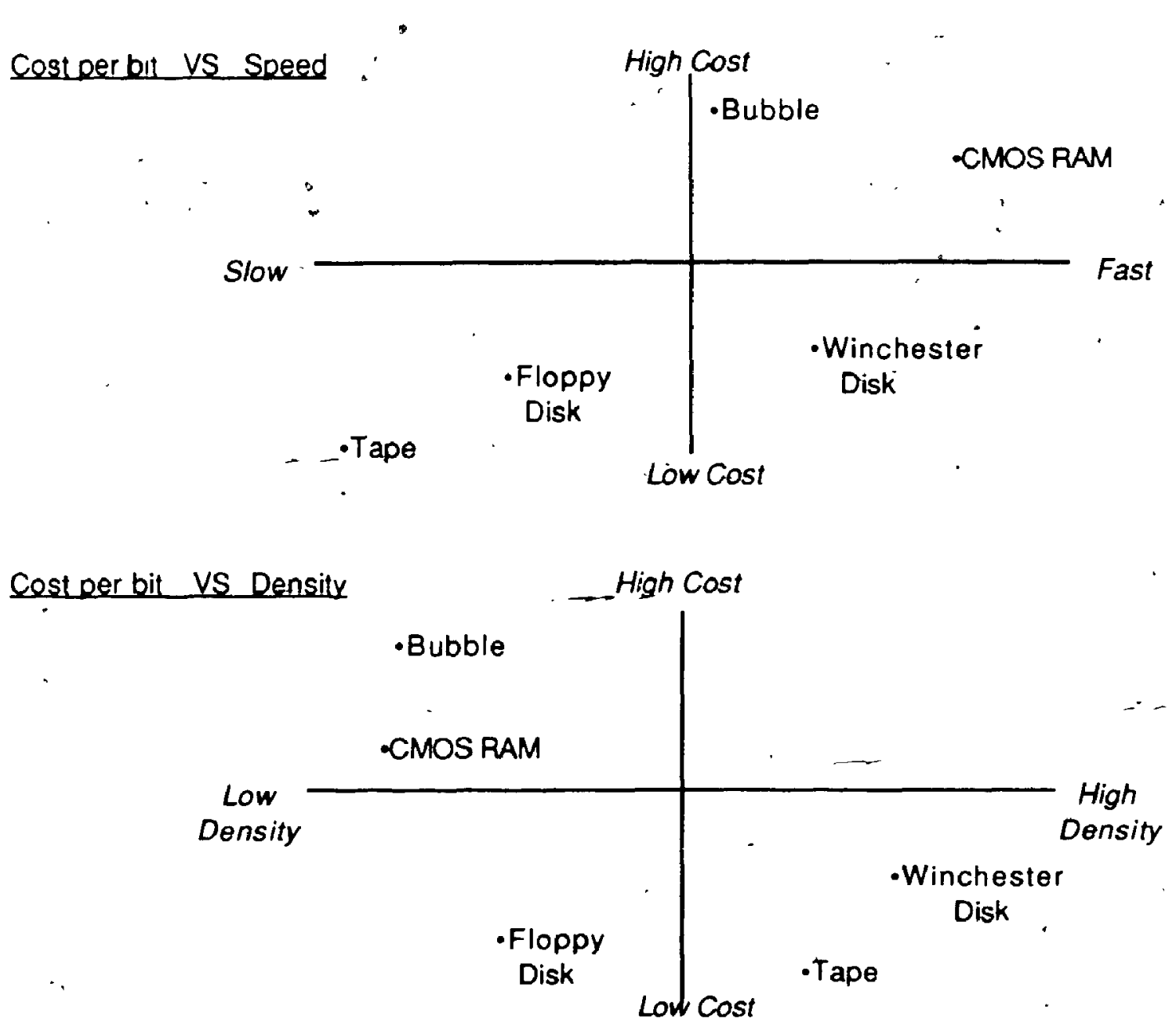

The unique features of Techsys' product lines stem from the Company's experience in designing and manufacturing customized storage systems for harsh environments over a 5-year period. This experience has allowed the Company to develop such features as fixed and removable (cartridges) memory systems, interchangeable CMOS RAM and bubble memory cartridges, stand-alone (the data recorder series) and OEM products, as well as floppy and hard disk emulation interfaces. The harsh environment market competition has not been able to match Techsys' wide product offerings. 


\subsubsection{S and SLMarketing Strategies}

The Company's.products are premium priced among traditional data storage products. A Stortite $I$ datarecorder is priced between $\$ 1,700$ and $\$ 4,000$ (U.S.) while a Stortite 1 cartridge is priced between $\$ 745$ and $\$ 3,695$ (U.S.) depending on the configurations. The prices of Stortite cartridge systems (without cartridges) are $\$ 295$ or $\$ 445$ (U.S.) depending on the interface desired. The removable cartridges are as low as $\$ 600$ (U.S.) for a 360 Kbyte CMOS to as high as $\$ 2,630$ (U.S.) for a 1 Mbyte bubble memory cartridge. The data packs span from $\$ 1,495$ (for a .5 Mbyte of bubble) to $\$ 3,495$ for a 2 Mbyte bubble pac. If reliability and a rugged environment are not factors in the purchase decision then a customer could buy an equal amount of storage (for example 1 Mbyte) for between $\$ 5$ and $\$ 20$ for a floppy disk or tape (versus the $\$ 3,695$ for Techsys' products).

Three factors are responsible for the high prices relative to data storage sfystems using other technologies. First is the comparatively high prieepf the bubble and CMOS RAM memory components. Second is the long distribution chain (which will be discussed under "Industry Analysis") requiring a markup of the price at each level. The third factor responsible for the high prices of the Company's products is the short production runs for any given contract. Customizing the products for the wide variety of customers prevents the Company from taking advantage of any production economies of scale.

These two families of products have had essentially the same marketing strategies. They are both distributed primarily by a direct salesforce although relationships do exist with distributors in Michigan, Ontario, the U.K., Australia and New Zealand, and wh manufacturer's representatives in 12 areas (covering.16 States) in the U.S. The external representatives have been ineffective in selling the Company's products, putting greater pressure on the direct sales force. Management believes that uncomplementary product lines, an inability by the Company to provide adequate support for the reps, and products that are difficult to sell because they are too expensive for the customers and too complicated for the reps, are contributory factors to their poor performance. In spite of their poor record (estimations are that less than $1 \%$ of total sales have been made by the 17 member team) the external representatives receive a $10 \%$ commission on any sales within their assigned territories, regardless of their participation in the sale. If a sale is made in a territory where there is a representative, Techsys will make sure that the rep provides some service (dropping off literature, picking up the purchase order etc.) to earn some of his commission. The products, once sold, are shipped by land (usually FOB New York) using United Parcel Service (UPS) unless the customer is located abroad, in which case the customier's preferred method of shipment is used. These have been satisfactory methods of shipment to this point in time.

In the past fiscal year the primary modes of communication have been press releases and trade shows. Limited financial resources have constrained the methods of promotion that the Company could use. Direct mail, magazine advertising and limited promotions have been utilized in previous years but the efforts were inconsistent and the results were not documented in detail, raising doubts as to their effectiveness. During the 1984-85 fiscal year the Company spent over $\$ 100,000$ on magazine advertising and had consistent sales from period to period for the first and only time in the Company's history. The monthly sales in other years fluctuated greatly. A new advertising campaign in Control Engineering and EDN magazines was started in July 1987 to try to repeat the consistent performance of 198485 .

Trade shows, which cost the Company between $\$ 5,000$ and $\$ 10,000$ each, have yielded poor quality leads recently. The high cost of exhibiting at these shows therefore, 
has not been justified so management has decided to place less emphasis on them. Techsys' realization that trade shows have decreased in value to the firm is supported by other "high-tech" product marketers who have reached a similiar conclusion.*

Two direct mailings were conducted from lists that wewe purchased from external agencies. Both of these efforts were costly failures. During one such direct mailing period there were no leads received that could be directly traced to the mailing itself. Direct mail efforts using in-house lists of past customers and qualified leads have been used more frequently and with much greater success. Marketing a product that is useful to such a small portion of the total data storage market means that the "hit" rate of an unsolicited mailing will be very small. Since direct marketing efforts are most effectively used when the target audience is known, the Company has not relied on this type of communication.

\subsubsection{Manufacturing and Production}

The manufacturing philosophy is intended to avoid using up capital in expepsive production facilities, to allow flexibility in changing product lines and to allow the Company to expand and reduce its production capacity in response to market requirements. As a result of this philosophy, work is subcontracted as much as possible and the final assembly and testing is conducted at the main facility.

The design and production process for any customized product begins when the engineers design a product suggèsted by the marketing department on a "schematic". Electronic design facilities are used at this stage. The schematics are sent to a service bureau where they are put on "paper plots". The plots are checked for errors and returned to the service bureau to be put on "contact sheets". The contacts are checked for errors and sent to a board manufacturer-where a printed circuit board (PCB) is made. Once the PCB is error free it is "stuffed" (the memories, CPUs and so on are connected). . The stuffed $\mathrm{PCB}$ is then tested using predominantly computerized testing methods and finally sent to the customer. With the current personnel and processes, it is felt that the plant could produce $\$ 1.5$ million in sales per year. It would be very easy to add the necessary employees to increase this figure significantly.

At least three of each product are developed in the design stages. This must be done in case a problem arises with one (e.g. it is destroyed) and also to ensure that the design works for more than just one prototype. Although this is more costly than producing just one for development purposes, it is felt to be necessary for quality control reasons.

No major changes are planned for in manufacturing and production in the next year. A change in the product emphasis will likely occur however dus to the introduction: of the PLC loader. This will require changes in subcontractors, suppliers, inventories and. so on. The sales of the Stortite 1 and Startite products have decreased naturally but the decrease wifl accelerate as more $R \& D$, matketing and sales efforts are being put on the PLC backup products. No formal product obsolescence strategy is being followed. However, the $S$ and $S 1$ lines will receive lestattention in the Company's communications. Action plan'4.1 outlines the strategy for the $S$ and $S 1$ lines in the coming year.

* William Shanklin and John K. Ryans Jr. "On Marketing Communications: The High Techiers are Consistent. But ...". Business Marketing. Sept. 1984, Vol. 69. No. 9. P. 105. 


\subsubsection{New Products}

A third product line, still in the development stages, will be made up of a series of Program Loading Devices (PLDs) that act as backup systems for Programmable Logic Controllers (PLCs). The T2770SB is a wall-mount version of the PLD and the first - product of the line. It was designed for and funded by the Chevrolet Pontiac Canada division of General Motors. A guaranteed purchase of 12 units with the possibility of more in the future was enough to generate a full scale development effort for related products. This new line of products brings a promising opportunity for-Techsys to venture into a different, yet related branch of business. This diversification will reduce the risk associated with relying on the $S$ and $S 1$ lines exclusively. Action plan 4.2 outlines the strategy for the PLD line in detail.

\subsubsection{Internal Problems and Weaknesses}

The Company's sales and profit situation has been a problem since its formation in 1982. Techsys has not yet had a year of profitable operations. Sales had shown a steady increase up until 1985 but declined by $22.6 \%$ in the $1985-86$ fiscal year. Figure 3 shows the Company's sales and profit history since its inception. The quickly increasing sales and lack of profits appeared to bequite typical of a new successful technology intensive firm. The sales decline of $1985-86$ has continued in 1986-87 as shown in Figure 4. Sales in 1986-87 were approximately equal to those in 1985-86

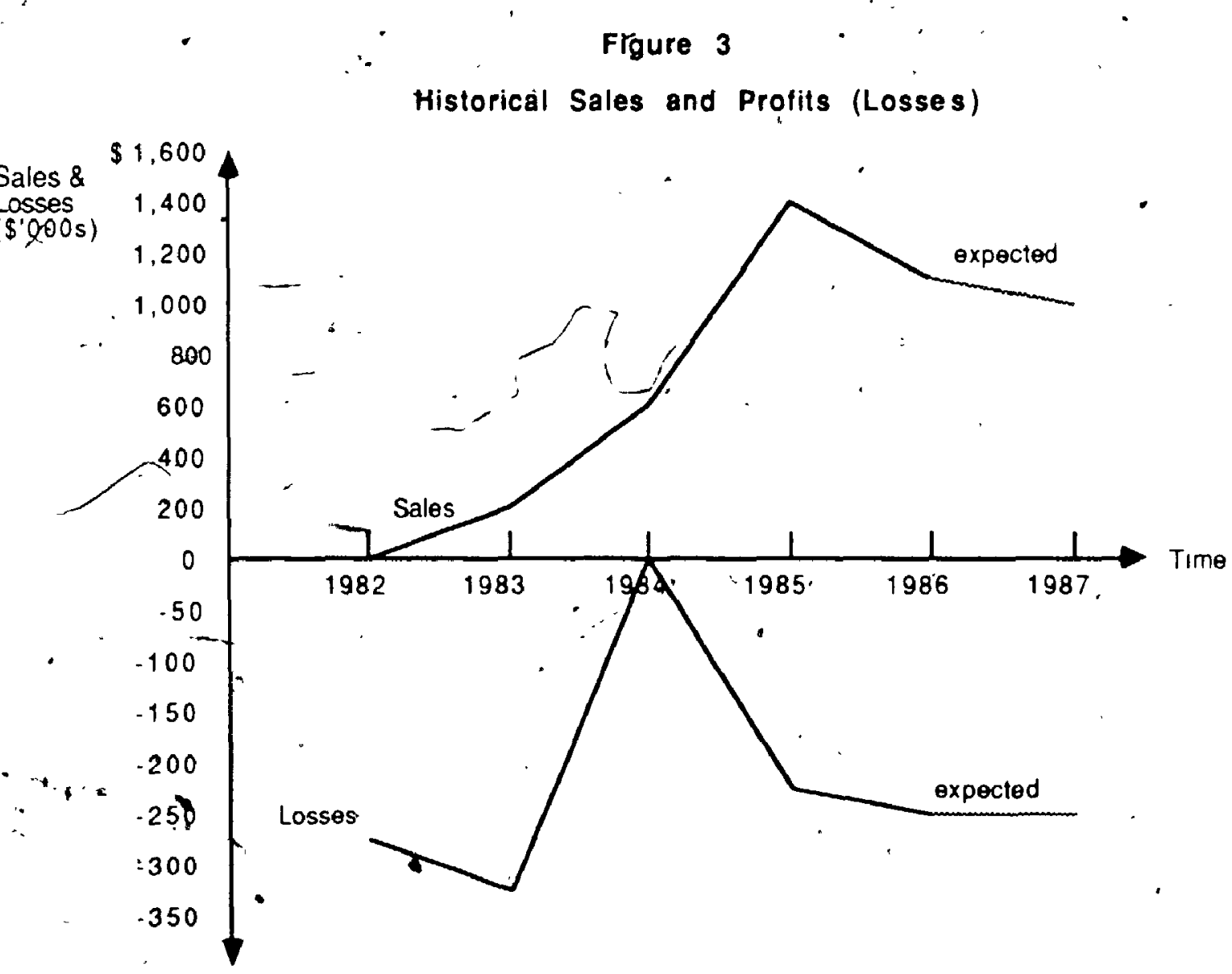

For the first seven periods ( 28 days in a period) of the 1986-87 fiscal year the Company had average per period sales (bookings) greater than the break even point of 
approximately $\$ 100,000$ - $\$ 110,000$. The period bookings varied greatly but the seven

1 period total represented a marginal profit. The three following periods, 8, 9, 10, yielded very few orders and brought the Company back into an unprofitable position for the year overall. Orders in periods 11 and 12, while much improved, were insufficient to yield a profitable year.

Two further problems are correlated with Techsys' poor sales and profit levels. They are results rather than causes of the financial difficulties. The first is the very high inventory level of approximately $\$ 400,000$ that was carried in 1985, 1986 and thus far in 1987. The combination of a decrease in sales and a maintained inventory level has caused the inventory turnover rate to decrease from 2.1 times in 1985 to 1.3 times in 1986.

Figure 4

1987 Orders Per Period

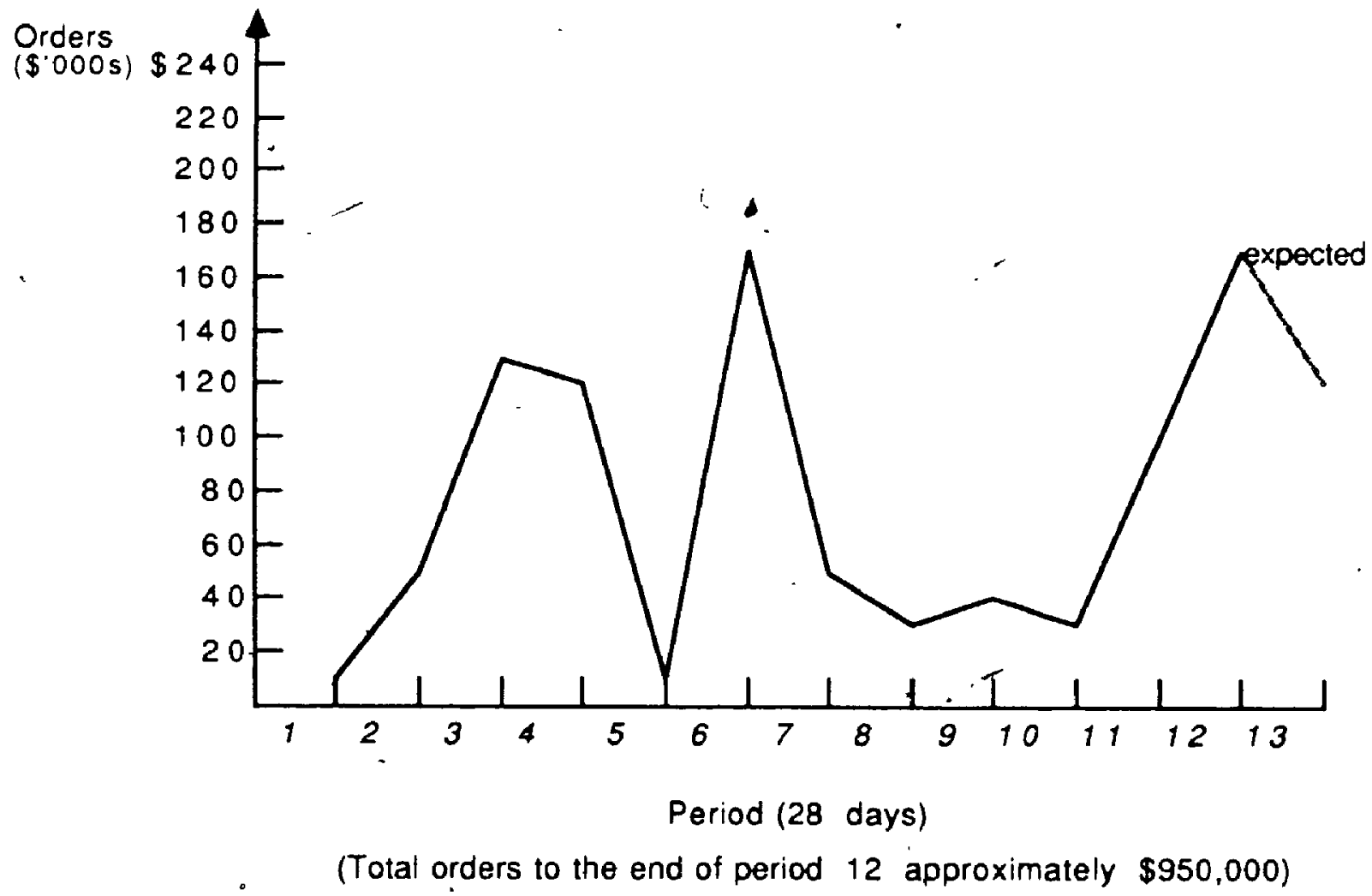

According to Dun and Bradstreet's Key Business Ratios, the turnover rate for an Industrial Electrical Equipment Mamufacturer is usually closer to 4 times per year.* This investment in inventory that is not being sold is a strain on the Company's cash position because it is not being turned into sales and Techsys must pay interest on the loans that financed its purchase.

The second result of the poor sales and profit situation is the difficulty the Company is currently having in raising operating funds through either equity'or debt

* Source: Dun and Bradstreet Canada. Business Information Systems and Sciences and Services. Key Business Ratios Canada Corporations, 1985. 
sources. With no backorder of contracts and a dismal sales and profit performance in the last two years, investors probably find Techsys to be too risky. This inability to raise operating funds accelerates and magnifies the eash flow problems.

The emphasis that the Company has placed on marketing has varied from year to. year. In the first year of operations the Company chose not to select a target market for fear oflosing an unknown but profitable segment. Targeting a certain market (or mark is) however, would have allowed for a concentrated marketing strategy that may have resulted in a narrower but deeper penetration, reducing marketing costs and energies for the same effect in sales. Another example is the inconsistent communications expenditures from year to year. Management recently discovered that the steadiest period in terms of sales in corporate history was when advertising space was purchased regularly over many periods. Without the consistent advertising, the sales per period are very erratic. Greater emphasis may also allow for some marketing research and planning activities to be conducted. These activities should lead to improved product offerings, more effective strategies and greater control over day to day operations.

The price of Techsys' Stortite 1 product line also poses a problem from a strategic point of view. Techsys' 1 Mbyte CMOS RAM cartridge (priced at $\$ 2,495$ ) is about $60 \%$ of the price of a similar capacity bubble cartridge (at \$3995). The CMOS product is still more expensive than a bubble memory cartridge from Compco (priced at approximately $\$ 1,750$ ). Compco is able to price their products significantly lower than Techsys because they produce their own bubble memory devices and Techsys does not. Although Techsys has advantages over Compco, it would be erroneous to dismiss the price differential as. unimportant to most potential consumers. The high price of the Company's products lends itself to selling small quantities only. Along with the high degree of customization, these small quantities do not allow the Company to-take-advantage of economies-of-scale (through mass production). Steps are being taken, by developing the Stortite CMOS cartridges priced at about $\$ 1500$, to compete with Compco on the price feature.

A problem ${ }^{A}$ which has made day-to-day operations and especially planning difficult is the frequent turnover and decline in the number of employees over the past year. In the 1986-87 fiscal year, eight personnel left the Company for a variety of reasons. Only two of these employees have been replaced. The benefit of these changes has been a decrease in the wages expense, but the loss has been a decrease in efficiency and morale.

The final area which may be labeled as a major internal weakness is distribution. Techsys uses a direct salesforce in addition to distributors and manufacturer's representatives. These secondary distribution parties appear to be ill-suited for Techsys' product line and ineffective at selling the products. This is demonstrated by the fact that less than $1 \%$ of Techsys' total sales have been sold as a direct result of an external representative. New methods of distribution are needed.

The distribution system itself is a serious weakness from Techsys' vantage point. Techsys neither manufactures the bubble memory (or other) devices nor does it sell to an end-user. This means that the Company is sensitive to both ends of the distribution system and controls neither end. The dangers are that either side may perform Techsys' "packaging" task, making the link in the chain where Techsys sits redundant. Since price is such a sensitive factor, the added markup put on the product from the extra distribution level, makes the product even more expensive for the end user. Thx is a problem that Téchsys cannot avoid as it is inherent in the organizational configuration while it sells bubble and related data storage products. 


\subsubsection{Internal Strengths and Opportunities}

In spite of the troubled times facing Techsys, there are identifiable strengths that the Company demonstrates and opportunities that present themselves.

The products, while high priced, are also high quality. The unlimited life of a bubble memory, its maintenance free feature, the non-volatility and extreme reliability features (able to withstand environments where other types of memory can not function) are testimony to its quality. The CMOS RAM based products are not maintenance-free (needing a new battery every 5 years or so) but are still non-volatile, very rugged and faster than bubbles. These features make both product types attractive to certain customers.

In order to develop such quality products, the Company has acquired extensive technical knowledge of bubble memories. This expertise has been tsed effectively in the support that is provided to current and past customers. Management feels that Techsys has aceumulated significant goodwill through their continuing service of their products. This feeling was supported by a market research study of Techsys' customers conducted in 1985 that found a bigh degree of satisfaction for the products and after sales servicing the Company provides.

Techsys has remained a small company in terms of employees ( 10 or 11), fixed assets and sales throughout their history. By remaining small it has also remained flexible enough to pursue small contracts for customized products which other, larger companies, would have considered inconsequential. This flexibility is probably the main reason why Techsys has continued operations while many of their competitors have not.

Finally, a strength which has come about in the past year is the tighter financial controls that have been put into place. The combination of a new financial officer and the necessity of tighter controls in light of the financial troubles have actually strengthened this aspect of Techsys' operations.

In addition to these strengths there are a number of opportunities which may improve Techsys' profitability. The first is the new emfloyee, who is an engineer with an interest in sales. This addition to Techsys would most effectively be utilized as a salesman/marketer responsible for generating leads and making sales calls. His engineering background also allows him to assist in design and applications support when needed.

The expansion of product offerings to include the less expensive CMOS Stortite cartridges with battery back-up as well as bubble memory cartridges should certainly increase the number of potential customers. This change in technological emphasis must be communicated to potential customers in an aggressive manner or the change will be irrelevant. Advertising and other mass communications have been scheduled for this purpose in section 4.3 of this plan.

The most significant opportunity available to Techsys appears to lie in the new PLC loader products. The portable version would seem to have immediate appeal to many PLC users. A version of the wall-mount loader has long term implications if it can be made to operate within the network computer designs.at GM and other automobile facilities. These opportunities must be researched for their demand potential and short and long term appeal.

The PLC loaders are particularly attractive to Techsys because they solve a 
fundamental problem that exists with the current products. They will be sold to an end user, not a systems integrator. The Company therefore "owns" one end of the distribution channel.

The marketing of these products is made easier because 1 . there are identifiable customers (current Futuro PLC-2 and PLC-3 users); 2. there is an established distribution system in McNaughton-McKay (Techsys' current U.S. distributor in Michigan) who is the largest seller of Futuro PLC-2s and PLC-3s in North America with a 20\% and 50\% market share respectively; 3 . the product has indisputable benefits over the current tape loader being used to solve the problem - a lower price, faster speed, and smaller size; 4 . the engineers who would purchase the product all read three known trade magazines, making communications much more effective and cost efficient; and 5. the PLC market is estimated at $\$ 940$ million worldwide and expected to grow over the next five years. ,

\subsection{External Analysis}

\subsubsection{Economic Analysis}

Techsys' prosperity is linked, to a certain extent, to the general economic conditions of the markets in which it competes. As the health of the economy declines, Techsys' prosperity declines but historically after about a one year lag. The same is true for an economic boom. The one economic factor that has had a major effect on Techsys' profit level is the U.S. - Carnadian exchange rate. Approximately 75\% of Techsys' sales are to Ämerican customers. A strong American dollar makes Canadian-made goods lesss expensive to an American buyer and, therefore, more attractive.

The Company absorbs the foreign exchange risk because it quotes prices in American dollars and keeps the price relatively stable. If the U.S. dollar improvech relative to the Canadian dollar then Techsys benefits from the differential. When the U.S. dollar declines relative to the Canadian dollar then Techsys' margin is reduced correspondingly. If the prices were quoted and fixed in Canadian dollars, the situation would reverse and Techsys could hedge against this risk.

Pseudo-economic indicators that are easier to follow than actuol indicators are the economic health of certain key industry sectors. For example the autom tive industry, as one of Techsys' main customers is directly tied to Techsys' financial health. The auto industry in turn must analyze disposable income, interest rates, unemployment rates and a multitude of other factors in their economic analysis. Other industry sectors include the process control industry, resource-based industries, and any industry where computers are starting to be used in environments that were previously considered too rugged.

\subsubsection{Industry Analysis}

The structure of the industry that Techsys has been competing in is presented in Figure 5. As mentioned in the internal analysis and as is evident in Figure 5, Techsys "owns" neither end of the process. They/ are forced to buy bubble (and other) memories and components from suppliers and sell to either level 3 or 4 , neither of which is an end user. This is a problem because Techsys can easily be forced out of the picture by a supplier that decides to integrate forwards and produce systems or a system builder who wishes to integrate backwards and produce bubble devices. This trend has already started with Memory Inc. (Techsys' supplier) which now produces systems and Compco (Techsys' competitor) which produces bubble devices. 


\author{
Figure 5 \\ Induetry structure
}

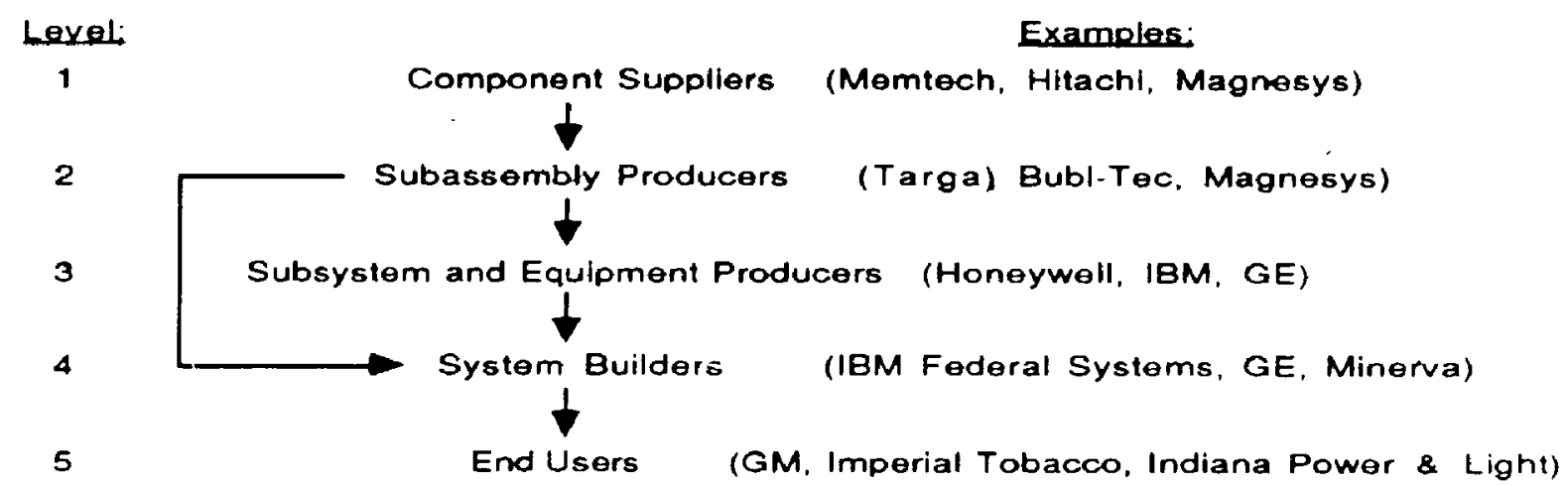

Dun and Bradstreet provides a listing of key business ratios for a number of industries. Table 1 provides a summary of these ratios for two groups - Electrical Equipment - Industrial, and Electical Equipment-Miscellaneous along with these same ratios for Techsys over a 3 year period. Techsys' performance in general, appears to be out of line with the industry figures. In particular, Techsys' substantial losses do not appear to be typical of firms in similar industries. This is shown by the profit/sales, profit/equity and sales/inventory ratios. The sales/inventory ratio has worsened in thelast three years because of decreasing sales and maintained inventory levels.

\title{
Table 1
}

\section{Industry Comparison of Techsys - Key Business Ratios*}

\begin{tabular}{|c|c|c|c|c|c|c|c|c|c|}
\hline Industry & $\begin{array}{l}(\%) \\
\text { CQGS }\end{array}$ & $\begin{array}{l}\text { (\%) } \\
\text { GM }\end{array}$ & $\frac{\mathrm{CA}}{\mathrm{CL}}$ & $\begin{array}{c}(\%) \\
\text { Profit } \\
\text { Sales_ }\end{array}$ & $\begin{array}{l}(\%) \\
\text { Profit } \\
\text { Equity }\end{array}$ & $\begin{array}{l}\text { Sales } \\
\text { Equity }\end{array}$ & $\begin{array}{l}\text { (days) } \\
\text { Coll. } \\
\text { Period }\end{array}$ & $\frac{\text { Sales }}{\operatorname{In} x^{\prime} y}$ & $\begin{array}{l}(\%) \\
\text { Debt } \\
\text { Eauity }\end{array}$ \\
\hline Techsys 1984 & 28.1 & 71.9 & 3.41 & .1 & .1 & 1.3 & 152.3 & 3.99 & 37 \\
\hline Techsys 1985 & 41.6 & 58.4 & 2.12 & $(15.7)$ & (35.1) & 2.23 & 80.1 & 3.5 & 59 \\
\hline Techsys 1986 & 47.1 & 52.9 & 1.57 & $(22.7)$ & $(54.9)$ & 2.4 & 51.2 & 2.8 & 132 \\
\hline Elect. Equip. & a & & & & & & & & - \\
\hline Industrial (1985) & 5) 72.9 & 27.1 & 2.0 & 3.7 & 8.5 & 2.3 & 63 & $4.2 *$ & 71.7 \\
\hline Elect. Equip & & & & & & & & & - \\
\hline Misc. (1985) & 77.3 & 22.7 & 1.5 & 0 & 0 & 3.3 & 55 & 4.2 & 171.2 \\
\hline
\end{tabular}

* Source: Dun and Bradstreet, Key Business Ratios, Canada Corporations 1985.

COGS - Cost of Goods Sold as a \% of Sales

GM - Gross Margin = Sales - COGS

CA/CL - Curreni Assests/Current Liabilities = Current Ratio

There are two major barriers to entering the industry. The first is that bubble memories are very difficalt to work with (this assumes a narrow industry definition, for example, rugged data storage system suppliers). The second is that opportunities are very 
difficult to identify. The diverse and large number of potential uses makes the identification of companies willing to pay the high price because of a strong need, very difficult.

The industry for the PLD line is one of industrial automation. This industry is expected to grow at $30 \%$ over the next year on a worldwide basis. PLC's will play a significant role in industrial automation for the next several years because they are specifically tailored to basic factory floor tasks and their performance is proven.

\subsubsection{Market Situation and Competitive Envirenment}

The size of Techsys' market is not easily determined because of the difficulty in defining the market An estimate of the market size was made in May 1986 by Techsys' management and it is felt that this estimate is valid for the current period. The sources used in making the estimates were independent market surveys, news items, magazine articles, and interviews with customers, prospects and industry participants.

The market may be considered to be the overlap of the three markets for data storage equipment, "ruggedized" equipment, and data storage equipment under 1 Megabyte. Figure 6 shows this overlap representing a $\$ 300$ million market in North America.

Figure 6

The Market for Targa's Rugged Data Storage Products 1

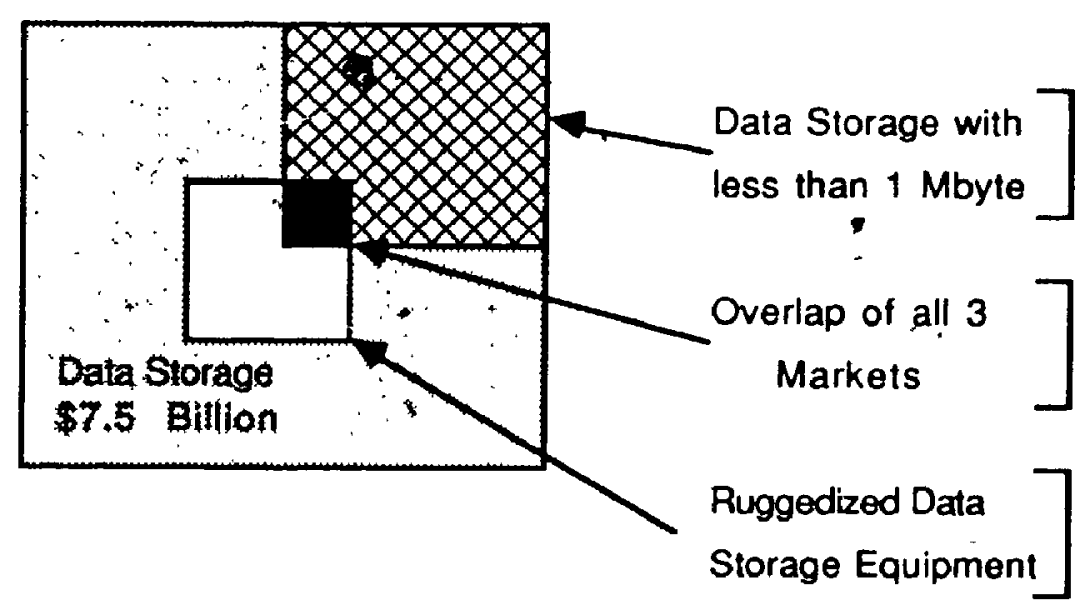

$\$ 2$ Billion

$\$ 300$ Million

For all of the segments that Techsys' products appeal to, the buying process is a lengthy one with several stages. A development stage is followed by a test period of several months where the customer assesses the product. If they are satisfied with the performance they may order three or four (or however many their initial need is). If, after 6 to 18 months they are still pleased, then they may place another order.

Techsys has concentrated on the North American market where $90 \%$ of their sales originate (75\% in U.S. and $15 \%$ in Canada). The Company also makes $10 \%$ of their sales elsewhere (predominantly in Europe), responding to unsolicited orders. 
The state of the market is such that bubble memory products are too expensive for virtually all but military applications. The military market is different from the industrial market in several ways. First, to compete a company must be military qualified and manufacture MIL SPEC products. This implies that the company has facilities of a certain size and quality and enough personnel to fulfill quality control specifications. Second, the buyers in this market are insensitive to price differences because they have a very large capital base (such as government departments and very large OEMs) or the products will operate in such a rugged environment that price is not a primary consideration. Third, the purchasing process is longer than in the industrial segment because of the lengthy bureaucratic procedures that must be followed when purchasing. These factors, and others, combine to make it difficult or impossible for Techsys to compete in this industry sector in the short term or forseeable future.

The technology has not progressed sufficiently to reduce the price of the bubble memories on a per bit basis so as to be a practical alternative. This trend has become even more acute by the recent decrease in price of CMOS RAM memory. Techsys now manufactures CMOS RAM cartridges with battery backup for approximately $60 \%$ of the price of a bubble memory cartridge of the same capacity. The previous generation of the CMOS technology was more expensive than bubble memory technology.

Hitachi Inc. is developing a new 16 Megabit bubble memory to replace the current 4 Megabit ones. This leap in density should broaden the appeal of bubble memories to - more customers, but the price of such a product is likely to be quite high. The technology is improving, although at a much slower rate than many had anticipated. The Hitachi bubble configuration is significantly different from Techsys' current bubble memory supplier - Memory Inc. (previously Intel). Switching bubble memory suppliers would therefore require that Techsys redesign their bubble memory based products.

Another trend in the market stems from the disk drive manufacturefs. Recently, they have been promoting their products (drives) as being very reliable for rugged environments. This attacks the reliability problem from a different viewpoint. Instead of having a ruggedized storage medium, they have a rüggedized holder for the medium. This trend has not produced solutions as reliable as Techsys' but may pose more significant competition in the future.

\section{Competition}

Competition for the $S$ and $S 1$ lines may be divided into desire, generic, product form and brand $\mathrm{p}$ petition. This classification separates the competitors into homogeneous groips according to their threat to the Company. Only the generic and product form complitors are threatening to Techsys.

Generic competition exists from the alternative methods of solving the problem of storing data in rugged environements. The two main alternatives are to 1. enclose a regular tape recorder or disk drive in a protective housing and 2. wire a computer in a harsh environment to a remote computer in a protected area. These two alternatives may be attractive in certain situations but are not feasible in many others.

Product form competition is much more significant to Techsys. The companies in this classification are offering products which function much the same as Techsys'. The major companies in this category are presented in Table 2 . They may be divided into direct competition (appealing to similar markets as Tochsys) and indirect competition (those companies targeting primarily the military market). 
Table 2

Competitive Summáry for the $\mathrm{S}$ and S1 Products

\begin{tabular}{|c|c|c|c|c|}
\hline \multirow[b]{2}{*}{ Company } & \multicolumn{3}{|c|}{ Competitive Factor } & \multirow[b]{2}{*}{$\begin{array}{l}\text { get } \\
\text { rket }\end{array}$} \\
\hline & $\begin{array}{l}\text { Product Type } \\
\text { er Eorm }\end{array}$ & $\begin{array}{l}\text { Company } \\
\text { or Product } \\
\text { Streneth }\end{array}$ & $\begin{array}{l}\text { Company } \\
\text { or Product } \\
\text { Weakness }\end{array}$ & \\
\hline Compco & $\begin{array}{l}\text {-bubble cartridges } \\
\text {-Mfr's subsystems } \\
\text {-Same as Techsys }\end{array}$ & $\begin{array}{l}\text {-better price } \\
\text {-vertical } \\
\text { integration } \\
\text {-Intel personnel } \\
\text {-well financed }\end{array}$ & $\begin{array}{l}\text {-only remov. } \\
\text { cartridges } \\
\text {-lower capacity } \\
\text { cartridges than } \\
\text { Techsys }(<720 \mathrm{~K})\end{array}$ & $\begin{array}{l}\text {-factory auto- } \\
\text { mation }(40 \%) \\
\text { - military }(40 \%) \\
\text {-other }(20 \%) \\
\quad\end{array}$ \\
\hline Bubbl-tec & $\begin{array}{l}\text {-board level products } \\
\text { only } \\
\text {-Hitachi cartridges }\end{array}$ & $\begin{array}{l}\text {-easy to use and } \\
\text { install }\end{array}$ & $\begin{array}{l}\text {-requires a soph- } \\
\text { isticated end } \\
\text { user }\end{array}$ & $\begin{array}{l}\text {-same industrial } \\
\text { users as us }\end{array}$ \\
\hline Hitachi & $\begin{array}{l}\text {-semi-conductors } \\
\text {-microprocessors } \\
\text {-RAM } \\
\text {-bubble components }\end{array}$ & $\begin{array}{l}\text {-low cost } \\
\text {-selling devices } \\
\& \text { cartridges - } \\
\text {-good position for } \\
\text { vert. integration } \\
\text {-very good for } \\
\text { OEM }\end{array}$ & $\begin{array}{l}\text {-poor customer } \\
\text { support } \\
\text {-lower capacity } \\
\text { cartridges than } \\
\text { Techsys } \\
\text {-complex to } \\
\text { design in }\end{array}$ & $\begin{array}{l}\text {-OEMs } \\
\text {-telecommun- } \\
\text { incations } \\
\text { and systems } \\
\text {-Japan is } 95 \% \\
\text { of their market }\end{array}$ \\
\hline Fujitsu & $\begin{array}{l}\text {-devices } \\
\text {-small systems }\end{array}$ & -low cost & $\begin{array}{l}\text {-low capacity } \\
\text { products } \\
\text {-not aggressive }\end{array}$ & $\begin{array}{l}\text {-OEMs } \\
\text {-same as Hitachi }\end{array}$ \\
\hline Sagem & $\begin{array}{l}\text {-bubble memory } \\
\text { components }\end{array}$ & * & * & $\begin{array}{l}\text {-aerospace } \\
\text {-Europe }\end{array}$ \\
\hline Memory Inc. & $\begin{array}{l}\text {-1 to } 4 \text { Mbit bubble } \\
\text { components, boards } \\
\& \text { subsystems }\end{array}$ & $\begin{array}{l}\text {-co. has a bubble } \\
\text { memory } \\
\text { HOTLINE } \\
\text { for applications } \\
\text { support } \\
\text {-low cost } \\
\text {-Intel personnel }\end{array}$ & $\begin{array}{l}\text {-their perception } \\
\text { in the market is } \\
\text { poor } \\
\text {-many unknowns }\end{array}$ & $\begin{array}{l}\text {-industrial and } \\
\text { military }\end{array}$ \\
\hline $\begin{array}{l}\text {-Plessey } \\
\text { Microsystems }\end{array}$ & $\begin{array}{l}\text {-defense products } \\
\text { cartridges \& boards } \\
\text {-custom designs } \\
\text {-same as Techsys }\end{array}$ & $\begin{array}{l}\text {-MIL qualified } \\
\text {-extremely rugged }\end{array}$ & $\begin{array}{l}\text {-high priced } \\
\text {-not aggressive in } \\
\text { industrial market }\end{array}$ & $\begin{array}{l}\text {-mostly military } \\
\text {-some industrial }\end{array}$ \\
\hline $\begin{array}{l}\text { Militáry: } \\
\text { (Sperry, } \\
\text { Honeywell, } \\
\text { Singer, } \\
\text { Genisco) }\end{array}$ & $\begin{array}{l}\text {-removable \& fixed } \\
\text { cartridges } \\
\text {-not just bubbles } \\
\text {-tape drives }\end{array}$ & $\begin{array}{l}\text { 7MIL qualified } \\
\text {-extremely rugged }\end{array}$ & $\begin{array}{l}\text {-high price althoug } \\
\text { not necessarily a } \\
\text { weakness in this } \\
\text { market }\end{array}$ & . \\
\hline
\end{tabular}

* Information not available 


\section{Table 2 - Competion - Continued}

Competitive Factor

\begin{tabular}{|c|c|c|c|c|}
\hline Company & Price & $\begin{array}{l}\text { Location \& } \\
\text { Distribution }\end{array}$ & Promotion & $\begin{array}{l}\text { Financial } \\
\text { Position }\end{array}$ \\
\hline Compco & $\begin{array}{l}\text { - } \$ 1000 \text { for system } \\
\text {-less than } \$ 500 \\
\text { for a } 360 \mathrm{kbyte} \\
\text {-living off } \$ 9 \mathrm{M} \\
\text { cartridge }\end{array}$ & $\begin{array}{l}\text {-located in } \\
\text { San Jose, CA } \\
\text {-sales reps. } \\
\text {-distributors }\end{array}$ & $\begin{array}{l}\text {-'Elect. Design' - } \\
\text { 'Venture Capital } \\
\text { Journal','CE','Def. } \\
\text { Electronics','Elec. } \\
\text { Eng'n Design' }\end{array}$ & $\begin{array}{l}-\$ 2.3 \mathrm{M} \text { in fin'g } \\
\text { in } 1985 \\
\text { in equity fin'g. }\end{array}$ \\
\hline Bubbl-tec & $\begin{array}{l}-\$ 2989 \text { for } 1 \text { Mbyte } \\
\text { supported by a } \\
\text { '80188' CPU } \\
-\$ 1111 \text { for } 1.5 \\
\text { Mbyte PCH-3 } \\
\text { - } \$ 4833 \text { for BDH-2 } \\
\text { bubble-dek }\end{array}$ & $\begin{array}{l}\text {-Located in } \\
\text { Dublin, CA }\end{array}$ & $\begin{array}{l}\text {-'Elect. Products', } \\
\text { 'PC Magazine', } \\
\text { 'Computer Design', } \\
\text { 'Electronic Design' }\end{array}$ & -OK? \\
\hline Hitachi & $\begin{array}{l}\text {-device costs } \$ 555 \\
\text { in lots of } 100 \text { or more } \\
\text { for a } 4 \mathrm{Mbit} \mathrm{MBM} \\
\text { module }\end{array}$ & $\begin{array}{l}\text {-Japan \& Illinois } \\
\text {-sales offices }\end{array}$ & $*$ & -Excellent \\
\hline Fujitsu & -low & $\begin{array}{l}\text {-Japan \& Illinois } \\
\text {-sales offices \& } \\
\text { distributors (not } \\
\text { many of thêm) }\end{array}$ & * & -Excellent \\
\hline Sagem & * & -Located in France & $\begin{array}{l}\text { 'Aviation Week } \\
\text { and Space } \\
\text { Technology' }\end{array}$ & * \\
\hline Memory Inc. & $\begin{array}{l}-4 \text { Mbit bubble } \\
\text { is } \$ 350 \text { in lots } \\
\text { of } 1000 \text { or more }\end{array}$ & $\begin{array}{l}\text {-Located in Folsom } \\
\text {-distributors } \\
\text {-sales reps in the } \\
\text { future }\end{array}$ & $\mathrm{CA}$ & $\begin{array}{l}\text {-about } 200 \\
\text { employees } \\
\text {-probably good? }\end{array}$ \\
\hline $\begin{array}{l}\text { Plessey } \\
-\end{array}$ & $\begin{array}{l}\text {-PME BB-1M is } \\
\$ 3983 \\
\text {-PME BB-1S is } \\
\$ 4596\end{array}$ & $\begin{array}{l}\text {-LI Pearl River, } \\
\text { New York } \\
\text {-England }\end{array}$ & $\begin{array}{l}\text {-'Electronic Prod.', } \\
\text { paid ads for bubble } \\
\text { systems in Defense } \\
\text { Electronics' }\end{array}$ & -Excellent \\
\hline $\begin{array}{l}\text { Military: } \\
\text { (Miltope, } \\
\text { Singer, } \\
\text { Honeywell } \\
\text { Genisco) }\end{array}$ & -very high & $*$ & * & $\begin{array}{l}\text {-Miltope and } \\
\text { Genisco are } \\
\text { small; } \\
\text { \&others are in } \\
\text { excellent pos. }\end{array}$ \\
\hline
\end{tabular}

*Information not available 


\section{Table 2 -Competion - Continued}

Company

Compco

Bubbl-tec

Hitachi

Fujitsu

Sagem

.

-in quite a few journals with articles and extensive ad campaign

- have personnel who were from Intel, therefore have technological expertise -good control over the process - veritcal integration (produce own bubbles) -they go after the military market although they don't have.MIL STD products -may be getting funding indirectly from Westinghouse

-don't know too much about them except that they are pretty small and making very similar products to those sold by Techsys

-bubble and related rugged memory products represent only a small portion of total operations

-an OEM integrator company

-strength may lie in future as a component supplier, picking up Intel's business

-technology leaders with a new $16 \mathrm{Mbit}$ bubble device nearing introduction -good prospects for integrating vertically and making Techsys' position in " the industry redundant

-don't hear about them - they don't pose a significant competitive threat currently -assume that they are much the same as Hitachi

-provide $40 \%$ of the data storage for central office equipment in France -do not know much about the company, they stay in Europe mostly

Memory Inc. -this is a large company with many capabilities due to its size and association with Intel -have concentrated on the sale of bubble devices but suspect that they will expand into cartridges and systems soon

Plessey -predominantly defense products (MIL SPEC) and ate therefore not direct competitors of Techsys'

Military -since Techsys is not qualified in the defense market, these competitors are indirect, going after contracts that Techsys does not bid for -the military market is very different from the industrial market

Of the direct competitors, Compco is the most significant. Their products are quite similar to Techsys', they stress the same benefits and appeal to many of the same customers. The products are made using their own bubble devices, have a lower memory capacity and accordingly are less expensive than many of Techsys' products. The bubble device suppliers (Memory Inc., Hitachi, Fujitsu) are also considered competitors because they offer a limited line of bubble memory systems and boards. If these companies choose to expand their product offerings upward (to include cartridges), they would pose a greater threat to Techsys' current product line.

Due to the nature of the products (ie. the varying configurations such that no two products are exactly alike), Techsys does not have any brand competitors in the 
conventional sense.

The primary competition for the wall-mount and portable PLD will be the Futuro 1770 SB tape loader that is used in conjunction with a program panel or T-50 terminal and utilizes a 3.5" microfloppy drive. The company that manufactures the 1770-SB is Electronic Processors Inc. (EPI) of Englewood Colorado. This company also produces the Starlink tape loader which is the same product as the Futuro loader only marketed under adifferent name. The advantage of this product is that it is compatible with many different types of PLCs not just one or two models from one manufacturer (as Techsys' will be). EPI is already a supplier for Futuro and presumably other companies and customers giving them a further advantage over Techsys. Relative to other tape technologies they also have a tape data storage format which provides better data integrity. Using tape loaders in general is a much slower method of making backups than using microfloppy diskettes. Tape loaders are also produced by such companies as ADPI (Troy, Ohio) and Braemar (Minneapolis, Minn.). Neither has had as much success as EPI however.

Futuro is expected to introduce a compact backup system for their PLCs. A lap top computer is the anticipated form of such a product. If this is not introduced in the first twelve months that Techsys' portable PLD is for sale, then the Company will be able to establish a customer base and reputation, gaining a competitive edge. If, however, the lap top computer is introduced shortly after Techsys' portable PLD or before, then the competition will be much more intense. Techsys will no longer have a size/weight advantage and will have a functionality disadvantage. The Company will have to stress speed, lower price and perhaps ease of use for the PLD line.

\subsubsection{Extemal Threats}

There are several extérnal threats confronting Techsys, making their situation a difficult ane in which to operate. The first, and most basic is the difficulty of defining the industry in which Techsys operates. This has been a threat and continues to be one because it means that there is a fragmented customer base. This, in turn, creates problems in communication, distribution, production and planning. In essence, it does not allow for a concentrated effort to be put forth by Techsys in the strategic marketing or production areas.

The final threat, stemming from the external environment is an increasingly protectionist philosophy demonstrated by the United States government. It is currently frowned upon for many government or quasi-govemement bodies to purchase electronics equipment from a Canadian firm. These bodies are forced to purchase form Techsys' U.S. based distributor MacNaughtoh-McKay in Michigan if they consider Techsys at all. For this reason, among others, Techsys is in favour of a free trade agreement between Canada and the United States.

\subsubsection{Past Performance VS Objectives}

The only objectives that Techsys sets are in the form of budgeted sales and expenses for the next fiscal year. The sales figures are reviewed and updated each week at the sales meeting. Techsys has not met the projected income, profit and growth levels that were anticipated in any year thus far.

Inability to reach the projected levels of sales and profits may have been caused by: 1 . the high price of the bubble memory products and failure to lower over time 2 . the lack of marketing coordination and concentration due to the many small and diverse market segments and resultingly 3 . the inability to take advantage of any production or 
management économies.

\subsubsection{Planning Constraint}

The major constraint in the marketing planning activities is the extremely limited funds and personnel time for any of the action plans. As such, a costly communications plan (which the Company desperately needs to build awareness) or recommendations to hire several employees are infeasible. This plan will therefore be constructed with the assumption of immediate cash requirements and minimal cash expenditures as key objectives.

\section{1}

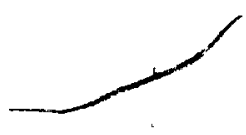


..Appendix 8 Continued

\section{Forecasts}

\subsection{Demapd Forecast}

The 'harsh environment storage' market for products under 5 Mbytes is estimated to be approximately $\$ 250$ Million (U.S.). Broken down by technology type, management estimates the markets to be: DisR \$75 Million; Tape \$100 Million; Bubble \$25 Million; and Semi-conductor (such as CMOS RAM) $\$ 50$ Million. Atternatively, the market could be divided into Military ( $\$ 150$ Million) and Industrial (\$100 Million) applications. One change that has become evident in the past couple of years is that the bubble segment (which Techsys has concentrated on) is perceived as "dead" as far as the industrial market is concerned. The extremely high price and small capacity of the current bubble devices along with the availability of adequate alternatives have prevented the technology from gaining wide acceptance by industrial users. The only viable consumer of bubbles is the government - for military and other applications. With large operating budgets, various governments are the only ones who can afford to buy the high priced products. They are also the consumers who need the ultra-reliability characteristic that bubbles offer the most.

The largest PLC manufacturer in the U.S. is Futuro with an approximate $45 \%$ market share. Techsys is therefore developing its first PLD to be compatible with Futuro's two largest sellers - the PLC-2 and PLC-3. Gould is the next largest PLC producer with about $20 \%$ of the market. A Bould compatible PLD will be the Company's next concern after the Futuro products are lanched. Following the assumptions in Appendix 8-1, the end-user market for PLDs for Futuro and Gould PLCs has been estimated as $\$ 10.2$ Million (US) in $1988 ; \$ 12.7 \mathrm{M}$ in $1989 ; \$ 14.9 \mathrm{M}$ in $1990 ; \$ 17.8 \mathrm{M}$ in 1991 ; and $\$ 20.9 \mathrm{M}$ in 1992. The five-year total market demand is therefore estimated to be $\$ 76.5$ Million (US).

\subsection{Sales Forecast}

Sales and expenses forecasts for the the Company are presented in Table 3. Optimistic, pessimistic and most likely estimates provide a range of values between which the actual figures are believed to fall. These have been based on past years' figures and on the expectation of no growth over the 1986-87 period. The Futuro PLC backup products' sales have been separated om the total and estimated with pessimistic, optimistic and most likely scenarios as: 1. Tables 4,5 , and 6 show these sales forecasts. The remainder of the sales in ble 3 (the company-wide estimates) come from the Stortite and Stortite 1 product lines. The sales from these two lines are expected to decrease as the research and development and marketing efforts for them decrease.

Table 3

Techsys Budgeted Income Statement - 1987/88

Probability
Sales
Cost of Sales:
Material
Labor
Gross Margin
Expenses:
General and Administration
Sales and Marketing
Research and Development/Engineering
Depreciation
Total Expenses

.2 Optimistic

$\$ 1,430,000$

$$
\begin{array}{r}
471,900 \\
71,500 \\
886,600
\end{array}
$$$$
\$ 200,000
$$$$
243,000
$$$$
186,000
$$$$
9.100
$$$$
638.100
$$

$$
\frac{.5 \text { Most Likely }}{\$ 1,040,000}
$$

.3Pessimistic $\$ 720,000$

\begin{tabular}{rr}
364,000 & 317,460 \\
62,400 & 62,040 \\
613,600 & 340,500 \\
\hline$\$ 200,000$ & 220,000 \\
243,000 & 267,300 \\
157,000 & 154,300 \\
9,100 & 9.100 \\
\hline 609.100 & 650.700 \\
\hline
\end{tabular}




$\begin{array}{lcrc}\text { Profit Before Taxes } & \$ 248,500 & \$ 4,500 & (\$ 310,200) \\ \text { Taxes and Tax Credits } & 60.000 & 5000 & 50.000 \\ \text { Net Profit } & \$ 308.500 & \$ 54.500 & (\$ 260.200) \\ & & & \\ \text { Expected Sales }=[(.2 \times 1,430,000)+(.5 \times 1,040,000)+(.3 \times 720,000)]=\$ 1,020,000 \\ \text { Expected Profit }=[(.2 \times 308,500)+(.5 \times 54,500)-(.3 \times 260,200)]=\$ 10,890\end{array}$

Table 4 PLD Optimistic Sales ('000's)

Calendar Year

Stand-alone wall-mount

Portable

Networking wall-mount Total (U.S.)

Canadian Total (x 1.32)

\section{7}

$\$ 34.5$

0.0

0.0
$\$ 34.5$$\frac{70.6}{\$ 625.1}$

1988

$\$ 45.5$

\section{$\$ 825.1$}

\begin{tabular}{rr}
1989 & \multicolumn{1}{c}{1990} \\
$\$ 63.9$ & $\$ 79.5$ \\
1219.6 & 2231.2 \\
488.8 & 806.5 \\
\hline$\$ 1772.3$ & $\$ 3117.2$
\end{tabular}

$\$ 2339.4 \$ 4114.7$
1991

$\$ 84.2$

3315.9

1340.5

$\$ 4740.6$

$\$ 6257.6$

Total for 5 years $=\$ 13,582,300(\mathrm{Cdn}$.

Table 5

PLD Most Likely Sales ('000's)

\begin{tabular}{|c|c|c|c|c|c|}
\hline $\begin{array}{l}\text { Calendar Year } \\
\text { Stand-alone wall-mount } \\
\text { Portable } \\
\text { Networking wall-mount } \\
\text { Total (U.S.) }\end{array}$ & $\begin{array}{r}1987 \\
\$ 27.1 \\
0.0 \\
0.0 \\
\$ 27.1 \\
\end{array}$ & $\begin{array}{r}1988 \\
\$ 43.0 \\
402.2 \\
35.2 \\
\$ \$ 480.4 \\
\end{array}$ & $\begin{array}{r}1989 \\
\$ \\
\quad 47.9 \\
888.7 \\
276.0 \\
\$ 1212.6\end{array}$ & $\begin{array}{l}1990 \\
\$ 58.2 \\
1445.3 \\
486.9 \\
\$ 1990.4\end{array}$ & $\begin{array}{r}1991 \\
\$ 60.1 \\
1934.0 \\
785.2 \\
\$ 2779.3\end{array}$ \\
\hline anadian & 35 & 634 & $\$ 1600,6$ & $\$ 2627.3$ & \\
\hline
\end{tabular}

Total for 5 years $=\$ 8,566,500(\mathrm{Cdn}$.

Table 6

PLD Pessimistic Sales ('000's)

\section{Calendar Year}

Stand-alone wall-mount

Portable

Networking wall-mount Total (U.S.)

Canadian Total ( $\mathrm{x}$ 1.32)
1987

$\$ 22.2$

0.0

$\frac{0.0}{\$ 222}$

$\$ 29.3$
1988

$\$ 34.4$

337.9

$\frac{11.6}{\$ 383.9}$

$\$ 506.7$

\section{9}

$\$ 37.2$

668.1

134.2

$\$ 839.5$
19.90

$\$ 44.0$

921.4

$\frac{273.8}{81239.2}$

$\$ 1239.2$

$\$ 1635.7$
1991

$\$ 44.1$

1012.8

415.0
$\$ 14719$

$\$ 1471.2$

$\$ 1942.2$

Total for 5 years $=\$ 5,222,700(\mathrm{Cdn}$.

\subsection{Competitive Forecast}

In recent years the competition for rugged data storage systems has either stopped producing the products (Texas Instruments, Intel) or gone out of business (Helix). Techsys' main competitor, Compco, has been spending a great deal of money on advertising and promotion (estimated at approximately $\$ 200,000$ for the current year). The company is also offering prices that dre significantly lower than Techsys' CMOS Stortite 1 
and about the same as those anticipated for the CMOS Stortite products. This is possible because they manufacture their own bubble devices, thereby eliminating one link in the distribution chain that Techsys must follow. In spite of this large investment it is felt that Compco will break even at best in the current year and in future years.

In addition to Compco, Memory Inc. and Hitachi also produce their own bubble devices. These companies have begun to produce systems similar to Techsys', and it is suspected that they will integrate upward at a much quicker pace in the future. These companies have an inherent advantage over Techsys and will begin to utilize it. All three companies will edgte Techsys' customers away as their produet lines become wider and deeper.

Techsys has perhaps a 1-2 year time frame with which to sell their data storage systems before these main competitors have comparable product lines. This is one reason for Techsys to shift its emphasis to another type of product line. The other reason is that the future of bubble memory technology in the industrial market is-bleak. It is predicted that unless Compco and Memory Inc. can sell in the Military market, they will not make a significant profit. This is in spite of their financial and distribution advantages over Techsys.

If Techsys' PLD sales start slowly, then relatively little competitive reaction is expected. "If sales climb quickly, however, two events will occur. The first is that Futuro will take notice and consider a) buitding a similar product or b) buying Techsys' product. Futuro apparently does not consider buying a product until it achieves a sales level of approximatety $\$ 10$ Million per year. This level is not expected to be reached by Techsys for at least 6 years. Second, competitors not currently producing PLDs will enter the market. In the second case, Techsys will have put up a significant barrier to entry already by contracting the Futuro PLC distributors so the new entrants need to look for markets elsewhere. Gould is the next largest vendor of PLCs in North America, so they are the most likely candidate for a compatible PLD. If Techsys cannot produce a PLD that is compatible with the Gould PLCs then the competition surely will.

Whether the PLDs sell quickly or not, the fact that a smaller, faster and less expensive product is on the market will attract attention. Techsys has no means of protection (outside of the distributors under contract) to the inevitable one or two competitors who will manufacture similar products. This indicates that management should apply for a design patent, produce the various compatible products at a rapid rate and try to contract as many distributors as possible.

\subsection{Technological Forecast}

Bubble memories currently are packaged in 4 Mbit housings. The next generation - the 16 Mbit chip was scheduled to be developed by Hitachi in 1987 . They predict that it will be about 1 year behind schedule. It is not until the generation after that - when the 64 Mbit bubble is developed - that bubble memory will be a marketable alternative with profitable industrial potential. The reasoning is that at this point, there will be enough memory in a small enough package at a cheap enough price to attract the industrial users. The $64 \mathrm{Mbit}$ bubble is not expected to be introduced for about 4 or 5 years.

The problem is not as simple as just waiting for bubble memories to progress two generations. In order for bubbles to have a true advantage, they must develop to a generation ahead of the CMOS RAM chip which is currently at $256 \mathrm{Kbits}$ of capacity. If the CMOS chip technology progresses to $4 \mathrm{Mbits}$ before the bubble gets to $64 \mathrm{Mbit}$, then CMOS will maintain its overall advantage over the bubble (being both faster and less 
expensive).

The final technological area that Techsys is concerned about is the development and introduction of PLC networking. General Motors predicts that they will have a computer network in their plants in as little as 1.5 years from now. They are currently têsting three networks in three plants and plan to make it company-wide as soon as the "bugs" are worked out.

For Techsys' purposes a 1.5 - 5 year time frame may be more accurate for these networks. The other automotive manufacturers are expected to follow suit about 2-5 years after the GM adoption.

The implications of the PLC networking forecasts are that Techsys should develop - the network compatible PLD as soon as possible so that it can be incorporated first into GM's computer acquisitions and second into the other automobile manufacturers plans. 


\subsection{Mission Statement}

Techsys is dedicated to being the best at providing data storage/program backup equipment to computer users who must operate outside the comforts of a normal office environment or who have requirements for greater than normal reliability of their computer systems. Techsys is dedicated to providing superior technological ways of reducing the risks and, hence, the costs of using computers in many non-traditional applications.

\subsection{Short - Term Objectives (within 1 year)}

1. Achieve a profit level of $\$ 100,000$ for $1987-88$.

2. Achieve a-sales level of $\$ 1,100,000$ for $1987-88$.

3. Achieve a sales level of $\$ 100,000$ for the new PLC support products for 1987-88.

A level of $\$ 1,000,000$ for the current products is therefore expected.

4. Launch the wall-mount PLD by September 1, 1987 and the portable PLD by January 1, 1988.

5. Introduce a Gould-compatible portable PLD by May 1, 1988

\subsection{Medium - Term Objectives (2-3 years)}

1. Introduce portable PLD products that are compatible with Texas Instruments and Gerteral Electric PLCs by July 1, 1989.

2. Achieve a profit level of $\$ 125,000$ in the $1988-89$ fiscal year (a $25 \%$ growth rate).

3. Achieve a profit level of $\$ 155,000$ in the $1989-90$ fiscal (a 25\% growth rate).

4. Build a backlog of orders of approximately 3 months by March 1, 1989 .

5. Receive 50\% of total sales from "end user" products by August 31, 1989.

6. Receive $75 \%$ of total sales from "end user" products by August 31, 1990.

$r$

3.4 Long - Term Objectives (More than 3 years)

1. Become the market leader in Futuro PLC System backupproducts by 1992 , and for all PLC types by 1995.

2. Maintain an average minimum level of profit growth of $25 \%$. 


\subsection{S and S1 Product Lines Plan}

\section{Action Plans}

The timely development and successful launch of the PLD line depends on having funds available to maintain the operations. The PLD line will not provide sufficient funds to keep Techsys operating until the beginning of 1989 at the earliest. It is of paramount importance then that the current lines keep on selling.

Before explaining what should be done with the Stortite and Stortite 1 (S and S1) lines and how it should be dong four reasons indicating that the product emphasis of Techsys needs changing are presented.

1. Techsys' competition has decreased in number but increased in calibre. Namely thebubble device manufacturers (Memory Inc., Compco, Hitachi) have developed wider and deeper product lines that directly compete with Techsys. Because they produce their own devices (and Techsys does not), they can price their products significantly lower than Techsys. When these competitors develop their product lines even more, Techsys will have no competitive advantage.

2. The bubble memory technology is not advancing as fast as other competitive 'rugged' technologies (such as CMOS RAM). Therefore, the price decreases and density increases that were expected to make the-bubble products attractive havenot come about. It is expected that such advances are still several years away. CMOS RAM, although less expensive than bubbles is still more expensive than many other "acceptable" competitive alternatives.

3. The demand for raggedized data storage systems never came to fruition as was expected in 1981-82 when the company started. Techsys has not made a profit in the 5 years of its existence and management feels it is time to move to other profitable areas.

4. Techsys has limited financial and personnel resources. When the opportunity for developing the wall-mount PLD arose, it became evident that a line of such products could be much more profitable than the $S$ and $S 1$ lines could be. It is, therefore, necessary to choose which direction the company should pursue and the choice made was the PLD line.

There are many issues that must be dealt with if Techsys is to phase out their current product lines over a period of 12-18 months. These issues are discussed below.

- . Current Customers: Techsys' current customers may be upset at the thought of losing the source of any replacement parts, servicing or even new systems for further projects. It will cost Techsys relatively little to offer to service their curent customers for a five-year period. Any parts that Techsys needs may be purchased as needed and provided to the customer at a highet rate than before (due to the loss of any quantity discounts). The product expertise of Techsys' engineers will be available indefinitely.

Euture Customers: It may be quite difficult to sell products to new customers (ie. companies who have not purchased from Techsys before) if they know that the lines are soon to be obsolete: Techsys will not advertise this fact but will not deny it if asked directly by a potential customer. Since Techsys is providing a 5 year servicing period, the customers will not be in a disadvantaged position. 
month period. After this time it is anticipated that providing current customers with replacement and "add-on" products and PLD sales will be sufficient to sustain the company. For this initial 6-12 month period, however, new sales of S and S1 products are imperative.

Inventory: Techsys' combined raw materials, work in process and finished goods inventory is currently valued at about the $\$ 350,000$ level. This is far too high since many of the products and parts that make up this inventory may become obsolete during the 1987-88 fiscal year. If these parts and products remain unsold in this period, Techsys may have to write them off as obsolete.

The production manager's job is to get this level down as low as possible over the next year. It would be desirable to keep a minimum level of parts in stock (if any) and order parts only when requested by a customer. If these parts become obsolete over the next 5 years, every effort will be made to project their customers' future servicing needs and purchase the requisite amount to keep in inventory.

$\mathrm{B} \& \mathrm{D} /$ Engineering: The emphasis of research and development as well as engineering will shift in the coming year. It will be necessary for Engineering to continue customizing the rugged systems as new customers are received. This will last for six months or perhaps longer if many new customers are found.

The proportion of time that is spent on the old products will diminish over the year. The speedy development of the PLD line - particularly the portable version - is a priority in the next few months. The quicker that the new products can be introduced, the sooner Techsys can stop relying on the $S$ and $S 1$ lines. In order for R \& D to continue on the PLD line, the Company must receive funding in the near future. Without sufficient external funding the development of the PLD line will be much slower because engineering manpower will remain limited. The dates stated then assume that financing will be received.

Marketing: The marketing effort for the $S$ and $S 1$ product lines, like the effort from the other departments, will decrease over the coming year. The sales efforts will be High S and S1/ Low PLD for the first 6-8 months but switch to High PLD/ Low S and S1 when a commencial yersion of the portable PLD is available.

The sales cycle for rugged data storage systems (and most industrial products in general) is usually several months long (from first contact to purchase). It is logical then for the sales department to concentrate on past and current purchasers as well as potential customers already aware and knowledgable about Techsys' products. In this way, the sales cycle may be shortened considerably. Techsys cannot afford to have the salesmen making cold calls and educating the contact on the product lines.

In order generate and pursue new qualified leads at a minimum sales effort, marketing will rely on advertising, direct mail, and press releases. The communtcations plan examines these efforts in detail. A 1/4 page, black and white ad has been made up already, so the advertising costs result from the media space only. At least six $4 / 4$ page spaces in EDN and Control Engineering will be purchased in the first six periods of the 1987-88 fiscal year. The ad, like the other communications elements for the beginning of the year, will feature board level products and CMOS RAM products. Several customers have expressed an interest in the bubble and CMOS boards and the lower price of the CMÓS Stortite products. After a 6-8 month period, marketing efforts will be placed more heavily on the PLD line. 
The price of the $S$ and $S 1$ lines was recently increased. The price insensitivity of the customers who still purchase the bubble memories (Military and other government agencies) and an anticipated price increase from Memory Inc. prompted this increase. The CMOS product will be used to sell to industrial customers and those who are price sensitive. If orders drop below $\$ 90,000$ for two consecutive periods a sale price will be offered to generate short term sales.

The distribution system will remain intact for the $S$ and $S 1$ products. The emphasis will be on direct sales, however, as this in the most convenient to the customers and Techsys.

A summary of some noteworthy activities and their anticipated dates is in Table 7. By following these general guidelines it is hoped that sufficient funds can be generated to sustain Techsys until the PLD line is available for sale. The objective sales level for the 1987-88 fiscal year from the $S$ and $S 1$ lines is $\$ 1,000,000$. In 2 years time, Techsys should just be servicing customers and filling unsolicited orders for these product lines.

Table 7

Schedule of Activities

Activity

PLD wall-mount introduction

PLD sales efforts start

Ad placements

PLD portable introduction

$S$ and $S 1$ sales efforts start to decline

\section{Dates '}

Sept. 1, 1987

Sept. 1, 1987

Sept. 87 - Feb. 87

Jan. 1, 1988

July 1,1988

The overall responsibility of this plan is the President's because of its importance and implications to all aspects of the Company. The plan can be broken into tasks however, whith different people responsible for each task: sales and distribution-Salesman; communications/ price-Marketing Manager; R\&D/engineering-Engineering Manager; inventory reduction - Production Manager; overall monitoring of plan - Director of Operations.

The evaluation criteria that should be used are the sales figures and the ratio of sales of PLD products to $S$ and $S 1$ products. The ratio of product line sales should reverse over time as follows:

Date

September 1, 1987

December 1, 1987

March 1, 1988

June 1,1988

\begin{tabular}{c}
$\%$ from $S$ and $S 1$ \\
\hline $95 \%$ \\
$90 \%$ \\
$85 \%$ \\
$80 \%$
\end{tabular}

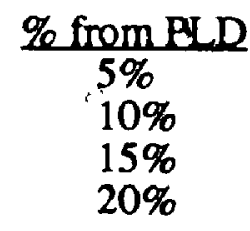

\subsection{PLD Development and Introduction Plan}

The future success of Techsys Electronics lies in the timeTy development and effective marketing of the new line of program loading devices (PLDs). This action plan outlines a development and introduction strategy that should improve the chances of the product line succeeding. The development of the PLD products is not directly controlled by the marketing department but there is an interdependency between the two areas that must be recognized if the products are to succeed. Marketing must provide customer input on the desired features, capabilities and specification for the product development. Engineering, in turn must incorporate these customer wants and needs into their designs 
and produce the desired product on schedule.

The development objectives that must be achieved if marketing is to provide an effective strategy for the new line of products are as follows:

1: To have a commercial version of the wall-mount PLD ready for manufacture and sale by September 1, 1987.

2. To have a commercial version of the portable PLD ready for sale by January 1 , 1988.

3. To develop a commercial, Gould compatible, portable,PLD by May 1, 1988 .

4. To have a commercial version of the network compatible, wall-mount PLD by January 1, 1990.

The objectives are prerequisites to this plan but do not guide it. If the above development objectives are not met then the marketing strategy will be ineffective or useless. A schedule of activities that are important to this plan is presented in Table 8.

Table 8

Schedule of Activities

$\begin{array}{ll} & \text { Activity } \\ \text { 1. } & \text { Commercial version of wall-mount } \\ \text { 2. } & \text { Develop magazine ad for PLDs } \\ \text { 3. } & \text { Develop portable prototype } \\ \text { 4. } & \text { Magazine article } \\ \text { 5. } & \text { Beta test portable PLD } \\ \text { 6. } & \text { Venture capital received } \\ \text { 7. } \quad \text { Introduce commercial portable } \\ \text { 8. } \quad \text { Press release for portable } \\ \text { 9. } \quad \text { Trade show dates } \\ \text { 10. } \quad \text { Gould-compatible portable developed } \\ \text { 11. } \quad \text { Direct mailings } \\ \text { 12. } \quad \text { Contract distributors } \\ \text { 13. } \quad \text { Prototype network } \\ \text { 14. } \quad \text { Beta test network } \\ \text { 15. } \quad \text { Commercial version of network }\end{array}$

Started
Current
July $1,+1987$
-
-
-
-

- Completed

Sept 1, 1987

Nov 1987

Nov 1987

Nov 1987

Dec 1987

$\operatorname{Jan} 1,1988$

Jan 1,1988

Jan 1988

Oct, Nov, Dec 1987/ Apr, May 1988

Jan 1, 1988

May 1,1988

Dec 1987/ March 1988/ July 1988

Current

Jan, 1989

Aug 31, 1988

Jan 1,1990

Aug 31, 1990

Jan 1, 1991

If the target product completion dates are met by the engineering department then the marketing elements are scheduled to provide the most impact from the target audience.

The target market for the 1987-88 fiscal year is present and future owners of Futuro PLC-2s and PLC-3s in North America. The automobile manufacturers, in particular will be targeted because they are the largest purchasers of PLCs. Futuro has approximately a $45 \%$ share of the over $\$ 400$ million (U.S.) North American PLC market.* The next closest competitor is Gould with a $20 \%$ share of the market. Management feels there is an opening in the market for PLC backups for a system that is faster and smaller than the currently available products. Since Futuro is the market leader . and the wall mount PLD was designed for their PLC, their customers have been chosen as the target market. Techsys is limiting itself to the North American segment because of financial, engineering and marketing constraints. If success is achieved in the North American market, Techsys yill consider a geographic expansion.

- "Source: Bruce C.P. Rayner, "Rrogrammable controllers move toward a $\$ 5$ billion business". Electronic

Business. June 15, 1987, p. 38. 
The following sections outline the marketing strategy that will be followed for the PLD products. This strategy will be reviewed formally every 3 months to determine its value and to revise it to reflect any market and company changes. In this way, the plan will be "rolled over" each quarter and remain a current, useful guide to follow.

\subsubsection{The Product Line}

Immediate market research is needed to determine what specifications are desired by the target market for the PLD line. Preliminary interviews with several employees of General Motors and other potential customers have been conducted. In addition, several lengthy discussions with the largest Futuro PLC distributor in North America have provided general specifications for the line. These findings should be verified with more formalized market research in an attempt to gain a detailed knowledge of what the customers want. A semi-structured telephone interview with Futuro PLC owners (obtain a list from McNaughton-McKay) would provide a much clearer picture of the type of product desired and the estimated demand for the product line. The sooner this research is done the better the product offering will be. It may prevent costly and time consuming errors in marketing and design.

Although the wall-mount PLD has advantages over the tape loader (faster, smaller and less expensive), it has two disadvantages as well. The first is the fact that the customer needs one PLD for each PLC instead of one tape loader for several PLCs. The second is that it is affixed to the wall and therefore requires the user to do something he is not doing now and thereby change his behatior. The first disadvantage makes the product more expensive for a customer than the tape loader because he would need to buy more of the product than he does currently. The second disadvantage puts up a barrier to sale because the user is forced to learn a new set of backup and loading procedures.

These two disadvantages perhaps overshadow the advantages for many potential buyers (as has been suggested by one distributor and several plant engineers). The wall-mount may therefore be limited to a few applications where speed is the overriding consideration or where a one-to-one ratio is desired. An example is a PLC which requires updates at regular intervals of 10 minutes, $1 / 2$ hour, 1 hour or some other fixed time period. For this purpose a tape loader is not useful bpt the wall-mount PLD would be ideal.<smiles>[CH][CH]</smiles>

A product with much greater potential is a portable version of the PLD. This product is only in the conceptualization stage of development but already promises (from preliminary customer reactions) to be desirable to many PLC owners. This portable PLD is used in the same way as the tape loaders the PLC owners currently use. That is, it is carried from PLC to PLe as needed. This feature solves the two problems of the wall-mount unit and allows the selling points listed below to provide several benefits to the customer.

Selling Point
Faster

Light Weight and Smaller Inexpensive

Easy to Use
Benefits Received by Customer

- Decreased downtime, therefore the owner saves money from a reduction in non-productive time.

-Minimizes the time that the engineer needs to make backups, allowing him to do other things in the plant. -Easy to carry over the shoulder from PLC to PLC. -Reduces the perceived risk of purchasing the product. - Does not require use of terminal to load or backup PLC. 
All benefits promote usage of the PLD. This implies that programs will be more up-to-date than before and fewer mistakes will occur from shift changes, fitting changes and so on.

The proposed medium for the portable PLD is a $31 / 2$ " floppy disk. These disks are easy to use and probably familiar to the product users. The use of diskettes allows Techsys to provide them with the PLD at an additional charge. Techsys will purchase the diskettes from the manufacturer, put Techsys labels on them, format them for the user and sell them at a premium price. Although the customer may choose to the diskettes elsewhere and format them himself, others will not want to bother and buy them from Techsys at the time of the PLD purchase.

In the long term, Techsys anticipates the auto manufacturers and other PLC users to incorporate a network for their factory computers. It will be necessary for the PLCs or the cell controllers (computers controlling several PLCs) to communicate upward with the factory-wide MIS system. Techsys' PLD product functions could be expanded and adapted to provide a backup system for this communications link. The product would use the wall-mount casing configuration but would have significantly different firmware and communications (network) electronics.

The market for the networking product is in the development stages because factory-wide networks are not as yet common and probably won't be for 3-10 years. It is necessary, however, for Techsys to plan for this expansion and have the desired products available by early 1990 when the MIS planning is being conducted and the contracting begins. Market research should also be conducted to determine how the PLD could be used and in what form it would be desirable. The best place to start such research would be with the automotive manufacturers since management feels they are about 3-5 years ahead of other PLC using industries technologically.

\subsubsection{Price}

The manufacturer's list prices and expected manufacturing costs for the PLD line of products are provided in Table 9. Quoting prices in U.S. dollars puts the exchange rate risk on Techsys but virtually all of the PLD sales are expected to be to American customers who demand price quotes in U.S. dollars.

$\begin{array}{lrr} & \begin{array}{c}\text { Table 9 } \\ \text { PLD Line Price List }\end{array} \\ \text { Product } & \text { Cost(Cdn) } & \text { Price (US) } \\ \text { Wall-mount } & \$ 450 & \$ 1,450 \\ \text { Portable } & 665 & 2,295 \\ \text { Networking wall-mount } & * & * \\ \text { Preformatted diskettes } & 55 & 145 \\ \text { *Unknown price range } & & \end{array}$

These product prices are still significantly below the Futuro tape loader which is priced at $\$ 3,845$ (U.S.). The lower prices, in addition to the advantages that Techsys' products offer over the Futuro loader, should provide the incentive necessary for trial.

For all of the PLD products the tentative discount schedule in Table 10 applies. In addition to this preset discount format there is a $2 \%$ discount if the customer pays within 10 days. The payment terms are therefore $2 / 10$, net 30 . This schedule may be revised 
before product introduction if additional information as to its appropriateness is received.

\section{Table 10 \\ PLD Discount Structure}

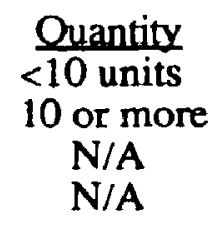
Discount
$15 \%$
$23 \%$
$31 \%$
$40 \%$

Assuming a 27\% Canadian-U.S. exchange rate differential and $8 \%$ for freight, duty and brokerage fees, Techsys' contribution margins for the products would be as in Table 11. The discount schedule matches the arrangement between McNaughton-McKay and Futuro for PLC sales. In some circumstances a higher than normal margin may be warranted for the distributor because Techsys is a small, unknown company. Since the distributor is not required to change his business practices or customer base and there is only minimal learning necessary for him, the discount structure is felt to be adequate.

Table 11

Techsys' Contribution Margins

Wall-mount

Portáble

Diskettes

\begin{tabular}{ll}
\multicolumn{2}{c}{ Discount } \\
\hline Without & With \\
\hline $51.3 \%$ & $50.4 \%$ \\
$54.0 \%$ & $53.2 \%$ \\
$42.2 \%$ & $41.2 \%$
\end{tabular}

An occasional sale price will be offered to the distributors to promote short term sales when sales are significantly below projections. One such sale is a planned $50 \%$ discount instead of the usual $40 \%$. It will be up to the distributors as to what they wish to do with their $10 \%$ savings - pass it on to their customers or keep it themselves.

\subsubsection{Distribution}

An entire action plan is devoted to the distribution of the PLD products. The discussion here only serves as an overview of the detailed plan.

The distribution of the PLD products is perhaps the single most important strategic element for the successful introduction of the line. The reason for this is that there are about 10 distributors of Futuro PLCs who account for approximately $90 \%$ of the total PLC sales in North America. If Techsys can obtain contracts with most of these 10 distributors then the PLD line has a very good chance to succeed. If Techsys is unable to obtain contracts with these distributors then the product line will have to be sold in other, less efficient ways. Should the majority of these sellers be signed, Techsys will have succeeded in erecting a major barrier to entry into the Futuro PLC backup mar ent that competitive vendors would not likely penetrate.

Because most of the North American sales are expected to be made in the U.S., management believes that a U.S. subsidiary/sales office is needed. This would also defend against any government or corporate regulations imposed on customers to buy from companies located in the U.S. The obvious locational choice is Michigan since Techsys will be concentrating on the automotive manufacturers market in the short and long terms. A further advantage of having a U.S. sales office is that it makes servicing the distributors 
(almost all of whom will be in the U.S.) easier with more frequent contacts at less expensive prices possible.

Techsys already has a network of manufacturer's representatives in the U.S. These reps will only carry the PLD products if: 1 . There is no distributor covering their territory 2. Their product line is compatible with the PLD line and 3. Techsys has been satisfied with their past performance. If these three conditions do not exist then the rep will not carry the new products.

\subsubsection{Promotion}

As with distribution, promotion has been given a detailed examination in the communications action plan. A synopsis of the action plan will be given here.

Promotion

Advertising

Trade Shows

Press Releases

Promotions

Articles/Publicity

\section{Explanation}

$\geq 6-1 / 4$ page spots in Programmable Controls and Control Engineering.

- 1 ad produced by ad agency emphasizing speed, price and weight. The same ad will be used for all spots.

-1 Show: Programmable Controls.

- 3 have been scheduled to coincide with various product developments during year.

- Distributor promotions used to increase short term sales.

-End-user promotions used to support the distributors and build awareness of Techsys.

- 2 scheduled - one each in EDN and Control Engineering.

All communications are designed to first build awareness of the PLD line and then move the potential customers to a stage where they prefer Techsys' PLD over the competition. The distributors' salesforces will then try to induce trial and purchase of the products.

The different elements of the promotional plan will be tied together by the unique selling proposition (USP) for the products. The USP combines a selling feature (speedy backups) with a resulting benefit (more time for other "productive" activities) in a unique way. The USP for these products is 'Techsys' speedy PLC backup systems will reduce downtime for the plant and the engineer". By focusing on the USP when the promotions are being created, all communications will be compatible, the target audience will receive the desired message and any ambiguities that could exist are reduced.

\subsubsection{PLD Plan Overview}

The persons responsible for the various aspects of this plan are: product development -Engineering Manager, specifications/market research-President, Marketing Manager, Salesman; marketing coordination-Marketing Manager; distributor support-President and Salesman; overall responsibility-President. Because the responsibilities spread over several departments of the company, the ultimate responsibility for the successful introduction of the product line is the President's.

In order to judge the success or failure of the development and introduction of the 
PLD line, specific evaluation criteria must be outlined. These criteria stem from the plan objectives and timetable stipulated at the beginning of this plan. If the introduction dates are not met then the plan will not be entirely successful. The more behind schedule, the less successful they will be. An objective of $\$ 100,000$ in PLD sales was set for the 1987-88 fiscal. This will rely on the wall-mount version until January 1 when a commercial portable PLD becomes available. After January 1, both the portable and wall-mount sales should rise although the wall-mount more slowly because of the anticipated weaker demand. The Director of Operations will be responsible for monitoring these criteria.

If Techsys does not obtain $\$ 100,000$ in financing by January 1,1988 or Product development falls more than 3 months behind schedule then contingency plan $A$ will be put into place. Contingency plan B will be implemented if the funding for the PLD line is not secured during the 1987-88 fiscal year. Contingency plan $\mathrm{C}$ will be implemented if total PLD sales are below $\$ 20,000$ by Period 9 . If, on the other hand, PLD sales reach the $\$ 100,000$ level by Period 9 then contingency plan $D$ will be put into effect to try and exploit the unexpectedly high sales.

\subsection{Communications Plan}

There are two requirements that the communications program must fulfill: 1. Generate enough sales from the current product lines to sustain the company and support the PLD product development, and 2. Generate interest in and promote trial of the new PLD products. It is necessary to make a smooth transition from reliance on one group of products to another group. Too much emphasis on either line at the wrong time may be detrimental to Techsys.

The plan is guided by the following objectives for the $S$ and $S 1$ product lines:

1. Build the CMOS RAM product knowledge level of the target markets for the Stortite 1 and Stortite products to $50 \%$ over the next year.

2. Gemerate a minimum of 40-50 qualified leads (potential customers with a $70 \%$ chance of purchase) per period for the $S$ and $S 1$ product lines.

The target audiences for the current lines are past product purchasers and industrial computer users operating in extremely rugged environments. The communications theme for the current product line is that Techsys has MORE - more interfaces, more experience, more media choices'. This theme differentiates Techsys from Compco who is stressing the reliability aspect of the products. It also points out a significant advantage that Techsys has over the competition - more available solutions to data storage problems.

The plan is also guided by the following objectives for the PLD line:

3. Introduce the PLD products, reaching an awareness level of $75 \%$ of the target audience by August 31, 1988.

4. $50 \%$ of the target audience for the PLD products should have knowledge of Techsys' three main benefits of speed, price and size by August 31, 1988.

The target market for the new line of PLDs is owners of Futuro PLC-2s and PLC-3s. The target audiences include the plant engineer who makes the PLC program changes, the officers responsible for making the purchase decision and the corporate executives who plan the companies' information systems. Techsys will concentrate on the 
automobile manufacturers in North America (the largest segment of PLC users)* in the

- 1987-88 fiscal year. The communications theme for the PLD product line will focus on the three benefits of speed, price and small size. These benefits are important to the target audience and are areas where Techsys has a clear advantage over the Futuro tape loader the main competition that is anticipated. Although the product has a non-volatile memory, the reliability benefit will not be stressed. When Futuro introduces their lap top computer

- then speed, price and ease of use will be the three benefits stressed.

The communications plan for 1987-88 has elements of advertising, trade shows, promotion, press releases, direct mailings and publicity. A schedule of when each of these components will be implemented is provided in Table 12 . The first six periods will be concerned with the current products and contribute to the accomplishment of the first two communications objectives. The last 6 periods will maintain the current products (with decreased efforts) but will also introduce the new PLD products to the target audiences. Each element will be examined separately in the following sections.

Table 12

Advertising and Promotional Schedule $\mathbf{~ 1 9 8 7 / 8 8}$

\begin{tabular}{llll} 
Direct Mailing & & \multicolumn{2}{c}{ S \& } \\
& & & \\
& & & \multicolumn{2}{c}{ FDE } \\
Publicity & PR- & PR- & PR- \\
& FDE & PLD & PLD \\
& Prods. & WM, & Port. \\
& & Art.- & \\
& & PLDS &
\end{tabular}

$S \&$

S1

PLD

FDE

Promotions Assorted promotions are ongoing (salesman of the month, Techsys pens etc.)

Trade Shows

Advertising $\mathrm{CE} /$

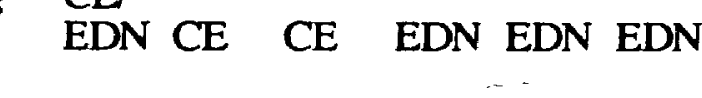

\begin{abstract}
Credit Bonus PLD Floppy System Starts $50 \%$ Give-

Off Away
\end{abstract}

Article

PLD -

Network

Prog. *

Cont.

\begin{tabular}{|c|c|c|c|c|c|c|c|c|c|c|c|c|}
\hline Advertising & $\begin{array}{l}\text { CE } / \\
\text { EDN }\end{array}$ & $\mathrm{CE}$ & $\mathrm{CE}$ & EDN & EDN & EDN & & & $\begin{array}{l}\mathrm{CE} \\
P L D\end{array}$ & $\begin{array}{l}\mathrm{CE} \\
P L D\end{array}$ & & $\begin{array}{l}\text { CE } \\
P L D\end{array}$ \\
\hline & $\begin{array}{c}l \\
\text { Sept. } 1\end{array}$ & 2 & 3 & 4 & 5 & ${ }^{6}$ Feb. & $\begin{array}{l}7 \\
14\end{array}$ & 8 & 9 & 10 & 11 & $12 \quad 13$ \\
\hline
\end{tabular}

Period (28 days)

*indicates a trade show that will be attended by an employee but Company will not exhibit. $P R$ - indicates a Press Release - WM - indicates wall-mount PLD Art.- indicates an article will be written and placed in a trade journal

"Source: Bruce C.P. Rayner,"Programmable controllers move toward a $\$ 5$ billion business", Electrenic Business. June 15, 1987, pp.30-38. 


\subsubsection{Trade Shows}

Some of the purposes of trade shows are to: 1 . build awareness of the Company and products; 2 . generate sales leads; 3 . monitor the eompetition; 4 . enhance goodwill by meeting with past, present and future customers; 5 . support the distributors' salesforces; 6 . investigate joint venture opportunities with other exhibitors; 7 . introduce new products to a large audience.

In the 1987-88 fiscal year, one show will be attended: the Programmable Controller show in April in Detroit. This show is close enough to Ottawa to minimize travel costs yet is geared to the target audiences of both the $S$ and S1 and PLD products.

The money that would have been spent on the other trade shows that Techsys has been to in the past (Autofact, PLC Show, ISA and Control Expo) can be spent in one of two ways. The first possibility is to purchase a new trade show display which features the new CMOS RAM and PLD products. The current display is outdated, prominantly displaying the rugged and reliable bubble memory products of the past. The second possibility is to take the $\$ 20,000-\$ 40,000$ savings and purchase more advertising space. A third option is to not spend the money at all. The recommended course of action is to purchase the new trade show display - a necessity for any trade show that will be attended in 1987-88 and purchase additional advertising space.

In addition to purchasing the display and exhibiting at the Programmable Controller Show, Techsys will send a representative to the other key shows to visit with customers, monitor the competition, and investigate joint venture opportunities with exhibitors. This will be significantly less' expensive than renting space for a booth at all of the shows and still allows for Techsys to yield some benefits from the shows. The cost of each of these four trips is approximately $\$ 1,000$ for a total of $\$ 4,000$. The cost of the one trade show attended is estimated to be $\$ 6,000$ and the new display approximately $\$ 5,000$. This $\$ 15,000$ total is about $\$ 15,000$ less than would have been spent on the 5 trade shows usually attended.

\subsubsection{Advertising}

A model of consumer behavior suggests that a consumer moves through a series of stages from being unaware of a product's existence to purchasing that product. Figure 7 shows this progression.

Figure 7

Hierarchy of Effects

$\alpha$

Awareriess $\rightarrow$ Knowledge $\longrightarrow$ Liking $\longrightarrow$ Preference $\rightarrow$ Conviction $\longrightarrow$ Purchase

Source: Robert J. Lavidge and Gary A. Steiner, "A Model for Predictive Measurements of Advertising Effectiveness." Journal of Marketing, October 1961, p. 61.

Following this model, advertising would be most effective in the awareness and knowledge stages, less so in the liking and preference stages and least of all in the latter two stages. This model is helpful in understanding how advertising may be used for Techsys' products.

Techsys' past advertising has been concerned with the first stage, awareness 
building, and concentrated on bubble memory products only. Management's opinion is that the desired audience is aware of Techsys' name and their bubble memory product line. They are not as aware that Techsys now provides a line of products using CMOS RAM memory instead of bubble memory. The advertising will generate sales leads and, along with the other forms of communication, mustry to move potential buyers into the 'knowledge', 'liking' and especially 'preference' stages for both the CMOS and bubble products. The 'conviction' and 'purchase' stages are reached through the salesforce. The salesforce is effective in the 'liking' and 'preference' stages but is most effective in the latter stages.

This movement will be aided by a series of advertisements in Control Engineering and EDN magazines. Twelve $1 / 4$ page spaces have been reserved for black and white ads in these two magazines. Because the magazines are published by the same company they offer a discount price for 12 ads in any configuration (e.g. 6 in CE and 6 in EDN or 10 in $C E$ and 2 in EDN and so on). The first 6-8 ads will focus on the current product lines with special mention of the availability of CMOS RAM products. These ads will be part of the 'more' campaign (outlined previously) which was developed by Wallace, Kearney and McGill. This will differentiate Techsys from Compco, who is currently in the middle of a well-financed, awareness-building compaign. The objective is to improve the audience's knowledge - moving it up to the preference stage as efficiently as possible.

In the latter 4-6 months of the fiscal year, the magazine spaces will be used for an ad about the PLD products. This will require that one other $1 / 4$ page, black and white ad be produced at a cost of approximately $\$ 5,000$. This new ad should use the USP for the PLD line to focus the headline and copy. The objective in this case is to build awareness of the fact that Techsys has a new line of products with identifiable benefits over the competition. The ads will also appear in some combination of Programmable Controls and Control Engineering.

These PLD ads should use an "Introducing a fast new way to make PLC backups .." framework and call for an action such as "inquire now". They must necessarily describe Techsys briefly because the target audience will be unfamiliar with the Company. The ad should not mention Techsys: other products as this will only serve to confuse the audience.

In addition to the awareness building function, these ads provide support to the distributors who are selling Techsys' PLD products. It is unlikely that the distributor's salesforce will reach everyone in the target audiences and these ads will fill some of the void. The ads also reach buying influencers who are inaccessible to the salesperson.

The total cost of the advertising portion of the communications plan is $\$ 27,176$. Five thousand dollars of thist is for production charges for a 1/4 page black and white ad. The remainder, $\$ 22,176$, is for the magazine space. Depending on the sales leads obtained from the initial ads, more spaces may be purchased with the money saved by not exhibiting at all 5 trade shows. The ad responses will be monitored and management will decide where and when to place the additional ads for desired supplemental impact.

\subsubsection{Bromotion}

Promotions may be used to stimulate short term sales, generate sales leads quickly, or support the sales representatives or other elements of the communications plan. The promotions for the coming year are of two varieties. The first type are distributor promotions which are designed to get the middleman to sell more of Techsys' products 
(stimulate short term sales). The manufacturer's representatives that handle the distribution of the Stortite 1 and Stortite products are geographically and functionally diverse. They are functionally diverse because they don't carry the same types of products, call on the same type of customers or sell in the same manner. This diversity makes any attempt at a standardized promotion difficult. The infrequent sales due to low demand for these products also makes any promotion other than a sizeable price reduction seem futile.

The PLD distributors, on the other hand, will be quite similar to each other because they are all successful at selling Futuro PLCs (the reason why they were chosen), and they all carry PLCs and related industrial products. Management expects that these middlemen will be making sales much more frequently than the representatives for the older products, making more types of promotions viable.

One promotion is a "salesman of the month" award, given to the salesperson who sells the greatest amount of Techsys products in excess of his forecasted amount of sales. A possible prize for the winner could be a dartboard with the Techsys logo on the face. Credit bonuses, directly tied to sales levels will also be an effective promotional tool. An example bonus system would be to give the salesman credit for $10 \%$ of the amount that he sells over the budgeted sales for his territory. A sample discount schedule is as follows:
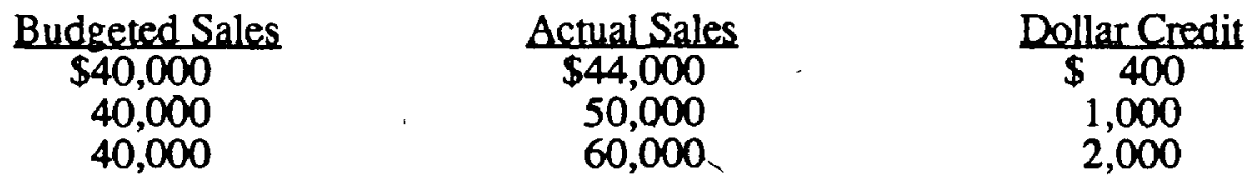

The salesman then gets a rebate on his next purchase of Techsys products in the amount of the credit earned.

- Another form of price promotion to be offered to the distributors is a limited time $50 \%$ discount off of the manufacturer's list price instead of the usual $40 \%$. This additional $10 \%$ may be passed on to the end user to increase short-term sales or be kept in part or in full by the distributors to increase the margin. In both cases Techsys' sales should be increased.

The second variety of promotions may be labelled "end-user promotions" which are designed to support the sales representatives and build awareness of Techsys among end users. The most important sales aid that will be produced is a series of 1 page "spec sheets" for the Stortite line, Stortite 1 line, PLD wall-mount, PLD Networking wall-mount and PLD portable.

Some promotional items may be used by the middlemen of both the current and the new product lines. Such items as "Techsys pens" (pens with the Techsys logo on them) which can be left behind after the salesman's visit can keep Techsys' name in front of engineers and other personnel for months. Even calculators, which can be purchased quite cheaply (again with the Techsys logo on them), can sęrve as a 'leave behind' reminder for special customers.

One promotion which applies to the PLD line but not the S and S1 lines is to give a free box of preformatted microfloppy diskettes with each PLD purchase. This is a tangible, substantial, product-related promotion that can be offered to the end user. Techsys can either pay for the promotion itself or require the distributors to cover a portion , of the cost of the diskettes. Once again these diskettes would have the Techsys logo on the label to serve as a constant reminder. The total cost of these promotions is approximately $\$ 4,650$. 


\subsubsection{Direct Mailing}

Direct mailings act as a method to service current customers by keeping them up-to-date on product and company information, generate leads, support distributors and sales representatives by building awareness before he/she makes a sales call, reinforce an advertisement by repeating a desired message and introduce a new product. Its effectiveness is limited, however, by the quality of the mailing list that is used.

The price of a direct mailing can vary widely. If it is necessary to purchase a mailing list, the cost can be very high. If the list is an internal one; the the cost is only for the mailing materials and postage: This latter form of mailing will be utilized in the coming year because the Company has a relatively good list of qualified contacts for the $S$ and $S 1$ lines and will start one for the PLD line.

Techsys will undertake three mailings (one each in December, March and July) to companies on Techsys' internal contact list. This includes previous customers, trade show leads, press release leads and other 'qualified' names. These contacts have expressed an interest in Techsys and its products and therefore represent a viable source of potential customers. The mailings are spaced at 4 month intervals so as to not overload them with Techsys information, which can cause the messages to be ineffective. The estimated total cost of the three mailings is $\$ 1,500$.

A regular direct mailing will also be established for the PLD product distributors. This mailing will be in the form of a newsletter sent out quarterly. It will be small approximately 35 middlemen - and therefore inexpensive. 'Regular features may include "what's going on at Techsys", "which distributors are doing well", "upcoming promotions", "new product horizon" and so on. This newsletter not only provides support for the representatives but also makes them feel like a group with a common interest. This can help make and keep distributor relations smooth-running.

\subsubsection{Publicity}

In the past, press releases have been a very effective method of generating qualified sales leads. Techsys uses a mailing list of approximately 60 trade magazines as the recipients of these press releases. About 10 of these magazines will receive a follow-up phone call to ensure that the release was received, understood and to assess the likelihood of it getting published. In order to get the press release published it must 1 . fit the editorial content and style of the magazine and 2 . say something significantly.new to deserve printing. A press release may receive extra attention if, in addition to the follow-up telephone call, a Techsys representative visited the magazine, perhaps with a demenstration kit. This would only be practical for the one or two magazines with the closest editorial fit to the press release. Either a Techsys sales representative or a distributor could make such a visit when in the same city as the magazine on a sales call.

The three product innovations that will have a press release in the coming fiscal year are: the non-volatile CMOS cartidge RAM disk, the wall-mount PLD and the portable PLD. In light of the fact that 2 out of 3 of these press releases are related to the PLD line, the magazines that receive the releases (selected as appropriate for the Stortite 1 and Storrite product lines) should be re-evaluated for editorial content. A screening of the magazines should filter the number that apply to the PLD down significantly. It may, however, be necessary to add some magazines that were not on the list previously.

When qualified leads are received as a result of the press releases, two new activities will be undertaken. The first is to keep track of which magazines run the press 
releases so that future efforts may be more focused and trends in readership may be identified. "The second is to record the requests for information on a categorized data base. If, for example, someone requests information on the CMOS RAM cartridges, he could automatically be sent information when any future CMOS innovations occur. A mailing list could be established for each product category - making direct mail efforts for sales, price changes and product improvements feasible.

Publicity provides mass exposure at no cost and has the advantage of being more credible than advertising and frequently more visible (as it often rises above the clütter of paid exposure). Although an article cannot be scheduled like paid advertising, an attempt can be made to have it published in a certain time frame. For instance, Techsys will contact the desired magazines (EDN, PC and CE) by telephone, mail and in person in an attempt to get the editors interested in a particular product or technology. The new PLD products are newsworthy to the readers of these magazines because of the drastic improvement in operating efficiency that the PLDs offer. Such an article must again concentrate on the three selling points of speed, price and size and the benefits that these features offer to the user. Pictures of Techsys' products would be very helpful in improving the recall of the readers (potential customers).

If possible it would be advantageous to place an ad in the same magazine issue and as close as possible to where the article appears. This would reinforce the message that Techsys is trying to get across and have a greater probability of being seen by any one reader. The marketing department will attempt to place two magazine articles in the coming fiscal year. Because customer testimonials are appropriate and advantageous for such articles; they will have to be written after the products have been beta tested with success.

\subsubsection{Communications Plan Overview}

The budget for the communications plan is outlined in detail in Table 13. Responsibility for all elements of the communications plan will be the Marketing Mañager's. He will not be able to complete each of the activities but will be responsible for the coordination and management of them. The marketing assistant will assist him with all activities.

Advertising:

Table 13

Communications Budget

Trade Shows:

Production of 1 ad

Magazine Space (EDN/CE)

$\$ 5,000$

22.176

$\$ 27,176$

Creation of new display

5,000

Cost of 1 show (rental space,travęl,

$\begin{array}{ll}\text { accomodàtions, expenses) } & 6,000 \\ \text { Representative at } 4 \text { shows } & .6000\end{array}$

$\begin{array}{ll}\text { accomodàtions, expenses) } & 6,000 \\ \text { Representative at } 4 \text { shows } & \end{array}$

$\begin{array}{ll}\text { accomodàtions, expenses) } & 6,000 \\ \text { Representative at } 4 \text { shows } & \\ 4,000\end{array}$

15,000

Promotions:

650

500 .

500

Techsys calculators (\$5 each)

3.000

4,650

Press Releases:

Diskette giveaway (\$3 each)

3 releases $\times 60$ mags $\times \$ 5 /$ package

Direct Màilings:

Customers $-3 \times 500 \times \$ 1$

Distributors $-4 \times 35 \times \$ 2$

TOTAL COST

1,500

280

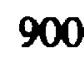


It is expected that the communications plan outlined will achieve the stated objectives of a $50 \%$ knowledge level of the CMOS prodicts, a minimum of $40-50$ qualified leads per period, a 75\% awareness level amorig the PLD target audience and a $50 \%$ knowledge level of the PLDs main benefits among the PLD target audiedce. These levels will be monitored according to the monitoring procedures in Section s. If the following events occur then contingency plan B will be implemented:

Leads - less than 25 per period for the S and S1 lines

Awareness of CMOS - less than $35 \%$

Awareness of PLD - less that $60 \%$ of end-user coverage

Knowledge of PLDBenefits - less than $35 \%$ of end-user coverage

Budget - More thâ. $25 \%$ away from targeted amount

\subsection{Distribution Plan for the PLD Line}

\subsubsection{Method of Distribution}

Distributing the Program Loading Devices is the most important aspect of the marketing strategy. Reaching the target market with personal contacts is necessary to complete the selling process. When choosing a method of distribution it is important to consider the costs involved, the effectiveness in reaching the target market and the ability of the firm to manage the distribution activities satisfactorily. The three methods of distribution that could be used for the PLD line are distributors, manufacturer's representatives and direct distribution.

Using direct distribution thods, Techsys would have to hire one or more additional salesmen to serve the PLD market. Since the current Techsys employees are unfamiliar with the PLC-owner markets, it would be advantageous to hire someone who pas such expertise. In Techsys' financial position, such an expansion in personnel is not feasible. Although this method offers potentially higher margins for Techsys, it is not an attractive altemative at this time.

Manufacturer's representatives 'would be a feasible alternative since Techsys would have to pay no fixed costs and only a commission of approximately $10 \%$ on sales. Several factors indicate that this method may be less than optimal for Techsys' situation. The first inclination would be to use Techsys' current manufacturer's reps for the PLD line. This would be unwise, however, because these reps neither carry complementary product lines to the PLD nor reach the target market desired by Techsys. This would prompt a search for new reps who fulfill these two requirements. Locating such representatives would be a lengthy and difficult process, if they could be located at all. Another consideration is that a large number of reps would be needed to attain the $90 \%$ coverage of the target market desired. This makes distribution relations a more cumbersome task.

The use of distributors would pose the same problematic task of locating a sufficient number to reach the majórity of Futuro PLC owners except that Techsys already sels the S and S1 lines through McNaughton-McKay, Futuro's lafgest PLC distributor. Through Barry Fredricks, a high level contact at McNaughton-McKay, Techsys was able to obtain a listing of all of the Futuro PLC-2 and PLC-3 distributors in North America. It is Mr. Gaudette's assertion that $80 \%$ to $90 \%$ of all Futuro PLCs are sold by a group of 10 or 11 major distributors. There are several reasons why this group is well-suited to selling PLDs and therefore desirable to Techsys. 
1. They are best able to reach the end user of the PLD because they have an established relationship with these companies.

2. Their current product line, which includes Futuro PLCs, is very compatible with

- Techsys' PLD. Their intimate knowledge of these products will be invaluable to Techsys.

3. From 1 and 2 it follows that these distributors have a keen understanding of the market and what is needed to be a successful vendor in the market. A McNaughton-McKay representative has shown this expertise by outlining the elements of a potential manufacturer/distributor relationship that he would agree to and the product specifications that would be desirable to his customers.

The relatively few distributors covering the majority of Techsys' target market would make the management of the distribytors much easier than if manufacturer's reps were contracted. Techsys' experience with' the largest of these distributors provides a significant starting point for recruiting purposes. If McNaughton-McKay is under contract with Techsys then other distributors will give the PLD line a chance and sign up as well.

\subsubsection{Why Carry Techsys' PLD Line?}

at

Having identified the use of distributors as the channel to reach the end-user, it is important to consider the proposition from the opposite point of view. That is, answer the question "Why would these select distributors want to carry Techsys' PLDline?" From the distributors' perspective, the following benefits should provide the necessary signing incentive:

1. Techsys' products complement their existing product line, making it longer and making the distributor look more complete to the end-user.

2. Techsys' products fit so well with the distributor's current line of products that the distributor does not have to do any additional work. He is familiar with the Futuro PLCs and already sells to the desired customers. Techsys' product is very easy to understand with clearly definable benefits, making the presentation to a potential customer easy. The distributor will not need to change his existing habits if he carries Techsys' products.

3. The margins associated with Techsys' products are high. The rates are almost exactly the same as the percentage on the Futuro products. The distributors' gross margin schedule is presented in Table 14.

\begin{tabular}{|c|c|c|c|c|}
\hline . & Distribu & $\begin{array}{l}\text { Table } 14 \\
\text { ross Margin S }\end{array}$ & dule* & \\
\hline $\begin{array}{l}\text { Small User } \\
\text { Large User } \\
\text { OEM }\end{array}$ & $\begin{array}{c}\text { Margin } \\
25 \% \\
17 \% \\
9 \%\end{array}$ & $\begin{array}{c}\text { Wall-mount } \\
\$ 373.75 \\
246.50 \\
130.50\end{array}$ & $\begin{array}{r}\text { Portable } \\
\$ 573.75 \\
390.15 \\
206.55\end{array}$ & $\begin{array}{c}\text { Diskette } \\
\$ 36.25 \\
24.65 \\
13.05\end{array}$ \\
\hline * Subject to Review & & & & \\
\hline
\end{tabular}


4. The up-front investment for the distributor is low. In addition to the minimal time requirements, the distributor's cash requirements are small. A total of about $\$ 10,000$ U.S. in any configuration of products will be necessary. The only stipulation is that 1 of each type of product and 1 demonstration unit be purchased.

5. Techsys offers a wide range of support vehicles for the distributors including:

(i) A full time distributor-relations manager

(ii) Training for the distributor's salesforce

(iii) 'A."hassle free" return policy

(iv) A toll-free service "hotline", with a technically-oriented operator.

(v) A supportive promotional campaign aimed at the end user. Advertising in Control Engineering and PC, several promotional activities, press releases and direct mailings are planned for the coming year. Two articles will be written with the intention that they be published in $\mathrm{CE}$ and PC. The distributor's salesmen will also be provided with sales aids such as 1 page spec sheets for each of the products, giveaway items and presentation suggestions.

\subsubsection{Why Not Carry Techsys' PLD Line?}

It is useful to anticipate reasons why a potential distributor might not want to carry Techsys' line of PLDs. It is even more useful to suggest counterarguments for this opposition.

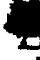
risk an investment and my reputation on such a venture.

Counterarguments: Although Techsys is unknown in the PLC market they are well known and respected in the rugged data storage system market and enjoys excellent relationships with their past and current customers.

Techsys has employed McNaughton-McKay for several years to sell their other product lines. This well-established distributor also carries the PLD line.

An extensive communications program aimed at PLD owners and users will be launched in the 1987-88 fiscal year. This campaign will build the awareness levels of both Techsys and the PLD line among the end users, making the selling job that much easier.

The PLD line has obvious advantages over the competition and provides margins that are comparable to those provided by Futuro.

Argument \#2: If the margins are the same as those offered by Futuro and the Futuro loader is twice as expensive, I am losing money by selling Techsys' PLD.

Counterargument: PLC backup system sales represent only a small proportion of any distributor's total sales in number and dollar value. This means that the change on the distributor's bottom-line will be minimal. In return for this minimal loss of revenue, the distributor's image is enhanced because he has a more complete liñe of products to offer and the lower price satisfies his customers. Because of the lower price, the end user is able to buy twice as many backup systems as before, for the same price if they are needed. He has a "package" (Futuro plus Techsys) which makes him more competitive against altemate PLCs such as Gould, GE, TI etc. 
Argument 2: Techsys is not an American company and a lot of my customers like to buy from a firm in the United States.

Counterargument: Techsys will have a manufacturing and sales facility in Michigan by 1990.

\subsubsection{Schedule of Activities}

With the framework of the distribution plan laid out, the specific steps that must be taken can be scheduled. These activities and their expected completion dates are provided in Table 15. A variable element in the schedule is when the distributor manager will be hired. It may be desirable to hire him/her before the distributors are approached if financially possible.

\section{Table 15}

\section{Schedule of Acitivities}

Activity

Identify top Futuro distributors

Develop presentation to contract distributors

Sales aids ready

Develop a contractual agreement for distributors

Approach all top distributors with presentation developed Contract distributors who cover:

$30 \%$ of market December 1,1987 $70 \%$ of market

$50 \%$ of market January 1, 1988

$60 \%$ of market February 1, 1988

Hire distribution manager

Establish American office
$90 \%$ of market
Completion Date

September 1, 1987

October 1, 1987

October 1, 1987

October 1, 1987

November 1, 1987

April 1, 1988

June 1, 1988

August 31, 1988

February 1, 1988

September 1, 1990

\subsubsection{Plan Overview}

There are three costs that will be incurred in the 1987-88 fiscal year: the presentation development $(\$ 500)$, the salaried distribution manager for 7 months $(\$ 20000)$ and the sales aids $(\$ 3000)$ for a total of $\$ 23,900$. The cost of the U.S. sales office is unknown as the details have not been finalized. These costs will not be incurred in the current fiscal year.

The President is responsible for this action plan until the time that a distributor manager is hired (February, 1988 tentatively). The criteria to be used to evaluate the relative success of this plan are 1 . the target dates outlined in Table $15 ; 2$. the sales lexels of the distributors who are contracted (budgeted levels will be set for each distributor); and 3. the market coverage reached by certain dates.

If the market coverages are 1/3 below their targeted levels at the dates outlined then the possibility of implementing Contingency Plan A will be investigated. The following chart summarizes the expected market coverage levels and the points that trigger the contingency plan.

$\begin{array}{ccc}\text { Date } & \text { Exp. Level Contingency Level } \\ \text { Dec 1/87 } & 30 \% & 20 \% \text { or less } \\ \text { Jan 1/88 } & 50 \% & 33 \% \text { or less } \\ \text { Feb 1/88 } & 60 \% & 40 \% \text { or less }\end{array}$

Date Apr 1/88 Jun $1 / 88$ Aug 31/88

\begin{tabular}{l} 
Exp. Level \\
\hline $70 \%$ \\
$80 \%$ \\
$90 \%$
\end{tabular}




\section{Elan Summaries}

An overview of all activities for the marketing plan can be found in Appendix 8-2. A financial budget and cash flow schedule by period is presented in Appendix 8-3.

$+$

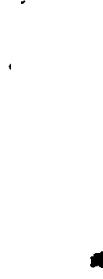

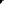

$+$

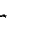




\section{Monitoring Procedures}

The monitoring procedures apply to the action plans outlined in the previous sectien. A summary of each plan's monitoring strategy is outlined below.

\subsection{S and S1 Product Lines Plan' Monitors}

Monitors: Various - Director of Operations, President and Marketing Manager

Key Factors: Sales ratios, inventory levels, sales of $S$ and $S 1$, number of leads for $S$ and $S 1$ products

Ranges: Sales Ratio - 85\% from S and S1(highest acceptable) / 15\% from PLD (lowest acceptable)

Inventory Levels - $\$ 50,000$ - $\$ 200,000$

Sales of S and S1 - At least $\$ 900,000$ for $1987-88$

- An average of $\$ 70,000$ per period. Higher sales in the beginning of the year (Avg. $\$ 100,000$ per period). Lower sales at the end of the year (Avg. \$50,000 per period).

Number of Leads - 25 per period minimum for the S and S1 lines

Review Periods:

Sales Ratios - By period

Inventory Levels - The end of each period

Sales of $S$ and $S 1$ - Weekly management meetings and at the end.of each period

Number of Leads - Weekly sales and marketing meeting and at the end of each period

Procedures:

Sales Ratio - This is done eastly' by the Director of Operations by comparing the sales of the period for both the S and S1 and PLD products.

Inventory Levels - An informal inyentory will be conducted by the Production Manager and staff, at the end of each period. A formal inventory

* will be taken at year end by the accounting firm employed by the company.

Sales and Leads of S and S1 - The salesmen keep track of orders and log them as the purchase order is received. They will be reviewed along with the leads at the weekly sales and marketing meeting and in more detail at the end of every period. The Director of Operations is responsible for this.

\subsection{PLD Development and Introduction Plan Monitors}

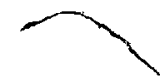

\section{Monitor: Director of Operations}

Key Factors: Funding, sales of wall-mount, sales of portable, development dates

Ranges:

Development dates: wall-mount and portable - within 1 month of spocified dates network - no later than 4 months of specified date

Funding: $\$ 200,000-\$ 500,000$ by year end $(\$ 100,000$ must be obtained by January 1,1988 ) 
Sales of wall-mount: Minimum of $\$ 10,000$ for $1987-88$ *

Sales of portable: Minimum of $\$ 70,000$ for $1987-88^{*}$

* These estimates are reasonable only if the products are developed on schedule. If the development is not on schedule then the sales figures will decrease accordingly.

Review Periods:

Development Dates - Weekly management meetings

Funding - November 1, January 1, April 1, July 1

Sales of wall-mount and portable - weekly management meetings and end of period totals.

Procedures:

Funding, Sales - These figures are monitored as part of the regular bookkeeping function. The figures will be reviewed at each weekly management meeting (where applicable) and formally at the end of each period. If the funding does not come through on time then the sales figures and development dates must be reviewed and amended. The causes should be isolated by the Director of Operations and the responsible officers, and remedies suggested.

Development - Engineering should create a development schedule with dates and activities outlined (a PERT chart or something comparable). This schedule will be reviewed weekly by the Director of Operations and Engineering Manager.

\subsection{Communications Plan Monitors}

Monitor: President

Key Factors: Leads, awareness level of CMOS RAM products, awareness level of PLD. products, knowledge level of PLD benefits and adherence to budget.

Ranges: Leads - 25 per period minimum for $S$ and $S 1$ lines

Awareness of CMOS - 35\% of past and current customers minimum

Awareness of PLD - $60 \%$ of coverage minimum

Knowledge of PLD - 35\% of coverage minimum

Budget - $10 \%$ of budget variance - $\$ 72,000-\$ 88,000$

Review Periods:

Leads - Weekly and at end of each period

Awareness and Knowledge levels - 6th, 9th and 13th periods

Budget - end of periods 3,6, 9, and 13

Procedures:

Leads - as in Section 5.2

Awareness and Knowledge Levels - A small random sampling of the target audiences will be contacted (5\% to $10 \%$ of total audience) with a structured set of questions. This will be organized by the Marketing Manager and carried out by the Manager, the Assistant Marketer and the Salesman. Results will be monitored by the President. If levels are below acceptable range then causes will be determined and corrective action taken.

Budgeted Spending - the President will monitor spending with the Director to determine the current level. Corrective action will be taken if outside of $10 \%$ range. 


\subsection{Distribution Plan Monitors}

Monitor. Marketing Manager

Key. Factor: Percentage of Futuro PLC market coverage with contracted distributors "

Range: Date

Dec $1 / 88$

Jan $1 / 88$

Feb, $1 / 88$

Apr $1 / 88$

Jun $1 / 88$

Aug 31/88
Contingency Level

$<20 \%$
$<33 \%$
$<40 \%$
$<46 \%$
$<53 \%$
$<60 \%$

Review Periods: An ongoing process but formally on the dates listed above.

Progedures:

A representative of McNaughton-McKay has given Techsys a list of all Futuro PLC distributors in North America. He has also agxeed to rank the top ten on an informal basis with Gavin. As a backup or corroborating source for this ranking Techsys could attempt to get estimates from the distributors themselves. Knowing . McNaughton-McKay's sales levels and market share for PLC's we can identify the total dollar value of PLCs sold in North America (an article in Business Electronics also provides an estimate of the dollar value of this market ). 


\section{Contingency. Plans}

Before the contingency plans are instigated a formal review of the situation, causes, probability of continuance and potential remedy effectiveness should be done. Five contingency plans have been developed to be implemented in the event of certain circumstances. Three of these plans apply to eight potential threats that may occur in the coming year. Two of the plans apply to three situations where significant opportunities may arise. In each plan the probability of occurance is estimated, the plan implementation triggers, the potential damage or benefit that may result and the major elements are provided. The probability ratings are in the form of ranges and reflect management's estimations of an event's likelihood. The responsibility of implementing all plans is the President's. The Director of Operations, who oversees the monitoring procedures, is required to keep the President abreast of any threatening or opportunistic situations.

\subsection{Plans to Counteract Threatening Situations}

Plan $A$

This plan should be implemented if one of the following events occurs:

\begin{tabular}{ll} 
Probability & \multicolumn{1}{c}{ Event } \\
$40 \%-60 \%$ & $\begin{array}{l}\text { Funding for PLD development is not obtained on schedule (tess than } \\
\$ 100,000 \text { by January 1, 1988). }\end{array}$ \\
$40 \%-60 \%$ & $\begin{array}{l}\text {.PLD product development falls significantly behind schedule (more than } \\
1-3 \text { months). }\end{array}$ \\
$40 \%-60 \%$ & $\begin{array}{l}\text {-The distributor coverage schedule is not achieved. } \\
\text { - Awareness and knowledge levels are below } 70 \% \text { of targets at scheduled *- } \\
\text { time periods. }\end{array}$
\end{tabular}

The damage that these events could do is serious but not necessarily fatal. Depending on the severity of the events, Techsys would probably be able to survive. If these events occur then one or more of the following actions should be taken:

1. Push PLD introduction dates back by whatever time length is necessary.

2. Maintain advertising of $S$ and S1. lines instead of switching to PLD advertisements.

3. Put the $S$ and $S 1$ products on sale again to generate operating funds in the short term. A 25\% discount may be wartanted.

4. Implement a signing bonus for indecisive distributors to prompt them to contract with Techsys. A free PLD may be the inducement needed.

5. Hire temporary engineering help to expedite the PLD development. A $\$ 5,000$ or $\$ 10,000$ investment would be justified to bring the products to market.

6. Attempt to develop a backlog of orders for the PLD line. It may be feasible to pre-sell some on the strength of a prototype (with certain sales conditions specified).

\section{Plan B .} implemented.

If one of the following threats manifests itself in the coming year Plan B should be

Probability

$60 \%-80 \%$-Sales of the $S$ and $S 1$ lines drop below $\$ 80,000$ per period.

$40 \%-60 \%$-Funding for the PLD line or additional venture capital is not secured.

These events are very serious and could very well be fatal if not acted upon quickly. 
Unlike Plan A, moré drastic actions must be taken if Techsys is to survive the events.

1. Put all products on sale with a $25 \%$ discount in price.

2. Locate a party who may be interested in licensing or purchasing some of Techsys' product designs. Prospects might include Memory Inc., Compco or Hitachi.

3. Lay off non-essential personnel and cut the officers' sálaries by $10 \%$ to $20 \%$ for a limited time. Consider a 4 day work week.

4. Locate smaller, less expensive facilities and move the business to save overhead costs.

5. Sell off some of the non-essential fixed assets such as office equipment, computers and furniture.

6. Sell the company outright.

Plan C

Plan C should be implemented if the following events occur:

$\frac{\text { Probability }}{40 \%-60 \%} \cdot$ Sales of the wall-mount and portable PLDs are below $\$ 20,000$ after period nine.

$60 \%-80 \%$-Futuro introduces a similar PLD before Techsys or shortly after.

$0 \%-20 \% \quad$ A competitor introduces a similar PLD before Techsys does.

These events are moderately serious but not fatal. They provide setbacks or hurdles that Techsys must overcome within their regular operations. Some of the options to improve the situation are:

1. Decrease the price of the PLDs and increase the number, size and coverage of the ads (by using different vehicles) significantly.

2. Stop emphasizing the size feature and switch to ease of use.

3. Conduct research to determine why the products are not selling and attempt to remedy the situation. This would require telephone and personal interviews

- with the distributors, their salesmen and end users.

4. Implement more distributor incentives to promote short tèrm sales increases.

5. Conduct distributor pep talks if motivation is the problem.

6. If the product has a significant advantage over the competition, use a head-to-head positioning strategy. If the competition has the advantage, then position Techsys' PLD so as to avoid comparison on that issue.

\subsection{Plans to Take Advantage of Opportunities}

Plan D

The following events will trigger Plan D:

Probability $20 \%-40 \%$ $0 \%-20 \%$

\section{Event}

-PLD wall-mount and portable sales are greater than $\$ 200,000$ by Period 9 . - Futuro offers Techsys the opportunity to become their PLD supplier or offers to buy the PLDs outright.

These opportunities provide outstanding benefits for Techsys and represent the best case scenario for the coming year. In the event that they occur it would be advantageous to exploit the opportunities by taking some or all of the following actions.

1. Hire more engineering and marketing personnel. 
2. Provide the distributors with a bonus of some sort. This will transmit the message that if Techsys does well, their distributors do well - building goodwill and improving distributor relations.

3. Expedite the Gould, GE, and Texas Instruments - compatible PLD development.

4. If sales of the PLD products are $\$ 400,000$ or more in $1987-88$ then redo the marketing plan completely for the PLDs.

5. If Futuro presents an attractive offer then accept it. If it is short sighted or unacceptable for some other reason, start to negotiate. While in negotiations, accelerate and intensify the PLD promotions to generate even more sales. This will provide negotiating leverage.

\section{Plan E}

This last contingency plan will be implemented if the price of bubble memories decreases drastically on a price per bit basis. The probability of this occuring is very slight (estimated at $0 \%$ to $5 \%$ by management) but could theoretically occur. If such a technological advance does take place, Techsys is in a very advantageous position. The $S$ and $S 1$ lines could be re-emphasized to take advantage of the situation. A new marketing plan would have to be developed to revisề the product strategies.

Two basic options exist based on the success of the PLD line at the time. First, if the PLD line is very successful then Techsys may want to sell their system designs to á supplier or competitor at a premium price. If the PLD line is not very successful then Techsys may wish to put renewed efforts on the bubble products. Even if such a price decrease occurs, there are still many problems with the rugged data storage market that make it only moderately attractive. 


\section{Appendix 8-1 \\ Assumptions to Market Demand Forecasts}

1. There is an installed base of 35,000 Futuro PLCs.

2. There is an installed base of 4,900 Futuro 1770-SB tape loaders.

3. There is an installed base of Gould Modicons which is $45 \%$ of that of Futuro.

4. Futuro sells 10,000 PLCs in 1987.

5. Futuro sells $1,4001770-\mathrm{SB}$ recorders in 1987 .

- 6. Dollar and unit sales of PLCs are both rising at $15 \%$ per year.

7. Techsys has enough engineering resources to keep up with new product introductions by Futuro and Gould.

8. Networked backup units will support 7 to 8 PLCs on average.

9. Networked backup units will each sell for about $\$ 4,000$ (end-user price) on average.

10. Introduction of networking to plants will be relatively slow - involving less than $25 \%$ of new PLC installations in 1992. 
Appendix 8-2

Schedule of Activities for Marketing Plan

\section{Activities}

PLD wall-mount introduction

PLD sales efforts start

Identify top Futuro distributors

Press Release - CMOS FDE products

$C E$ and EDN ads $-S$ and $S 1$

Develop presentation to contract distributors

Sales aids ready

Develop a contractual agreement for distributors

$\mathrm{CE}$ ad $-\mathrm{S}$ and $\mathrm{SI}$

ISA trade show (visit)

Portable PLD prototype

Develop magazine ad for PLDs

CE ad for PLD line

PLC trade show (visit)

Press Release - wall mount PLD

Article on PLDs

Approach all top distributors with presentation

$30 \%$ of PLD distributor market covered

Beta Test PLD portable

EDN ad $-S$ and $S 1$

Direct Mailing - $S$ and $S 1$

Autofact trade show (visit)

Venture capital received

$50 \%$ of PLD distributor market covered

Introduce portable PLD

EDN ad $-S$ and $S 1$

Press Release - Portable PLD

$60 \%$ of PLD distributor market covered

EDN ad

Hire Distribution Manager

Direct Mailing - S and S1

Credit Bonus System starts

Programmable Centrollers trade show (Exhibit)

$70 \%$ of PLD market covered

CE ad - PLD

Gould compatible portable developed

CE ad - PLD

Control Expo trade show (visit)

PLD - 50\% off promotion

$80 \%$ of PLD market covered

CE ad - PLD

Direct mailing - PLD line

Floppy disk give-away

Article - PLD network

$90 \%$ of PLD market covered
Dates

September 1

September 1

September 1

September

September

October 1

October 1

October 1

October

October

November

November

November

November

November

November

November

December 1

December

December

December

December

January 1,1988

January 1

January 1

January

January

February 1

February

February

March

March

April

April

April

May

May

May

June

June

July

July

August

August

August 31 
Appendix 8-3

Financial Budget and Cash Flow Requirements of Marketing Plan

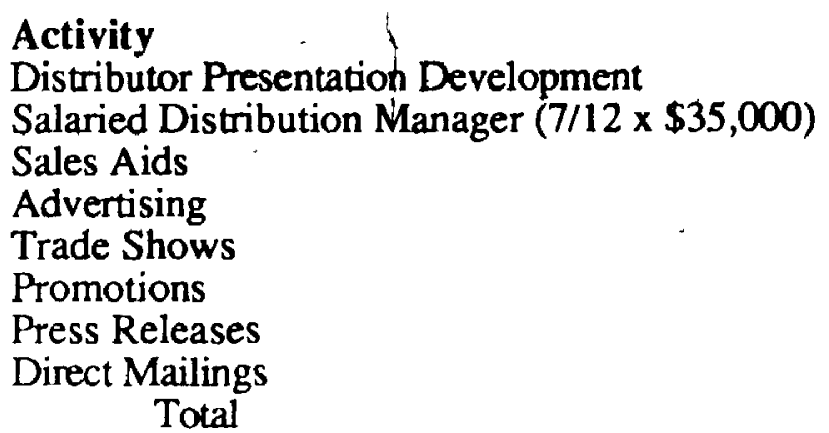

Activity

Distributor Presentation Development

Salaried Distribution Manager $(7 / 12$ × $\$ 35,000)$

Sales Aids

Advertising

Trade Shows

Promotions

Press Releases

Total

Cash Flow Requirements by Period

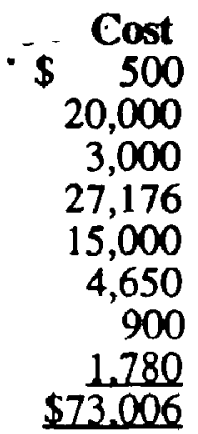

$\$ 5180$

6940

8140

4030

2140

4840

3050

8340

10,840

4840

4340

4840

5750

$\$ 73.270$

Note: Totals do not match due to rounding of numbers 


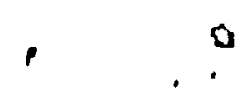

Operational Marketing Plan
for Techsys Electronics Inc.

\section{Appendix 9}




\section{Executive Summary}

Q

This document is Techsys' first annual marketing plan since the Company's formation in 1982. It contains a summary analysis of the situation in which Techsys operates, outlining both the strengths and weaknesses discovered. It also contains the objectives for the coming and future years and outlines action plans designed to achieve these objectives. Monitoring procedures and contingency plans are also provided as methods to maintain the plan throughout the year and deal with improbable events.

The situation annalysis revealed that the industrial market for bubble memory data storage systems is not viable for Techsys in the near future. Some potential does exist in the military market for military qualified manufacturers. It is unlikely that the Company could become such a manufacturer during the 1987-88 fiscal year.

Realizing that bubble memory products are too expensive for the industrial market, management is changing the Company's direction by modifying current products and developing new ones. To make the Stortite 1 and Stortite product lines more price competitive with Compco and other competitiors, CMOS RAM (with a battery backup) memories are used instead of the bubble memories. Using this technology, the price of the CMOS cartridges is about $60 \%$ of the bubble memory cartridges of similar capacity. This, combined with a speed advantage, should attract industrial buyers to Techsys' products in the coming year.

A new product line of Programmable Logic Controller (PLC) backup systems is in the design and development stages. This line of program loading devices (PLDs) will have a wall-mount version (to be fastened to the wall beside a PLC) a portable version (to be carried from PLC to PLC), and a networking wall-mount (to backup various components of the computer network of a factory). Initially these PLDs will only be compatible with Futuro PLC-2s and PLC-3s (as they are the market leaders with a $45 \%$ market share). Once the Futuro compatible PLDs are commercialized, Techs'ys' PLDs will be designed to operate with PLCs from Gould, General Electric and Texas Instruments. utn the coming year, the automobile manufacturers in North America will be targeted. This industry is the largest PLC purchaser to date.

The distributors used by Futuro to sell their PLCs were selected as the most suitable for Techsys' PLD line. Their knowledge of the technology, the market and the customers needs will be very valuable to the Company. Designing a suppart system for the 10 or 11 distributors who cover $90 \%$ of the target market is a primary objective of this plan.

A comprehensive communication plan has been developed to support the Stortite 1, Stortite and PLD product lines. Magazine advertising will be the consistent core throughout the year and will be complimented by direct mailings, press releases, promotions and one trade show. These activities will focus on the Stortite 1 and Stortite lines in the first six months of the year but the emphasis will switch to the PLD line in the latter six months as the products are developed. Total cost of the communications is under $\$ 50,000$. The entire marketing plan has a budget of approximately $\$ 73,000$. 
Section

1. Situation Analysis $\quad 142$

1.1 Markets $\quad 142$

1.2 Problems and Threats $\quad 142$

1.3 Strengths and Opportunities 143

2. Forecasts 143

2.1 Sales Forecasts 143

2.2 Competitive Forecasts $\quad 144$

2.3 Technological Forecasts 145

3. Objẹctives

3.1 Mission Statement 145

3.2 Short-Term Objectives $\quad 145$

3.3 Medium-Term Objectives 145

3.4 Long-Term Objectives. 145

4. Action Plans 145

4.1 S and S1. Product Lines Plan 145

4.2 PLD Development and Introduction Plan 146

4.2.1 Marketing Strategies $\quad 146$

4.3 Communications Plan $\quad$. 147

4.4 Distribution Plan for the PLD Line 148

5. Monitoring Procedures 149

5.1 S and S1 Product Lines. Plan Monitors 149

5.2 PLD Developthent and Introduction Plan Monitors . 149

5.3 Communications Plan Monitors 150

- 5.4 Distribution Plan Monitors 151

6. Contingency Plans

6.1 Plans to Counteract Threatening Situations 151

6.2 Plans to Take Advantage of Opportunities . 153

\section{Tables}

1. Techsys Budgeted Income Statement - 1987-88 143

2. PLD Sales Forecast

3. PLD Pricing Structure 146

4. Advertising and Promotional Schedule - 1987-88 148

\section{Appendices}

9-1 Assumptions for PLD Sales Forecasts 154

9-2 Comprehensive Schedule of Activities . 155

9.-3 Financial'Budget for 1987-88 Marketing Plan 156 


\subsection{Markets}

\section{Situation Analysis}

The Company's customers for the Stortite 1 and Stortite ( $S$ and $S 1)$ lines are original equipment manufacturers (OEMs) and system integrators in North America who desire ultra-reliable data storage systems. The industry sectors that these companies participate in are: mobile instrumentation, non-tactical defense and aerospace, resource industrial automation and manufacturing and plant automation.

The customers for the new PLC program load devices (PLDs) will be current and future owners of Futuro PLC-2s and PLC-3s in North America. Oncesales of the Futuro compatible PLDs are established, a Gould-compatible PLD will be developed.

Wall-mount, portable and networking versions of the PLD will be available in the major PLC makes. The largest user of PLCs and Techsys' target market over the next year is automobile manufacturers.

\subsection{Problems and Threats}

The Company's sales and profit situation has been a problem since its formation in 1982. A 22.6\% drop in sales from 1984-85 to $1985-86$ and a cumulative net loss of approximately $\$ 1,000,000$ to date are evidence of this problem. One result of the poor sales and profit levels is a $\$ 400,000$ inventory level. An inventory turnover rate of 2.1 times in 1985 and 1.3 times in 1986 versus the Industrial Electrical Equipment Manufacturers' average of 4 times in 1985* demonstrates the extent of this problem. A second result is the difficulty in raising operating funds through debt or equity sources because of a lack of backordered sales. This inablility accelerates and magnifies the cash flow problems.

The emphasis that the Company has placed on marketing has varied from year to year and has promoted erratic per period sales and not allowed for sufficient planning and marketing research. Greater control in the marketing function should lead to improved product offerings, more effective strategies and greater control over day to day operations.

Specific elements of the marketing strategies for the $S$ and $S 1$ lines present problems for the Company. The products are very expensive to produce and as a result are premium priced in a price sensitive, competitve market. This puts them at a serious disadvantage to Compco and other competitors with lower prices. The distribution system presents another problem in that Techsys does not manufacture bubble (or other) devices nor does it sell to the end user. The dangers are that either side of the chain may perform Techsys' "packaging" task, making the link where Techsys sits redundant: This added distribution level, and the added price markup that goes with it, makes the products even more expensive for the end user.

The Company's principle competitor at the present time is Compco. Their products are quite similar to Techsys', they stress the same benefits and appeal to many of the same customers. Their competitive advantage lies in the lower price of most of their products, achievable because they produce their own bubble devices. Techsys has been able to mitigate this problem somewhat with the introduction of a battery-backed CMOS Stortite line of products which is priced competitively to the Compco bubble products and is much faster as well. Other bubble device suppliers (Memory Inc., Hitachi and Fujitsu) are also considered competitars because they offer a line of bubble memory systems and boards which is small but growing. This growth is necessary if they are going to appeal to enough customers to approach profitablity.

* Dun and Bgadstreet Canada, Business Information Systems and Sciences and Sarvices. Key Business Ratios Canada Corporations, 1985. 
The most serious competitive threat for the PLD line is expected to be Futuro. They currently have a tape loader which sells for $\$ 3,845$ (approx.) and is slower and larger than Techsys' PLD. They. are expected to introduce a lap top computer that will perform the same functions as Techsys', PLD but will be much more powerful. When this lap top computer is introduced Techsys will no longer have a size advantage but will still have speed and price advantages. Regardless, the competition will be much tougher than if just the tape loader was available.

\subsection{Strengths and Opportunities}

Techsys, having been faced with increasingly difficult situations such as the loss of key personnel and consistent unprofitability, is a leaner organization than it was one year ago, and has developed much tighter financial and operational controls. These strengths will have a significant effect on the Company's ability to be compettive in the future.

Management has now focused on what is felt to be Techsys' competitive advantage - the ability to provide more solutions to customers' data storage problems. By concentrating on this advantage in advertising and sales efforts Techsys should be able to strengthen their competitive and financial position.

The most significant opportunities for Techsys in the 1987-88 fiscal year stem from new products. The Stortite CMOS product is expected to attract new customers to Techsys' lower priced but still ultra-rehiable offerings in the coming year. The PLD line, however, presents the opportunity for the Company to move in a new strategic direction with a line of PLC backup systems. With the competitive advantages of a smaller product, lower price and faster speed, the PLD line has a chance to become successful in the growing process control industry.

Management has decided to pursue the PLD opportunity while maintaining the $S$ and S1 lines in the coming year. Although the PLD opportunity has the potential to support the Company in the future, the $S$ and $S 1$ lines are crucial to providing the necessary operating and development funds over at least the 1987-88 fiscal year. Corporate resources will be split between the two product categories over the coming year. Management believes that this is the best way to attack the new.market without sacrificing the traditional one.

\subsection{Sales Forecast}

\section{Forecasts}

Sales and expense forecasts for the Company for the 1987-88 fiscal year are presented in Table 9-1. These estimates are based on prior years' performances and the expectation that sales will remain at about the same level as they have for the last two years.

Table 9-1

Techsys' Budgeted Income Statement - 1987/88

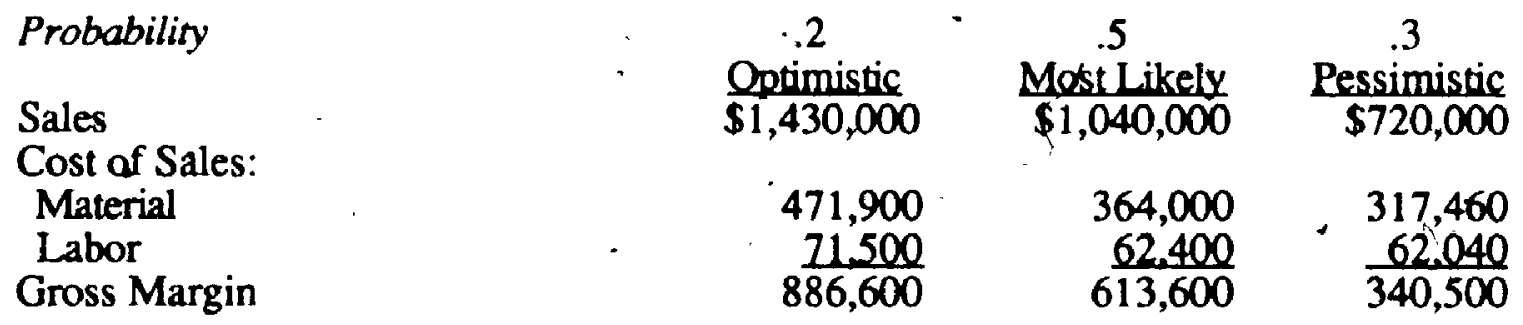




\section{Expenses: \\ General and Administration \\ $\$ 200,000$ \\ $\$ 200,000$ \\ 220,000 \\ Sales and Marketing \\ 243,000 \\ 243,000 \\ 267,300 \\ Research and Development/Engineering \\ 186,000 \\ 157,000 \\ 154,300 \\ Depreciation Total Expenses \\ 9.100 \\ 9.100 \\ 9.100 \\ 638.100 \\ 609.100 \\ 650.700 \\ Profit Before Taxes \\ Taxes and Tax Credits \\ $\$ 248,500$ \\ $\$ 4,500$ \\ $(\$ 310,200)$ \\ 60.000 \\ 50,000 \\ 50,000 \\ Net Profit \\ $\$ 308.500$ \\ $\$ 54.500$ \\ $(\$ 260,200)$ \\ Expected Sales $=[(.2 \times 1,430,000)+(.5 \times 1,040,000)+(.3 \times 720,000)]=\$ 1,020,000$ \\ Expected Profit $=[(.2 \times 308,500)+(.5 \times 54,500)-(.3 \times 260,200)]=\$ 10,890$}

The PLD product sales have been estimated with pessimistic, optimistic and most likely scenarios as well. Table 9-2 shows these forecasts. The assumptions behind these forecasts are provided in Appendix 9-1.

Table 9-2

PLD Sales Forecasts (\$000's)

Calendar Year

\section{Optimistic}

Portable

Networking wall-mount Total (U.S.)

Canadian Total (x 1.32) 1987

$\$ 34.5$

0.0

$\frac{0.0}{5345}$

$\$ 34.5$

$\$ 45.5$
$\$ 55.9$

498.6

70.6

$\$ 625.1$
Most Likely

$1987 \quad 1988$

$\$ 27.1$. $\$ 43.0$

$0.0 \quad 402.2$

$0.0 \quad 35.2$
5271

$\$ 27.1 \quad \$ 480.4$

$\$ 825.1 \cdot \$ 35.8 \cdot \$ 634.1$
Pessimistic

$1987 \quad 1988$

$\$ 22.2 \$ 34.4$

$0.0 \quad 337.9$

$\frac{0.0}{\$ 22.2} \frac{11.6}{\$ 383.9}$

\subsection{Competitive Forecasts}

Compco, Memory Inc. and Hitachi have begun to produce systems similar to Techsys' (in addition to the bubble devices). It is suspected that these companies will integrate upward at a much quicker pace in the future. These companies will exploit their inherent advantage over Techsys and edge 'Techsys' customers away as their product lines become wider and deeper.

Techsys has perhaps a 1-2 year time frame with which to sell their data storage systems before these main competitors have comparable product lines. This is one reason for Techsys to shift its emphasis to another type of product line. Another reason is that the future of bubble memory technology in the industrial market is bleak. It is predicted that unless Compco and Memory Inc. can sell in the military market, they will not make a significant profit. This is in spite of their financial and distribution advantages over Techsys.

The introduction of the PLD products will attract attention in the market because they will be smaller, faster and less expensive than many alternatives. Futuro is expected to introduce a competitive product (the lap top computer) within 6 months of Techsys' PLD introduction. In addition, other companies may develop similar products for Gould, General Electric and Texas Instruments PLCs. Techsys must maintain its price and speed advantages, produce various compatible products at a rapid rate, and develop a network of distributors to protect itself from these competitors. 


\subsection{Technological Forecast}

Hitachi predicts that it will have a $16 \mathrm{Mbit}$ bubble memory by 1988 . It is not until a 64 Mbit bubble is available that enough memory in a small enough package at a cheap enough price will make the bubble memory a marketable alternative to more conventional storage media. The $64 \mathrm{Mbit}$ bubble is not expected for about 4 or 5 years which is too long for Techsys.

General Motors will hàve computer networks in all of their plants in 1.5 to 5 years. The other automotive manufacturers are expected to follow suit about 2 to 5 years after the GM adoption. Techsys should develop the network compatible PLD as soon as possible so that it can be incorporated first into GM's computer acquisitions and next into the other automobile manufacturers' plants.

\subsection{Mission Statement}

\section{Objectives}

Techsys is dedicated to being the best at providing data storage/program backup equipment to computer users who must operate outside the comforts of a normal office environment or who have requirements for greater than normal reliability of their computer systems. Techsys is dedicated to providing superior technological ways of reducing the risks and, hence, the costs of using computers in many non-traditional applications.

\subsection{Short-Term Objectives (within 1 year)}

1. Achieve a profit level of $\$ 100,000$ for $1987-88$.

2. Achieve a sales level of $\$ 1,100,000$ for $1987-88$.

3. Achieve a sales level of $\$ 100,000$ for the new PLC support products for 1987-88 therefore a level of $\$ 1,000,000$ for the current products.

4. Launch the wall-mount PLD in September, 1987 and the portable PLD in January, 1988.

5. Introduce a Gould-compatible portable PLD in May, 1988

\subsection{Medium - Term Objectives (2-3 years)}

1. Introduce portable PLD products that are compatible with Texas Instruments and General Electric PLCs in July, 1989.

2. Achieve a profit level of $\$ 125,000$ in the $1988-89$ fiscal year (a $25 \%$ growth rate).

3. Achieve a profit level of $\$ 155,000$ in the $1989-90$ fiscal (a $25 \%$ growth rate).

4. Build a backlog of orders of approximately 3 months in March, 1989.

5. Receive 50\% of total sales from "end user" products by August 31, 1989.

6. Receive $75 \%$ of total sales from "end user" products by August 31, 1990.

\subsection{Long - Term Objectives (More than 3 years)}

1. Become the market leader in Futuro PLC System backup products by 1992, and for all PLC types by 1995.

2. Maintain an average minimum level of profit growth of $25 \%$.

\subsection{S and S1 Product Lines Plan}

\section{Action Plans}

These two product lines, which have supported the Company for five years, will continue to do so into the 1987-88 fiscal year. The revenues generated from selling these products will also partially fund the PLD line development.

In order to generate and pursue qualified leads, marketing will rely on advertising, direct mail and press releases. The communications plan examines these efforts in detail. At least six, 1/4 page spaces will be purchased in EDN and Control Engineering for the first six to eight months of 1987-88. The ad, like other communications elements for the beginning of the year will feature board level products and CMOS RAM products. Several 
customers have expressed an interest in the bubble and CMOS boards and the lower price of the CMOS Stortite products. After the 6-8 month period, marketing will be placed more heavily on the PLD line.

The price of the S and S1 lines was increased to take advantage of the price insensitivity of the organizations who still buy the bubble memories. The CMOS products will be recommended for the mostly industrial users who are price sensitive. If orders for the $S$ and $S 1$ lines drop below $\$ 90,000$ for two consecutive 28 day periods, a sale price (of about $25 \%$ off) will be offered to generate short term sales.

The distribution system will remain intact. The emphasis will be on direct sales as this is the most convenient to the customers and Techsys. The President has overall responsibility for the plan because of its importance and implications to all aspects of the Company.

\subsection{PLD Development and Introduction Plan}

The target market for the 1987-88 fiscal year is present and future owners of Futuro PLC-2s and PLC-3s in North America. Futuro's share of the $\$ 400$ Million (U.S.) North American PLC market is $45 \%$ while the next closest competitor is Gould with 20\%.* The largest purchaser of PLCs are automobile manufacturers but any industries where process controls are needed is a potential customer. Techsys is limiting itself in the short term to the North American segment because of financial, engineering and marketing constraints. If successful in this market, Techsys may expand to other geographic regions.

\subsubsection{Marketing Strategies}

The PLD line is in the design stage of development. Discussions with potential customers indicate that the wall-mount will have minimal sales potential because it requires the customer to learn a new set of backup and loading procedures and one PLD is needed for every PLC. The portable PLD is also faster, smaller and less expensive than the current Futuro 1770SB tape loader yet is used in much the same way. Minimizing the amount of time that the engineer must put into this "non-productive" task and making it easier to complete (by making the loader easy to carry around and operate) are the benefits of this product. Research is needed to move the networking PLD from the idea stage to conceptualization and development stages if the product is to be available for the automotive manufacturers by early 1990 when they are implementing their network computer systems.

A discount pricing strategy is best suited for the PLC backup system market. The prices of Techsys' PLDs will be kept significantly below the major competitors' prices. This is possible due to the low cost of manufacturing the product and the very high margins acceptable in the market. Table 9-3 has the costs, list prices and margins expected for the PLD line.

Table 9-3

PLD Pricing Structure

$\begin{array}{lccc}\text { Product } & \text { Cost }(\mathrm{Cdn}) & \text { List Price (US) } & \text { Margin } \\ \text { Wall-mount } & \$ 450 & \$ 1450 & 51.3 \% \\ \text { Portable } & 665 & 2295 & 54.0 \% \\ \text { Networking wall-mount } & \mathrm{a} & \mathrm{a} & \mathrm{a} \\ \text { Preformatted Diskettes } & 55 & 145 & 42.2 \%\end{array}$

a Unknown range

"Source: Bruce C P. Rayner, (1987). "Programmable controllers move toward a \$5 billion business", Electronic

Business. Jume 15, p. 38. 
A standard discount schedule, tentatively giving small users $15 \%$ off; large users $23 \%$ off; OEMs $31 \%$ off and distributors $40 \%$ off will be offered. An additional $2 \%$ is offered for quick payment (i.e. 2/10, net 30). In addition, an occasional sale price will be offered to the distributors to promote short term sales when they are significantly below projections.

The PLDs will be distributed through Futuro PLC distributors. Approximately 10 distributors cover almost $90 \%$ of the North American market of Futuro PLC owners. Contracting these 10 is a major objective that, if accomplished, will erect a significant barrier to entry to all but Futuro.

The promotional strategy is comprised of advertising (at least six 1/4 page ads in Programmable Controls and Control Engineering), trade shows (exhibiting at one, attending 4 others), four press releases, distributor and end-user promotions and two magazine articles. The unique selling proposition that will tie these elements is : "Techsys' speedy PLC backup systems will reduce downtime for the plant and the engineer".

The Marketing Manager is responsible for coordinating the various marketing elements. Overall responşibility for the development and marketing of the PLD products is the President's.

\subsection{Communications Plan}

In the 1987-88 fiscal year communications will have two campaigns. The first must support the $S$ and $S 1$ lines by generating sales leads, while the second must build awareness and support the PLD distributors' salesforces. The benefits of speed, low price and small size will be used in the communications efforts for the PLD. When Futuro introduces a portable loader to compete with Techsys' PLD, the size benefit will no longer be a competitive advantage but may still be a useful selling feature when combined with the speed and price advantages. The benefit of having more solutions to data storage problems than the competition will be used for the $S$ and $S 1$ lines throughout the year.

The timing of the communications is such that the PLD line will not be promoted for about 4-6 months until the portable version is available. Until that time, communications will be focused on the $S$ and $S 1$ products and particularly the CMOS versions. A schedule of when each of the components will be implemented is provided in Table 9-4.

Each communication element has some costs associated with it except for publicity. It will be necessary to have a new trade show display created to replace the current outdated one at a cost of $\$ 5,000$ Exhibiting costs for the Programmable Controls show and traveling expenses for ISA, Autofact, Control Expo and the PLC show are another $\$ 10,000$. The creation of a PLD ad by Wallace, Kearney and McGill is $\$ 5,000$ while the magazine space in EDN/CE is about $\$ 22,176$ for twelve, 1/4 page spaces. Salesman of the month promotions, Techsys pens, calculators and diskettes add another $\$ 4,650$. Three press releases will be approximately $\$ 900$ while quarterly direct mailings add another $\$ 1,780$. The total anticipated cost for communications is about $\$ 49,500$.

The responsibility for all communications efforts is the Marketing Manager's. The marketing assistant will help with the implementation of the various activities. 


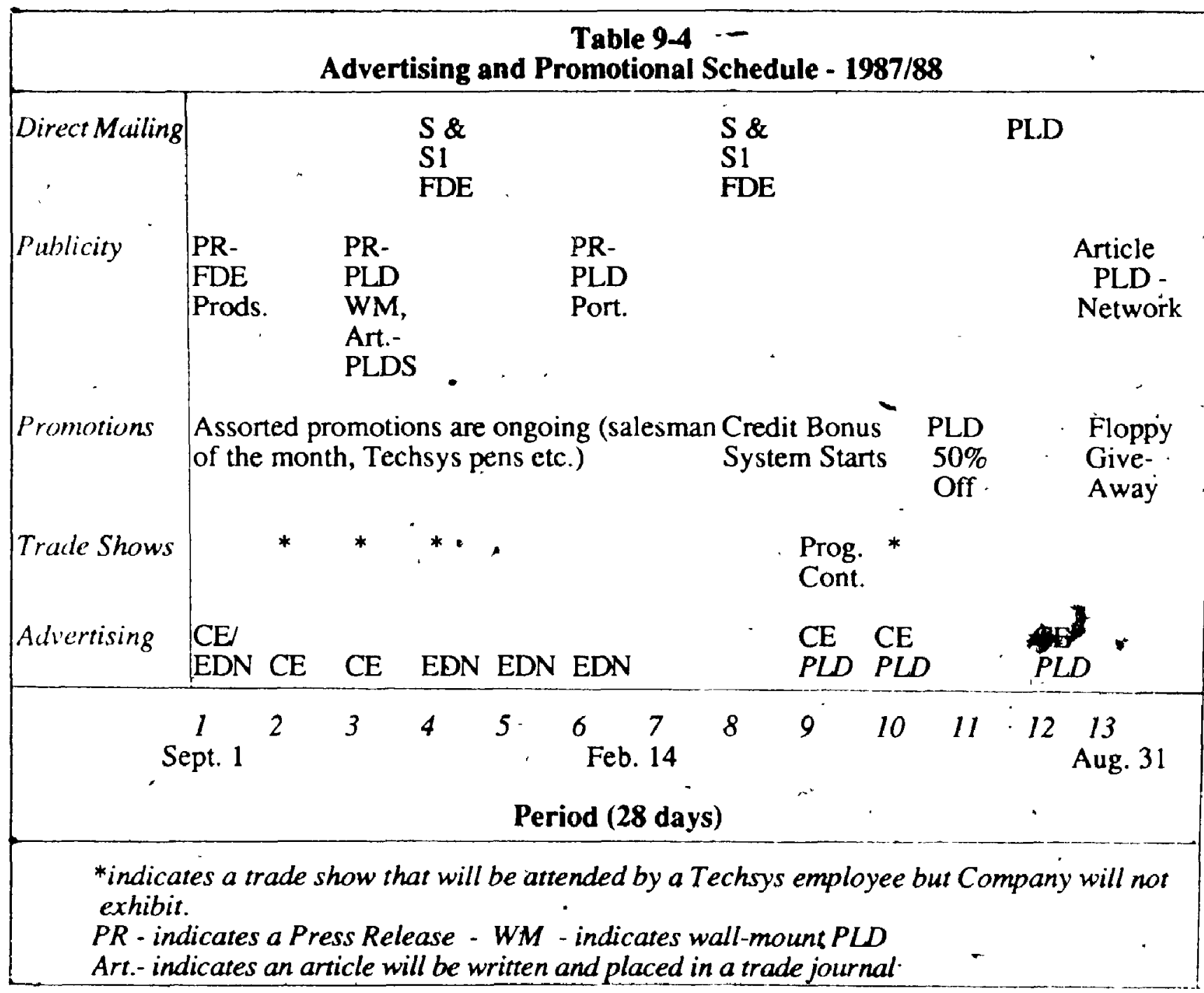

\subsection{Distribution Plan for the PLD Line}

There are several reasons why the top 10 or 11 Futuro PLC distributors are well suited to selling Techsys' PLDs:

1. They are best able to reach the end user of the PLD because they have an established relationship with these companies.

2. Their current product line, which includes Futuro PLCs, is very compatible with Techsys' PLD. Their intimate knowledge of these products will be invaluable to Techsys.

3. From 1 and 2 it follows that these distributors have a keen understanding of the market and what is needed to be a successful vendor. A McNaughton-McKay representative has shown this expertise.by outlining the elements of a potential manufacturer/ distributor relationship that he would agree to and the product specifications that would be desirable to his customers.

From the distributor's viewpoint, the addition of Techsys' PLDs would make their product line longer and more complete for the end user. A small up front investment of perhaps $\$ 10,000$ U.S. and the small afnount of learning necessary minimizes the risk for them. Support vehicles including: a full time distributor-relations manager, salesforce training, a toll-free service "hotline" and a comprehensive communtcaitons compaign aimed at the end user, should attract the distributors. 
The costs associated with this plan include developing a presentation for distributors $(\$ 500)$, hiring a salaried distribution manager $(\$ 20,000$ in this fiscal year) and developing spec sheets for the various product lines $(\$ 3,000)$. The evaluation criteria are the target dates outlined in the last section of this plan, the sales levels of the distributors and the coverage of the target market.

\section{Monitoring Procedures}

The monitoring procedures apply to the action plans outlined in the previous section. A summary of each plan's monitoring strategy is outlined below.

\subsection{S and S1 Product Lines Plan Monitors}

Monitors: Various - Director of Operations, President and Marketing Manager

Key Factors: Sales ratios, inventory levels, sales of $S$ and $S 1$, number of leads for $S$ and $S 1$ products

Ranges: Sales Ratio - 85\% from S and S1(highest acceptable) / 15\% from PLD (lowest acceptable)

Inventory Levels $-\$ 50,000-\$ 200,000$

Sales of S and S1 - At least $\$ 900,000$ for $1987-88$

- An average of $\$ 70,000$ per period. Higher sales in the beginning of the year (Avg. $\$ 100,000$ per period). Lower sales at the end of the year (Avg. \$50,000 per period).

Number of Leads - 25 per period minimum for the $S$ and $S 1$ lines

\section{Review Periods:}

Sales Ratios - By period

Inventory Levels - The end of each period

Sales of $S$ and $S 1$ - Weekly management meetings and at the end of each period

Number of Leads - Weekly sales and marketing meeting and at the end of each period

Procedures:

Sales Ratio - This is done easily by the Director of Operations by comparing the sales of the period for both the $S$ and $S 1$ and PLD products.

Inventory Levels - An informal inventory will be conducted by the Production Manager and staff, at the end of each period. A formal inventory will be taken at year end by the accounting firm employed by the company.

Sales and Leads of S and S1 - The salesmen keep track of orders and log them as the purchase order is received. They will be reviewed along with the leads at the weekly sales and marketing meeting and in more detail at the end of every period. The Director of Operations is responsible for this.

\subsection{PLD Development and Introduction Plan Monitors}

Monitor: Director of Operations

Key Factors: Funding, sales of wall-mount, sales of portable, development dates Ranges:

Development dates: wall-mount and portable - within 1 month of specified dates 
network - no later than 4 months of specified date

Funding: $\$ 200,000-\$ 500,000$ by year end $(\$ 100 ; 000$ must be obtained by January 1, 1988)

Sales of wall-mount: Minimum of $\$ 10,000$ for $1987-88^{*}$

Sales of portable: Minimum of $\$ 70,000$ for $1987-88^{*}$

Review Periods:

Development Dates - Weekly management meetings

Funding - November 1, January 1, April 1, July 1

Sales of wall-mount and portable - weekly management meetings and end of period totals.

Procedures:

Funding, Sales - These figures are monitored as part of the regular bookkeeping function. The figures will be reviewed at each weekly management meeting (where applicable) and formally at the end of each period. If the funding does not come through on time then the sales figures and development dates must be reviewed and amended. The causes should be isolated by the Director of Operations and the responsible officers, and remedies suggested.

Development - Engineering should create a development schedule with dates and activities outlined (a PERT chart or something comparable). This schedule will be reviewed weekly by the Director of Operations and Engineering Manager.

\subsection{Communications Plan Monitors}

Monitor: President

Key Factors: Leads, qwareness level of CMOS RAM products, awareness level of PLD products, knowledge level of PLD benefits and adherence to budget.

Ranges: Leads - 25 per period minimum for $S$ and $S 1$ lines

Awareness of CMOS - 35\% of past and current customers minimum

Awareness of PLD - $60 \%$ of coverage minimum

Knowledge of PLD - 35\% of coverage minimum

Budget - $10 \%$ of budget variance $-\$ 72,000-\$ 88,000$

Review Periods:

Leads - Weekly and at end of each period

Awareness and Knowledge levels - 6 th, 9 th and 13 th periods

Budget - end of periods $3,6,9$, and 13

Procedures:

Leads - as in Section 5.2

Awareness and Knowledge Levels - A small random sampling of the target audiences will be contacted (5\% to $10 \%$ of total audience) with a structured set of questions. This will be organized by the Marketing Manager and carried out by the Manager, the Assistant Marketer and the Salesman. Results will be monitored by the President. If levels are below acceptable range then causes will be determined and corrective action taken.

- These estimates are reasonable only if the products dre developed on schedule. If the development is not on schedule then the sales figures will decrease accordingly. 
Budgeted Spending - the President will monitor spending with the Director to determine the current level. Corrective action will be taken if outside of $10 \%$ range.

\subsection{Distribution Plan Monitors}

Monitor: Marketing Manager.

Key Factor: Pertentage of Futuro PLC market coverage with contracted distributors

Range: Date Contingency Level

Dec $1 / 88$

Jan $1 / 88$

Feb $1 / 88$
$<20 \%$

$<33 \%$

$<40 \%$
Date

Apr $1 / 88$

Jun $1 / 88$

Aug 31/88
Contingency Level $<46 \%$

-. $<53 \%$

$<60 \%$

Review Periods: An ongoing process but formally on the dates listed above.

Procedures:

A MacNaughton and McKay representative has given Techsys a list of all Futuro PLC distributors in North America. He has also agreed to rank the top ten on an informal basis with Gavin. As a backup or corroborating source for this ranking Techsys could attempt to get estimates from the distributors themselves. Knowing McNaughton-McKay's sales levels and market share for PLC's we can identify the total dollar value of PLCs sold in North America (an article in Business Electronics also provides an estimate of the dollar value of this market ).

A comprehensive action plans schedule of activities can be found in Appendix 9-2. The financial budget for the action plans is in Appendix 9-3 along with the cash flow requirements in each period.

\section{Contingency Plans}

\subsection{Plans to Counteract Threatening Situations}

Plan A

This plan should be implemented if one of the following events occurs:

Probability Event

40\%-60\% -Funding for PLD development is not obtained on schedule (less than $\$ 100,000$ by January 1,1988 ).

40\%-60\% -PLD product development falls significantly behind schedule (more than 1-3 months).

$40 \%-60 \%$ - The distributor coverage schedule is not achieved.

40\%-60\% -Awareness and knowledge levels are below 70\% of targets at scheduled time periods.

The damage that these events could do is serious but not necessarily fatal. Depending on the severity of the events, Techsys would probably be able to survive. If these events occur then one or more of the following actions should be taken:

1. Push PLD introduction dates back by whatever time length is necessary.

2. Maintain advertising of $S$ and S1 lines instead of switching to PLD advertisements.

3. Put the S and S1 products on sale again to generate operating funds in the short term. A 25\% discount may be warranted.

4. Implement a signing bonus for indecisive distributors to prompt them to contract with Techsys. A free PLD may be the inducement needed. 


\section{...Appendix 9 Continued}

5. Hire temporary engineering help to expedite the PLD development A $\$ 5,000$ or $\$ 10,000$ investment would be justified to bring the products to market.

6. Attempt to develop a backlog of orders for the PLD line. It may be feasible to pre-sell some on the strength of a prototype (with certain sales conditions specified).

\section{Plan B} implemented.

If one of the following threats manifests itself in the coming year Plan B should be

Probability

$60 \%-80 \%$

Event

$40 \%-60 \%$

-Sales of the $S$ and $S 1$ lines drop below $\$ 80,000$ per period.

- Funding for the PLD line or additional venture capital is not secured.

These events are very serious and could very well be fatal if not acted upon quickly.

Unlike Plan A, more drastic actions must be taken if Techsys is to survive the events.

1. Put all products on sale with at least a $25 \%$ discount in price.

2. Locate a party who may be interested in licensing or purchasing some of Tećhsys' product designs. Prospects might include Memory Inc., Compco or Hitachi.

3. Lay off non-essential personnel and cut the officers' salaries by $10 \%$ to $20 \%$ for a limited time. Consider a 4 day work week.

4. Locate smaller, less expensive facilities and move the business to save overtyad costs.

5. Sell off some of the non-essential fixed assets such as office equipment, computers and furniture.

6. Sell the company outright.

Plan C

Plan C should be implemented if the following events occur:

Probability

Sales of the wall-mount and portable PLDs are below $\$ 20,000$ after period nine.

$60 \%-80 \% \quad$ Futuro introduces a similar PLD before Techsys or shortly after.

0\%-20\% A competitor introduces a similar PLD before Techsys does.

These events are moderately serious but not fatal. They provide setbacks or hurdles that Techsys must overcome within their regular operations. Some of the options to improve the situation are:

1. Decrease the price of the PLDs and increase the number, size and coverage of the ads (by using different vehicles) significantly.

2. Stop emphasizing the size feature and switch to ease of use

3. Conduct research to determine why the products are not selling and attempt to remedy the situation. This would require telephone and personal interviews with the distributors, their salesmen and end users.

4. Implement more distributor incentives to promote short term sales increases.

5. Conduct distributor pep talks if motivation is the problem.

6. If the product has a significant advantage over the competition, use a head-to-head positioning strategy. .If the competition has the advantage, then position Techsys' PLD so as to avoid comparison on that issue. 


\subsection{Plans to Take Advantage of Opportunities}

Plan D

The following events will trigger Plan D:
Probability Event
$20 \%-40 \% \quad \cdot P L D$ wall-molnt and portable saies are greater than $\$ 200,000$ by Period 9.
$0 \%-20 \% \quad$ Futuro offers Techsys the opportunity to become their PLD supplier or offers to buy the PLDs outright.

These opportunities provide outstanding benefits for Techsys and represent the best case . scenario for the coming year. In the event that they occur it would be advantageous to exploit the opportunities by taking-some or all of the following actions.

1. Hire more engineering and marketing personnel.

2. Provide the distributors with a bonus of some sort. This will transmit the message that if Techsys does well, their distributors do well - building goodwill and improving distributor relations.

3. Expedite the Gould, GE, and Texas Instruments - compatible PLD development.

4. If sales of the PLD products are $\$ 400,000$ or more in $1987-88$ then redo the marketing plan completely for the PLDs.

5. If Futuro presents an attractive offer then accept it. If it is short sighted. or unacceptable for some other reason, start to negotiate. While in negotiations, accelerate and intensify the PLD promotions to generate even more sales. This

- will provide negotiating leverage.

Plan E

This last contingency plan will be implemented if the price of bubble memories decreases drastically on a price per bit basis. The probability of this occuring is very slight (estimated at $0 \%$ to $5 \%$ by management) but could theoretically occur. If such a technological advance does take place, Techsys is in a very advantageous position. The $S$ and S1 lines could be re-emphasized to take advantage of the situation. A new marketing plan would have to be developed to revise the product strategies.

Two basic options exist based on the success of the PLD line at the time. First, if the PLD line is very successful then Techsys may want to sell their system desigits to a. supplier or competitor at a premium price. If the PLD line is not very successful then Techsys may wish to put renewed efforts on the bubble products. Even if such a price decrease occurs, there are still many problems with the rugged data storage market that make it only moderately attractive. 


\section{- Appendix 9-1 Assumptions For PLD Sales Forecasts}

1. There is an installed base of 35,000 Futuro PLCs.

2. There is an installed base of 4,900 Futuro 1770-SB tape loaders.

3. There is an installed base of Gould Modicons which is $45 \%$ of that of Futuro.

4. Futuro sells 10,000 PLCs in 1987.

5. Futuro sells $1,4001770-S B$ recorders in 1987.

6. Dollar and unit sales of PLCs are both rising at 15\% per year.

7. Techsys has enough engineering resources to keep up with new product introductions by Futuro and Gould.

8. Networked backup units will support 7 to 8 PLCs on average.

9. Networked backup units will each sell for about $\$ 4,000$ (end-user price) on average.

- 10. Introduction of networking to plants will be relatively slow - involving less than $25 \%$ of new PLC installations in 1992.

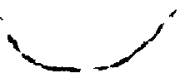


Appendix 9-2

\title{
Comprehensive Schedule of Activities
}

\author{
Activities \\ Identify top Futuro distributors \\ Press Release - CMOS FDE products \\ $\mathrm{CE}$ and EDN ads - S and S1 \\ PLD wall-mount introduction \\ PLD sales efforts start \\ Develop presentation to contract distributors \\ Sales aids ready \\ Develop a contractual agreement for distributors \\ $\mathrm{CE}$ ad $-S$ and $\mathrm{S} 1$ \\ ISA Show (Visit) \\ Portable PLD prototype \\ Develop magazine ad for PLDs \\ CE ad for PLD line \\ Autofact Trade show (Visit) \\ Press Release - wall mount PLD \\ Article on PLDs \\ Approach all top distributors with presentation \\ $30 \%$ of PLD distributor market covered \\ Beta Test PLD portable \\ EDN ad $-S$ and $S 1$ \\ Direct Mailing - $S$ and S1 \\ Trade Show (Visit) \\ Venture capital received \\ 50\% of PLD distributor market covered \\ Introdute portable PLD \\ EDN ad - S and S1 \\ Press Release - Portable PLD \\ $60 \%$ of PLD distributor market covered \\ EDN ad - PLD line \\ Hire Distribution Manager \\ Direct Mailing - S and S1 \\ Credit Bonus System starts \\ Programmable Controllers trade show (Exhibit) \\ $70 \%$ of PLD market covered \\ CE ad - PLD \\ Gould compatible portable developed \\ CE ad - PLD \\ Control Expo trade show (Visit) \\ PLD - 50\% off promotion \\ CE ad - PLD \\ $80 \%$ of PLD market covered \\ Direct Mailing - PLD \\ Floppy disk give-away \\ Article - PLD network \\ 90\% of PLD market covered
}

Dates

September

September

September

October

October

October

October

October

October

October

November

November

November

November

November

November

November

December

December

December

December

December

January 1, 1988

January

January

January

January

February

February

February

March

March *

April

April

April .

May

May

May

June

June

July

July

August

August

August 31 
Appendix 9-3

Financial Budget for 1987-88

Marketing Plan

Distributor Presentation Development

Salaried Distribution Manáger (7/12 x \$35,000)

$\$ 500$

20,000

Sales Aids

3,000

Advertising

27,176

Trade Shows

15,000

Promotions

4,650

Press Releases

900

Direct Mailings

1.780

Total

$\$ 73,006$

\section{Cash Flow Requirements by Period}

Period Expenditures

1 Advertising (\$4180); Pens ( $\$ 500)$; Calculators $(\$ 500)$

2 Dist. Presentation (\$500); Sales aids $(\$ 3,000)$; Ad $(\$ 2090)$

Press Release (\$300); Salesman of the Month $(\$ 50)$;

Audit Show (\$1000)

3 Develop PLD ad (\$5000); Ad (\$2090); Audit Show (\$1000)

Salesman of the Month (\$50)'

4 Ad $(\$ 2090)$; Salesman of the Month (\$50); Audit Show (\$1000) Press Release $(\$ 300)$; Direct Mailing $(\$ 590)$

5 Ad (\$2090); Salesman of the Month (\$50)

6 Distribution Manager (\$2700); Ad (\$2090); Salesman of the Month (\$50)

7 Distribution Manager (\$2700); Press Release (\$300); Salesman of the Month $(\$ 50)$

3050

8 Distribution Managet (\$2700); Trade Show Display $(\$ 5,000)$; Direct Mailing (\$590); Salesman of the Month (\$50)

9 Distribution Manager (\$2700); Ad (\$2090); PC Show (\$6000); Salesman of the Month (\$50)

10 Distribution Manager (\$2700); Ad (\$2090); Salesman of the Month (\$50); Audit Show (\$1000)

11 Distribution Manager (\$2700); Direct Máiling (\$590); Salesman of the Month (\$50) $\quad \because$

12 Distribution Manager (\$2700); Ad (\$2090); Salesman of the Month (\$50)

13 Distribution Manger (\$2700); Salesman of the Month (\$50);

Floppy Disk Giveaway $(\$ 3,000)$ 


\section{Appendix 10 Amended Schema for Marketing Plan Development}




\section{SECTION 1 - SITUATION ANALYSIS}

STEP 1 - Process

Objectives: Obtain an understanding of where the company is, how it got there, and what factors are affecting its products and operations.

Uncover trends, problems or opportunities so that they may be dealt with in the following sections of the marketing plan.

This section along with the others must be developed with the company's marketing strategies in mind. These strategies should be provided in a Strategic Marketing Plan which is developed before the annual plan. The main activity in this section will be research including secondary sources, interviews with company personnel, company documents and external sources etc. A thorough understanding must be gained so that it may be transmitted to the users of the marketing plan. The purpose of the plan as a whole should be clear to the planner. The two most common purposes are: 1. to use the plan as a tool for raising investment and 2 . to use the plan as an operational guide for the compeny's marketing activities in the next fiscal year. The plan intended to act as an investment raising tool will

- be longer than the operational plan because it will include descriptions of terms and concepts with which the internal users will be familiar. The plan for external use must, by nature, be more descriptive and therefore, lengthy. This schema is intended to develop an annual marketing plan that will be used to guide the firm's marketing operations.

Following the preliminary research must be an analysis of the data uncovered, (economic, industry, company sales, profits etc.) and an effort to detect any trends. There are therefore two areas which must be developed:

1. An analysis of past and present issues, and

2. A diagnosis of where the company and its products are headed in the next year or more.

In summary, information gathering, analysis and reporting.

STEP 2 - Components

Internal Analysis

Products:

brief analysis of products including: the technology used, the main features, benefits, selling points, history, quality, breadth, price -servicing characteristics -end user product vs intermediary product -product life cycle (PLC) stage or technology life cycle (TLC) stage where the PLC traces product sales and profit over time and the TLC traces the technology application; technology sales and production cycle. -product sales, bookings, expenses, profits -market share of product

-major target markets for product - may require an action plan or market research (survey of potential customers and/or interviews with market experts) -positioning, reputation -timing of obsolescence of products 
-patent position

-marketing strategy utilized -product, price, promotion and special attention on distribution methods used

-figures by technology type, product line, product, market segment, size, model, type where available and appropriate

Manufacturing/Production:

-analysis of key processes, factors, history and development

-future developments (i.e. new equipment, retooling, aging equipment)

-capacity of plants (source of product)

-flexibility of manufacturing

-location of major plants

-efficiency ratings on major processes

Company strengths and weaknesses:

-financial - ratios (e.g. current ratio, return on assets), cash

availability, stability

-goodwill/badwill - reputation in customers' and competitors'

minds, emphasis on servicing products

- vertical integration - ability to control production and distribution

of products

-personnel - turnover rate, expertise, unionization, skill level,

capacity, potential problems with the marketing/R\&D interface

-marketing - existence of formal marketing function

-R\&D - extent of use, need, availability

-manufacturing - efficiency, lead times, capacity, production

automation

-new products - opportunity for development

-situation specific strengths and weaknesses

External Analysis

Economic Analysis:

-key factors affecting company

-GNP, exchange rates, unemployment, interest rates, disposable income etc.

-major industry sectors of importance (e.g. Automobile, resources etc.)

Industry Analysis:

-industry standards of profit, wages, growth

-analysis of industry (SIC), what types of firms, products, operating practices (do as close as possible with existing sources of information - if necessary, develop a new industry description that best describes the firm so that qualitative analyses may be done)

-leader in the industry, role played

- barriers to entry

-capacity utilization

-geographic diversity or concentration - international analysis

Market Situation:

-size of total market, major segments, characteristics - importance

of government and military/defense segments to firm - international segments 
-analysis of market segments - demographics, geography; benefits sought, buying behavior, preferences, motivations to purchase, international segments

-marketplace dynamics - trends, shifts, patterns or behavior

Competitive Environment:

-competing technologies, products, and companies

-market shares of major players

-positioning of products in the market on key customer comparison factors

-level of technology of competitive products

-anticipated changes in the market - social, technological, political, legal

-marketing strategies employed by competition - products, pricing, promotion, and distribution, segments -competition's strengths and weaknesses

-technology vs product competition

Externa! problems and opportunities:

-market - trend of decreasing/increasing purchases .

-specific segments - unmet demand in certain segments

-competition - increasing/decreasing competitive pressures

-regulation - industry specific, market specific, company specific

-economic- inflation, interest rates, disposable income, consumption patterns

-political - changes in government bodies, regulation, opinions

-international - new markets appear, old markets decline, regulations, tariffs, quotas, new governments, agreements etc.

-degree of pursuit of international markets

Previous Performance VS Objectives

-Budgeted to actual sales, profit, growth, expenses, marketing objectives, production objectives, etc.

-Explain Variances

\section{Planning Assumptions and Constraints}

Any assumptions necessary for the development of this plan that the user may find relevant

- e.g. no new products within the next fiscal year, no technological improvements for 2 years.

Any constraints that limit the marketing activities and hence the plan development - ex. government regulations regarding advertising, sales quotas etc.

\section{STEP 3 - Information Sources}

For the Internal Analysis:

-market research reports

-previóus business plans or marketing plans

-financial statements

-sales and production reports

-informed persons within the company (e.g. department heads, salesmen)

-consultants (knowledgeable persons outside the company)

-shareholders

-customers 
For the External Analysis:

-market research reports (Frost and Sullivan or company specific)

-Statistics Canada publications/government documents

-Dun and Bradstreet reports

-trade association

-trade magazines

-consultants

-embassies

-libraries

-patent reviews

-government agencies/officials

-informed persons such as suppliers, distributors, wholesalers, customers, potential customers

-Bank of Canada

-company records

-newspapers

-competitive literature (advertisements, press releases, spec sheets, annual reports)

-trade shows

\section{SECTION 2 - FORECASTS}

\section{STEP 1 - Process}

Objective:' Using the analysis from the first section, along with other sources of information, project where the company is headed in the short and long term.

There are several ways to forecast including test markets, surveys of buyer intentions and sales force composites (bottom-up approach). More sophisticated techniques such as regression or correlation analysis are also available. Smaller firms may use trend analysis (the projection of past data into the future) or executive judgement with great success. The problem with trend analysis is the a priori assumption that the past is indicative of the future. There are methods available (ex. exponential smoothing) to avoid some of the pitfalls of this method but the basic assumption remains the same. Executive judgement may be the simplest method but it relies solely on the executive's ability to assimilate all relevant information and develop forecasts independently. The use of any particular method will depend on the specific industry and company characteristics, company resources as well as the forecaster's preferences.

It is recommended that the forecaster identify pessimistic, most likely and optimistic forecasts for such factors as sales, profits, and the economic indicators. This will help improve the monitoring procedures.

\section{STEP 2 - Components}

\section{Demand and Sales:}

-estimation of the size of the industry, market, and segments

demand

-company, product, segment

-in units and dollars

-profits and contribution margin figures - growth rates

Competitive:

-sales, prices, product introductions, promotions, distribution changes

-technologies to be used by competitors

-new companies entering the market 
Technology:

-next generation of technologies used

-introduction of new, competing technologies

-expected changes in technological advantages

-shifts from supply side to demand side technologies

Economic:

-examine economic analysis

-Inflation, GNP, exchange rates, income

Other:

-situation specific occurances that will affect the company or market or industry in some significant way.

STEP 3 - Information Sources

-situation analysis

-marketing research reports

-sales call reports

-orders

-informed persons

-sales meeting summaries

-technical reports

-financial statements/records .

-federal and local government publications

-Statistics Canada reports

-customers

-competitive literature

-suppliers, distributors, wholesalers

-trade magazines

-trade association

-professional organizations

-consultants

-embassies/foreign governments

-may have to conduct a survey or some other form of primary research to obtain sufficient information to forecast because the products may be so new or secondary information may be so difficult to find

\section{SECTION 3 - OBJECTIVES}

STEP 1 - Process

Objective: Establish quantifiable, measurable and realistic statements of the desired results of the company's operations in areas of strategic importance.

The objectives are not what one expects to happen in the future (as were the forecasts), but rather what the company will strive for. They must be realistically attainable so that they are motivational rather than demotivational for the personnel responsible for their attainment. They must be quantifiable and measurable if possible. This allows for monitoring to take place and a measures of success to be developed.

There are two basic ways that the objectives may be set: top-down and bottom-up: In the top-down approach, top management interprets economic, industry and market trends and forecasts (sections 1 and 2 of the plan) and translates them into objectives. Instead of this interprotation they may also use test market or survey results as a guide. Whatever method, they must take the company's available resources (capital, personnel, I 


\section{financial) into account.}

In the bottom-up approach, top management solicits the opinions of the line personnel (ex. sales representatives) for their sales, profit, and other objectives. These lower level personnel set the objectives which they, themselves must meet, and submit them to upper management for approval.

In both cases, the objectives should be set in consultation with any relevant outside groups such as advertising or public relations agencies, consultants, accountants etc.

\section{STEP 2 - Components}

Mission Statement: -definition of the company's business, purpose, motives, scope of activities

Objectives:

-relatively few (perhaps $6-8$ ), divided into short, medium and long term -potential objectives pertain to:

1. profit margin

2. profit growth

3. new product development

4. sales to major accounts

5. pricing policy

6. inventories/distribution

7. sales promotion

8. marketing research

9. field sales effort

10. advertising themes
11. customer/product, service

12. exports or international markets

13. advertising expenditures

14. dealer relations

15. sales training

16. other marketing overseas

17. packaging

18. order backlog

19. funding

20. new product R\&D

-other objectives may be related to financial measures such as Retum on investment (ROI), Return on assets (ROA), inventory turnover.

\section{STEP 3 - Information Sources}

-sections 1 and 2 - situation analysis and forecasts

-ad agencies

-market research reports

-informed persons

-sales meeting summaries

-technical reports

-financial statements

-other company records

-competitive literature

-suppliers, distributors, wholesalers

-customers

\section{SECTION 4 - ACTION PROGRAMS}

\section{STEP 1 - Process}

Objective: Develop step-by-step procedures that individuals will follow in order to achieve the objectives for the coming year and beyond.

These action plans stem directly from the objectives and necessarily must take the situation analysis and forecasts into account. 
Once again this can be done using the top-down or bottom-up approach. Using the

top-down approach, top management develops the programs and merely informs the responsible individuals of their responsibilities. In the bottom-up approach, the planner develops the programs in conjuction with the parties who will be responsible. An agreed upon ptogram is developed to be carried out by the lower-level personnel.

When developing the action programs it will probably be necessary to observe a cutoff point, after which no new information will be taken into account in the action program being developed. It is recommended that the programs be written with a great deal of flexibility in mind so that later revisions and updates will be made easier.

The steps in each action plan development are as follows:

(i) outline the necessary steps

(ii) develop a financial budget for the plan

(iii) develop a timing schedule

(iv) outline expected results of the program

(v) compose a schedule of responsible, departments (or individuals) along with their rolecor duty in the implementation

(vi) include a section on evaluation criteria while the plan is in progress andupen completion to judge success

(vii) identify a contingency plan trigger (i.e. if market share drops below $5 \%$ then contingency plan B will be implemented).

It should be noted that budgets and time schedules should be included for each action program if they-are meant to act as stand-alone documents. If this is not a necessity then all of the schedules and budgets could be put into a master schedule and placed at the end of the section or in an appendix.

These programs may be developed in conjunction with or by an ad agency, PR agency or other internal or external, knowledgable bodies for acceptance by upper management. The programs may be very detailed (as an advertising plan would be) or very brief.

\section{STEP 2 - Components}

-the steps necessany to achieve the objectives set

-who is responsible for each step (individual, department, task forte etc.)

-when each step must be started and completed

-available alternatives in the event of a delay

-methods of evaluation

-support necesssary (by division, individual)

-financial budgets for each plan

-explanation of how the action plan will help achieve the objective(s)

-the estimated impact of the completion of the action plan on sales, profits, expenditures, etc.

-accompanying tables and schedules where appropriate or necessary

Possible action programs may be in the following areas:

1. communictions

2. sales promotion and display plans

3. major packaging plans

4. special market research projocts 
5. pricing

6. special cost reduction plans

7. market segments selected and targeted

8. positioning

9. distribution plans

10. after sales - service and warranties

11. co-relationships - joint ventures, licensing - International strategies

12. product line plans

13. new product $R \& D$

STEP 3 - Information Sources

-suppliers, distributors, wholesalers

-professional organizations

-consultants

-informed persons

-sales meetings summaries

\section{SECTION 5 - MONITORING PROCEDURES}

\section{STEP 1 - Process}

Objective: Develop a set of procedures that allow management to keep abreast of the progress of the various programs, isolate any deviations from the plan, and attempt to understand the variances and make any modifications deemed necessary.

The steps in the process would be as follows:

1. Isolate the key factors in the program (they are probably directly related to the objective that the program was developed to achieve).

2. Identify the range of acceptable values of these key factors.

3. Designate an individual responsible for monitoring the program. This individual s/"puld be someone with knowledge of the plan but not the person responsible for its implementation.

4. Identify periods when structured monitoring will take place (ex. monthly), and

5. Identify the procedure to be followed.

†

e.g. Compare sales figures of Product $\mathrm{X}$ in February with the objective sales level for February. Identify any significant variances and try to isolate their cause. Classify the cause according to these criteria: (i) Internal cause (ii) External cause (iii) Controllable (iv) Uncontrollable

\section{STEP 2 - Components}

-what kind of feedback information will be needed

-a schedule of review periods

-criteria for measuring effectiveness of action programs

-performance reports which allow for isolation and analysis of variance

-benchmarks for success

-identification of person responsible for monitoring each program

\section{STEP 3 - Information Sources}

-suppliers, distributors, wholesalers

-consultants

-patent reviews

-market research reports

-sales call reports

-orders 
-complaints

-informed persons

-sales meeting summaries

-technical reports

-financial statements

- other company records

\section{- SEĆTION 6 - CONTINGGNCY PLANNING}

\section{STEP 1 - Process}

Objective:

Identify possible future crises or drastic improvements in the situation and develop plans that will outline the actions to be followed should the activities take place.

Top management would examine the situation analysis and forecasts in an attempt to identify possible future crises or drastic improvements that may develop. These events are isolated and assessed according to 1. their likelihood and 2. the benefits or damage that would accrue should they occur.

Possible ways to prevent, counteract or protect from the crises and exploit the opportunities should be identified. These plans are then outlined with the actions to be taken and key factors specified.

\section{STEP 2 - Components}

-list of major threats and opportunities for which congngency plans are needed -a few plans that can be activated should drastic unexpected events $\alpha c$ cur

-perhaps 1 or 2 options for a downturn and 1 or 2 for an improved situation -events that will act as triggers for the contingency plans ex. sales level, profit level, machinery breakdown, strike

-who will implement the contingency plan

-an outline of the major elements of the plans

\section{STEP 3 - Information Sources}

-trade magazines

-trade associations

-industial sector reports

-market research reports

-informed persons

-technical reports

-sales meeting summaries

-Statistics Canada publications

-the first 5 sections of the Marketing Plan 


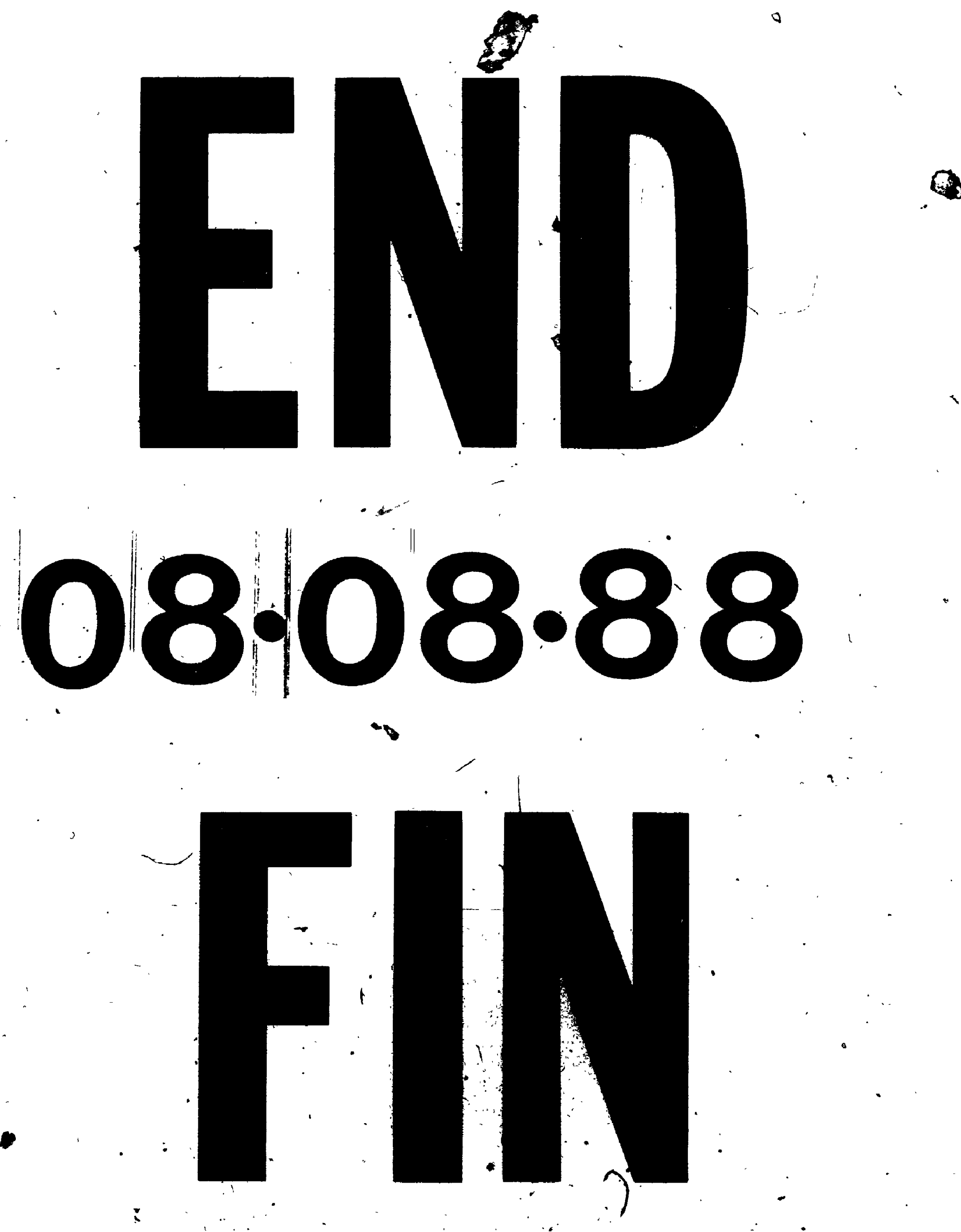

